\title{
Development of Advanced Coal Devolatilization and Secondary Pyrolysis Kinetics Models for CFD (and process simulation)
} Codes

\author{
Kiran Pandurang Chaudhari \\ West Virginia University
}

Follow this and additional works at: https://researchrepository.wvu.edu/etd

\section{Recommended Citation}

Chaudhari, Kiran Pandurang, "Development of Advanced Coal Devolatilization and Secondary Pyrolysis Kinetics Models for CFD (and process simulation) Codes" (2011). Graduate Theses, Dissertations, and Problem Reports. 4703.

https://researchrepository.wvu.edu/etd/4703

This Thesis is protected by copyright and/or related rights. It has been brought to you by the The Research Repository @ WVU with permission from the rights-holder(s). You are free to use this Thesis in any way that is permitted by the copyright and related rights legislation that applies to your use. For other uses you must obtain permission from the rights-holder(s) directly, unless additional rights are indicated by a Creative Commons license in the record and/ or on the work itself. This Thesis has been accepted for inclusion in WVU Graduate Theses, Dissertations, and Problem Reports collection by an authorized administrator of The Research Repository @ WVU. For more information, please contact researchrepository@mail.wvu.edu. 
Development of Advanced Coal Devolatilization and Secondary Pyrolysis Kinetics Models for CFD (and process simulation) Codes

\section{Kiran Pandurang Chaudhari}

Thesis submitted to the

College of Engineering and Mineral Resources

at West Virginia University

in partial fulfillment of the requirements

for the degree of

Master of Science

in

Chemical Engineering

Dr. Richard Turton

Dr. John Zondlo

Dr. Charter Stinespring

Dr. Chris Guenther

Department of Chemical Engineering

Morgantown, West Virginia

2011

Keywords: MFIX, PC Coal Lab, Coal Devolatilization, Secondary Pyrolysis, Soot.

Copyright 2011 Kiran Pandurang Chaudhari 


\section{Abstract \\ Development of Advanced Coal Devolatilization and Secondary Pyrolysis Kinetics Models for CFD (and process simulation) Codes}

\section{Kiran Pandurang Chaudhari}

Detailed kinetic expressions for the gasification of a wide variety of coals in existing Computational Fluid Dynamics (CFD) codes such as Multiphase Flow with Interphase Exchanges (MFIX) developed by NETL. These expressions describe the fundamental steps taking place in the gasification of coal, namely, coal devolatilization, tar-gas chemistry, soot formation and the heterogeneous and homogeneous gasification reaction along with combustion reactions. For this purpose, the data generated by PC Coal Lab (PCCL) is used to simulate the gasification of various coals in CFD codes. The CFD code of most interest is MFIX, which is used to describe the hydrodynamics, heat transfer and chemical reactions in the reacting fluidsolids systems comprising the contents of a gasifier. The implementation of gasification kinetics in MFIX is currently done through a set of subroutines making up the Carbonaceous Chemistry for Continuum Modeling $\left(\mathrm{C}_{3} \mathrm{M}\right)$ code. $\mathrm{C}_{3} \mathrm{M}$ has default gasification kinetics for only a few coals. While on the other hand, PC Coal lab can predict the gasification kinetics for over 2000 coal species. This project focuses on the development of a seamless connection between PC Coal Lab and the $\mathrm{C}_{3} \mathrm{M}$. The interface is designed to allow MFIX to transfer information through $\mathrm{C}_{3} \mathrm{M}$ to PC Coal Lab, run PC Coal Lab with the input data from MFIX, send kinetic information back to $\mathrm{C}_{3} \mathrm{M}$ in a form that allows $\mathrm{C}_{3} \mathrm{M}$ to update and continue the MFIX simulation using updated parameters from PC Coal Lab. Current work is focused on developing similar expressions for biomass devolatilization. In this research PCCL predictions for biomass devolatilization were compared with experimental results and they show a good agreement with experimental results. The algorithm developed is being used to develop a Graphical User Interphase (GUI) at NETL site Morgantown by Phil Nicolletti. 


\section{Acknowledgments}

First, I wish to express my appreciation to my graduate advisor, Dr. Richard Turton for his guidance and encouragement throughout this work. The quality of this work is a reflection of expert advice that has been received. Appreciation is also extended to Dr. Chris Guenther, Dr.Ronald Breault and Dr.Mehrdad Shahnam for their advice and direction.

There have been many people whose cooperation and assistance have been vital during this research. I am grateful to Philip Nicoletti who helped me with MFIX. I would also like to thank Dr. Stephen Niksa for his vital advice on PC Coal Lab.

Acknowledgment also goes to my lab mates Dr. Debangsu Bhattacharyya, Job Kasule and Dustin Jones along with my friends Tanya Tandon,Vamsi Aluru, Soumya Gujjar, Kedar Panday, Manasa Chennuri, Anand Ranpara and Veeru Talreja for their support.

Financial support provided through National Energy Technology Laboratory (NETL), Morgantown is gratefully acknowledged.

Finally special thanks are expressed to my beloved parents who supported my early education and kept faith in me. 


\section{Contents}

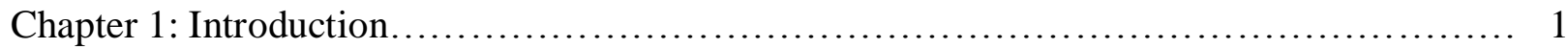

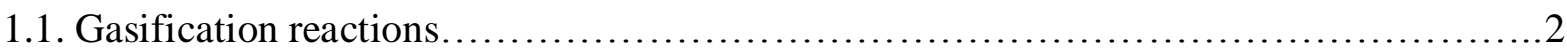

1.2. Need for Gasification model...................................................... 4

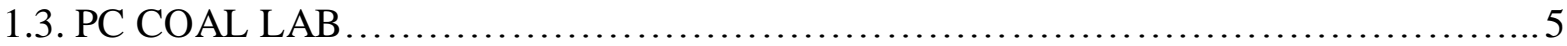

1.4. Multiphase Flow with Interphase Exchange....................................... 7

Chapter 2:Gasification Kinetics...................................................... 11

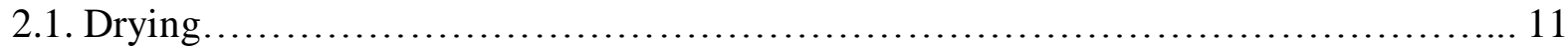

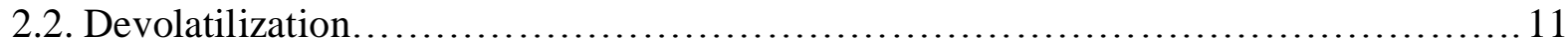

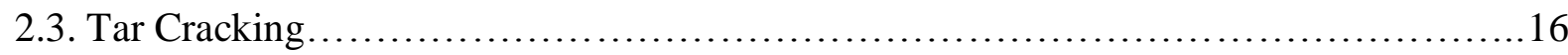

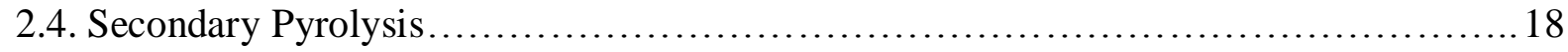

2.5. Combustion and Gasification reactions......................................... 20

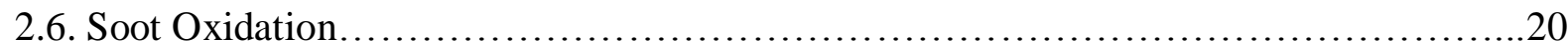

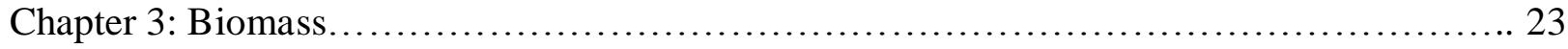

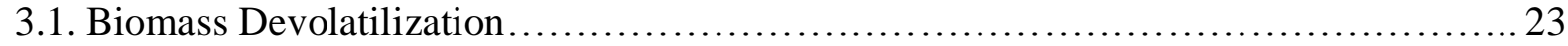

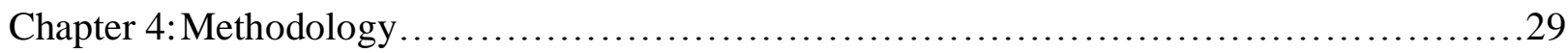

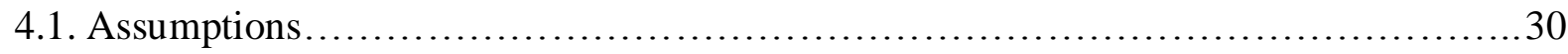

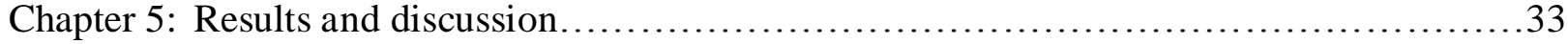

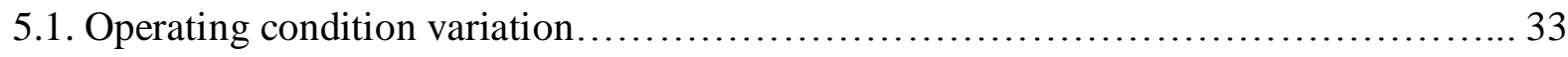

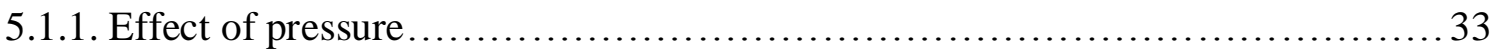

5.1.2. Effect of temperature ........................................................... 34

5.1.3. Effect of heating rate.................................................... 34

5.2. Comparison of devolatilization kinetic parameters................................... 35

5.3. Comparison of stoichiometric coefficients.............................................. 36

5.4. Comparison of PCCL coal devolatilization predictions with

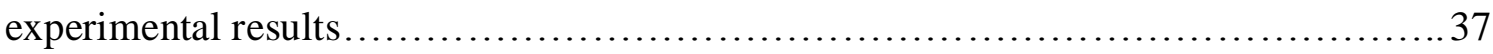

5.5. Comparison of yields of devolatilization products....................................... 39

5.6. Substitution for MFIX rate parameters using PCCL output.......................... 43

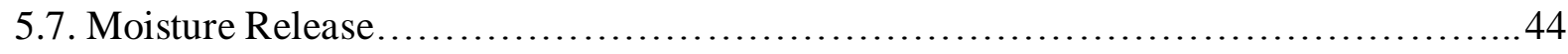

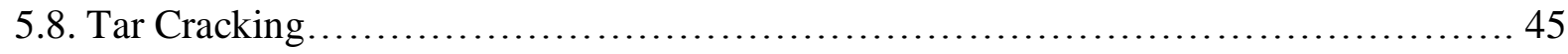


5.9. Secondary Pyrolysis with soot Oxidation.................................. 47

5.10. Biomass Devolatilization............................................... 51

5.11. Algorithm.......................................................... 55

Chapter 6: Conclusions ......................................................56

Chapter 7: Future Work ................................................ 57

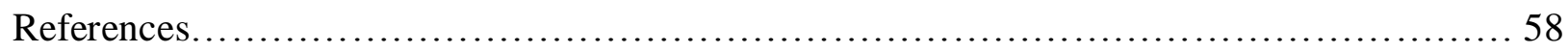

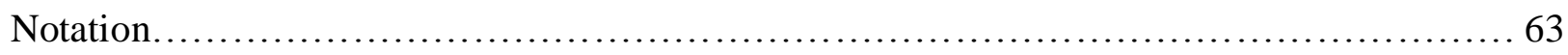

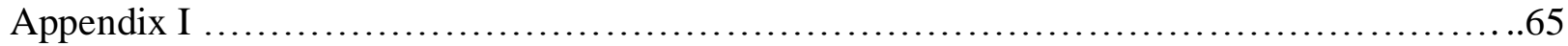




\section{List of Tables}

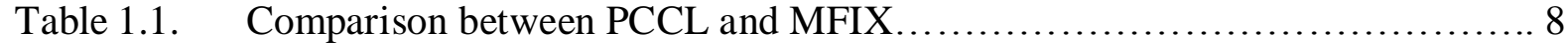

Table 2.1. Devolatilization kinetic rate constant for three types of coal.................13

Table 2.2. Tar cracking kinetic data for three coals.............................. 17

Table 3.1. Kinetic parameters for biomass devolatilization $\ldots \ldots \ldots \ldots \ldots \ldots \ldots \ldots \ldots \ldots .24$

Table 3.2. Kinetic parameters for rice husk and wheat straw pyrolysis.............. 25

Table 3.3. Kinetic parameters for Biogran and Pine sawdust..................... 25

Table 3.4. Kinetic constants for wood pyrolysis................................ 26

Table 4.1. Comparison of $\%$ of $\mathrm{C}$ in devolatilization product yield for PRB coal.........30

Table 4.2. Comparison of $\%$ of $\mathrm{C}$ in devolatilization product yield for Lignite coal.......31

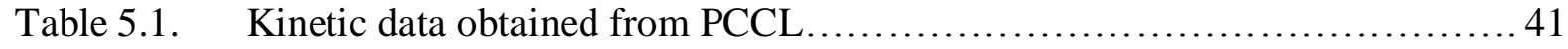

Table 5.2. Comparison of devolatilization products obtained from PCCL and MFIX.... 43 


\section{List of Figures}

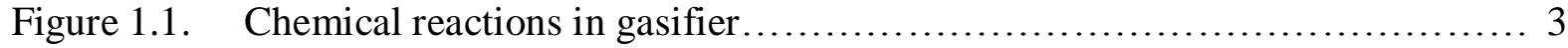

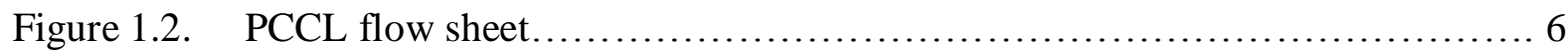

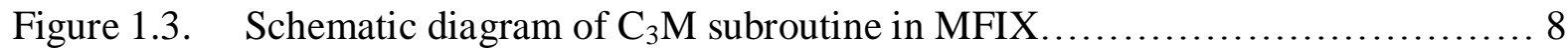

Figure 2.1. $\quad \mathrm{FDC}_{\mathrm{i}} \mathrm{SP}_{\mathrm{j}} . \mathrm{rpt}$ file showing secondary pyrolysis yields for PRB coal.......... 18

Figure 3.1. Reaction mechanism in bio-FLASHCHAIN ........................... 27

Figure 5.1. Effect of pressure on the yields of $\mathrm{CO}_{2}, \mathrm{CO}, \mathrm{CH}_{4}$, tar and total volatile matter with heating rate $1500^{\circ} \mathrm{C} / \mathrm{s}$ at $1316^{\circ} \mathrm{C} \ldots \ldots \ldots \ldots . . . .34$

Figure 5.2. Effect of temperature and heating rate on yield of $\mathrm{H}_{2}$ yield at heating rate of $1500{ }^{\circ} \mathrm{C} / \mathrm{s}, 1500^{\circ} \mathrm{C} / \mathrm{s}$ and $30000^{\circ} / \mathrm{s}$.

Figure 5.3. Graph showing effect of heating rates on the yields of $\mathrm{H}_{2}, \mathrm{CH}_{4}, \mathrm{CO}$, $\mathrm{H}_{2} \mathrm{O}$ and $\mathrm{CO}_{2}$ at operating temperature of $955^{\circ} \mathrm{C}$ at $500 \mathrm{psi}$

Figure 5.4. Figure showing comparison between devolatilization reaction

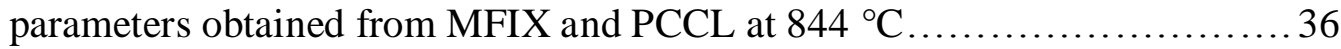

Figure 5.5. Comparison of Stoichiometric coefficients for devolatilization reaction generated from MFIX and PCCL for PRB and Lignite TC25 coal.

Figure 5.6. Graph showing total volatile yield obtained for Linby coal via PCCL and experiments at same operating conditions....

Figure 5.7. Graph showing total volatile yield obtained for Pittsburgh \# 8 and Illinois \# 6 via PCCL and experiment(EXP) at same operating conditions

Figure 5.8. Graph showing total volatile yield obtained for Pittsburgh \# 8 and Illinois \# 6 via PCCL and experiment at $1600 \mathrm{~K}$ and $2400 \mathrm{~K}$ 39

Figure 5.9. Transport flow gasifier for MFIX simulation.

Figure 5.10. Comparison of PCCL( PC) and MFIX(MC) simulations for $\mathrm{CH}_{4}$ yield at same operating conditions(Temperatures $844^{\circ} \mathrm{C}$ and $1316^{\circ} \mathrm{C}$ ) 42

Figure 5.11. Comparison of PCCL( PC) and MFIX(MC) simulations for $\mathrm{CO}_{2}$ yield at same operating conditions(Temperatures $844^{\circ} \mathrm{C}$ and $1316^{\circ} \mathrm{C}$ ).

Figure 5.12. TheFigure showing moisture release along reactor length for Lignite coal at $900{ }^{\circ} \mathrm{C}$ and a heating rate of $1000^{\circ} \mathrm{C} / \mathrm{s}$ in PCCL 
Figure 5.13. The moisture release along reactor length for PRB coal at $900{ }^{\circ} \mathrm{C}$ and heating rates of $1000^{\circ} \mathrm{C} / \mathrm{s}$ and $17496^{\circ} \mathrm{C} / \mathrm{s}$ in PCCL

Figure 5.14. The evolution of gas species during tar cracking along reactor length for PRB coal at $900{ }^{\circ} \mathrm{C}$

Figure 5.15. The evolution of gas species during secondary pyrolysis along the reactor length for Lignite coal at $1000^{\circ} \mathrm{C}$

Figure 5.16. The evolution of gas species during secondary pyrolysis along

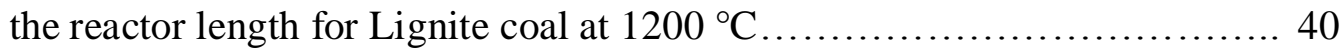

Figure 5.17. The evolution of $\operatorname{char}(\mathrm{A})$ and water (B) during oil malee pyrolysis.......... 51

Figure 5.18. A comparison of secondary pyrolysis prodcut yields obtained from experiments and PCCL for beechwood(BW), mix spruce( MS) and rice husk (RH) at $950^{\circ} \mathrm{C}$ 52

Figure 5.19. A comparison of pyrolysis prodcut yields obtained from experiments and PCCL for beechwood (A), softwood (B) at $800^{\circ} \mathrm{C}$

Figure 5.20. A comparison of pyrolysis prodcut yields obtained from experiments and PCCL for beechwood (A), softwood (B) at $1000{ }^{\circ} \mathrm{C}$. .54 


\section{Chapter 1}

\section{Introduction}

Coal is the world's most abundant and widely distributed fossil fuel source and an extremely important fuel today. Coal gasification is the method by which coal is converted to gas to generate power or processed into generating fuels or chemicals. In Gasification coal is converted into a gaseous mixture of hydrogen, carbon monoxide, carbon dioxide, methane, tar and other higher hydrocarbons by applying heat under pressure in the presence of steam and a controlled amount of oxygen in a unit called the gasifier. The standard method of describing the composition of coal is using proximate and ultimate analyses. The proximate analysis of coal gives the ash, moisture, volatile matter and fixed carbon content while the ultimate analysis gives the carbon, oxygen, hydrogen, nitrogen and sulfur content of the coal.

The gasification of coal at moderate temperatures goes through 4 stages: (1) primary devolatilization; (2) pyrolysis of secondary volatiles; (3) homogeneous reforming of non condensables and (4) char conversion via oxidation and gasification. (Naik et al., 2006) Moisture release occurs at the initial stage of reaction. Volatile matter in the coal is released as several gas phase species through devolatilization. Fixed carbon participates in combustion and gasification reactions. Ash may act as a catalyst for some gas phase reactions but it is not consumed. Devolalitilzation occurs at a much faster rate than gasification reactions. Many studies have been published discussing the kinetics for coal gasification.

There has been growing interest in mathematical modeling of coal processing. Different approaches have been presented to describe the gasification of coal and its behavioral changes due to varying operating conditions and process dependence on the coal's individual properties. The current research focuses on relating two such approaches. The first is that used in the software package called PC Coal Lab (PCCL) and the other is the approach currently used in the CFD package called MFIX. 


\subsection{Gasification Reactions}

The following brief description gives an overview of the most probable reactions happening during coal gasification.

Devolatilization reaction occurs as follows:

$$
\begin{gathered}
\text { Moisture }(\text { in coal }) \rightarrow \text { steam } \\
\text { Coal } \rightarrow C_{\alpha} H_{\beta} O_{\gamma} N_{\delta} S_{\varepsilon} \text { ash + volatiles }
\end{gathered}
$$

The volatiles consist of combustible gases like $\mathrm{CO}, \mathrm{H}_{2}, \mathrm{CH}_{4}$ and $\mathrm{C}_{6} \mathrm{H}_{6}$ together with $\mathrm{CO}_{2}, \mathrm{H}_{2} \mathrm{~S}$, $\mathrm{N}_{2}$ and tar.

Char oxidation takes place in following manner: (Wen and Chaung, 1979)

$$
\begin{aligned}
C_{\alpha} H_{\beta} O_{\gamma} N_{\delta} S_{\varepsilon} a s h+\left(\frac{\alpha}{\phi}-\frac{\gamma}{2}-\frac{\beta}{2}-\varepsilon\right) O_{2} \rightarrow 2(1 & \left.-\frac{1}{\phi}\right) \alpha C O+\left(\frac{2}{\phi}-1\right) \alpha C O_{2} \\
& +\left(\frac{\beta}{2}-\varepsilon\right) H_{2} O+\varepsilon H_{2} S+\frac{\delta}{2} N_{2}+a s h
\end{aligned}
$$

Gasification and Combustion Reactions are represented as:

Heterogeneous reactions:

$$
\begin{gathered}
2 \mathrm{C}(s)+\mathrm{O}_{2} \rightarrow 2 \mathrm{CO} \\
\mathrm{C}(\mathrm{s})+\mathrm{CO}_{2} \rightarrow 2 \mathrm{CO} \\
\mathrm{C}(\mathrm{s})+\mathrm{H} 2 \mathrm{O} \rightarrow \mathrm{H}_{2}+\mathrm{CO} \\
\mathrm{C}(\mathrm{s})+2 \mathrm{H}_{2} \rightarrow \mathrm{CH}_{4}
\end{gathered}
$$

Homogeneous reactions:

$$
\begin{gathered}
2 \mathrm{CO}+\mathrm{O}_{2} \rightarrow 2 \mathrm{CO}_{2} \\
\mathrm{CH}_{4}+2 \mathrm{O}_{2} \rightarrow \mathrm{CO}_{2}+2 \mathrm{H}_{2} \mathrm{O} \\
\mathrm{C}_{6} \mathrm{H}_{6}+\frac{15}{2} \mathrm{O}_{2} \rightarrow 6 \mathrm{CO}_{2}+3 \mathrm{H}_{2} \mathrm{O} \\
2 \mathrm{H}_{2}+\mathrm{O}_{2} \rightarrow 2 \mathrm{H}_{2} \mathrm{O} \\
\mathrm{CO}+3 \mathrm{H}_{2} \rightarrow \mathrm{CH}_{4}+\mathrm{H}_{2} \mathrm{O} \\
\mathrm{CO}_{2}+4 \mathrm{H}_{2} \rightarrow \mathrm{CH}_{4}+2 \mathrm{H}_{2} \mathrm{O} \\
\mathrm{FeS}_{2}+2 \mathrm{H}_{2} \rightarrow 2 \mathrm{H}_{2} \mathrm{~S}+\mathrm{Fe}
\end{gathered}
$$




$$
\begin{aligned}
& \mathrm{FeS}_{2}+2 \mathrm{CO} \rightarrow 2 \mathrm{COS}+\mathrm{Fe} \\
& \mathrm{H}_{2} \mathrm{~S}+\mathrm{CO}_{2} \rightarrow \mathrm{COS}+\mathrm{H}_{2} \mathrm{O} \quad(\text { Qizhi Ni et al., 1994) } \\
& \mathrm{CaCO}_{3} \rightarrow \mathrm{CaO}+\mathrm{CO}_{2} \\
& \mathrm{CaMg}\left(\mathrm{CO}_{3}\right)_{2} \rightarrow \mathrm{CaCO}_{3}+\mathrm{MgO}+\mathrm{CO}_{2} \text { (Campbell 1978) }
\end{aligned}
$$

Reactions other than carbon gasification may approach equilibrium in the available reaction time. Operating conditions such as heating rate, pressure, temperature and properties of coal have significant effects on the coal behavior in the gasification process. All these reactions are shown in pictorial form in Figure 1.1

The accuracy and validity of CFD models depends on the kinetic models used to describe homogeneous and heterogeneous reactions that take place in the gasifier. The homogeneous gas-phase reactions, taking place between pure components, are well known but the initial devolatilization and subsequent tar cracking reactions are less well documented especially at conditions at which the initial devolatilization takes place. Hence a good prediction of kinetics for these reactions is needed. PCCL's predictions of coal devolatilization products, tar gas chemistry and gasification reactions taking place for a wide variety of coals are in good agreement with experimental results obtained from laboratory measurements. (Niksa, 2008)

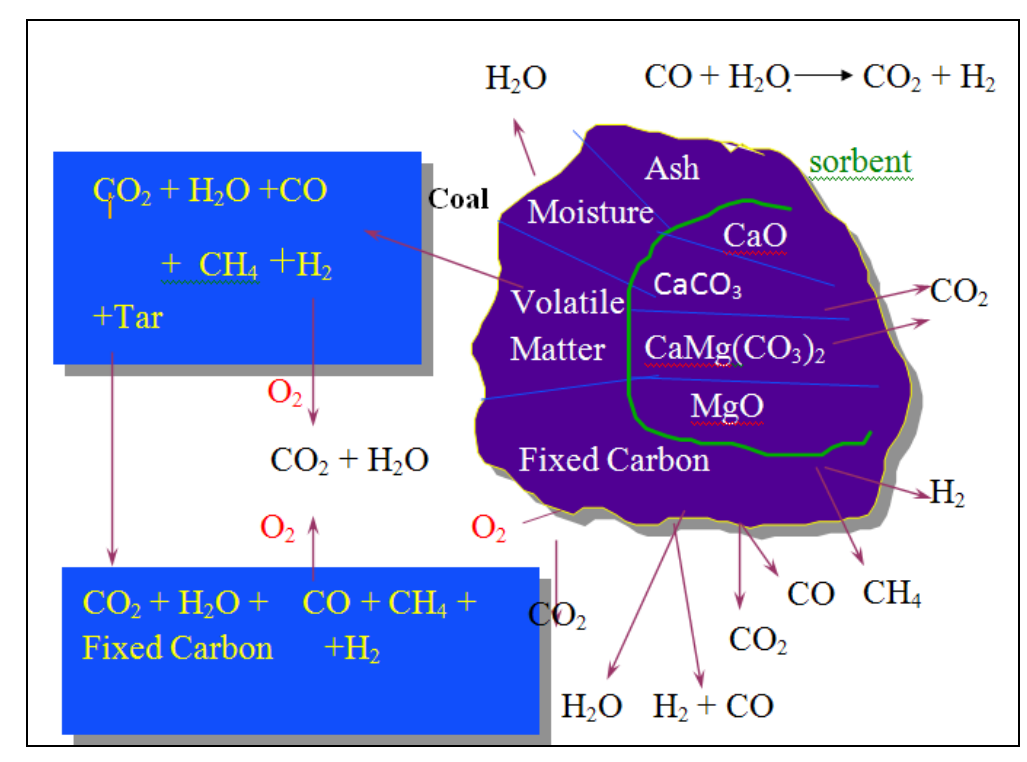

Figure 1.1 Chemical reactions in gasifier (internal DOE document) 
The predictions from PCCL consist of the complete distributions of all major primary devolatilization products such as $\mathrm{CO}_{2}, \mathrm{H}_{2} \mathrm{O}, \mathrm{CO}, \mathrm{CH}_{4}, \mathrm{C}_{2} \mathrm{H}_{4}, \mathrm{C}_{2} \mathrm{H}_{6}, \mathrm{C}_{3} \mathrm{H}_{6}, \mathrm{C}_{3} \mathrm{H}_{8}, \mathrm{H}_{2}, \mathrm{H}_{2} \mathrm{~S}, \mathrm{HCN}$, Tar, and Char - as well as the elemental compositions of tar and char and the tar molecular weight distribution. It also predicts the subsequent secondary pyrolysis of primary volatiles into $\mathrm{CO}_{2}, \mathrm{H}_{2} \mathrm{O}, \mathrm{CO}, \mathrm{H}_{2}, \mathrm{CH}_{4}, \mathrm{C}_{2} \mathrm{H}_{2}$, and soot

MFIX uses the default gasification reaction kinetics subroutines available in $\mathrm{C}_{3} \mathrm{M}$, which are limited to few coal types. Moreover these kinetic expressions do not give accurate predictions. Hence we need to have more accurate predictions of coal gasification kinetics and for a wider variety of coals. Therefore, the main objective of this work is to use the predicted kinetics given by PCCL and transfer these results to MFIX by modifying the $\mathrm{C}_{3} \mathrm{M}$ code. This work will essentially comprise of developing an algorithmic bridge which will transfer the predictions of PCCL to MFIX by updating the relevant kinetic parameters in $\mathrm{C}_{3} \mathrm{M}$. The primary focus of this research will be to transfer information on kinetics for devolatilization and tar cracking reactions from PCCL to MFIX. The process will be initiated by the user when the ultimate and proximate analysis for a coal is input in PCCL, the reaction kinetics generated from it will be transferred to $\mathrm{C}_{3} \mathrm{M}$ in a readable form and these new values will be used in MFIX. Hence the data transfer for the path PCCL $\rightarrow \mathrm{C}_{3} \mathrm{M} \rightarrow$ MFIX will be implemented.

Alternatively, if the user gives the proximate and ultimate analysis for a given coal as input to MFIX, then they should be able to run PCCL using that information and transfer the reaction kinetics to MFIX and update the $\mathrm{C}_{3} \mathrm{M}$ default kinetics and perform the simulation. This path would be MFIX $\rightarrow$ PCCL $\rightarrow \mathrm{C}_{3} \mathrm{M} \rightarrow \mathrm{MFIX}$.

\subsection{Need for a Gasification Model}

One of the main reasons for developing sophisticated models for coal combustion and gasification is the different time scales that exist for the various chemical processes. For example, volatiles burn away in tens or hundreds of milliseconds, whereas char burnout requires a few seconds and char gasification requires tens of seconds. The modeling of coal reaction kinetics is both important and necessary to understanding and predicting the performance of modern gasifier (Niksa, 2008). Mathematical models help to identify key factors involved in coal 
type selection, gasifier design and gasification conditions in the gasifier. Such models also save the time and cost of building and operating an experimental set up.

\subsection{PC COAL LAB (PCCL)}

PCCL is a set mathematical models that predicts a fuel's (mainly coal and biomass) devolatilization and gasification behavior by simulating processes as they would occur in simple laboratory test facilities. The focus of the current research is to develop a systematic method to take the results and kinetic expressions generated in PCCL Version 4.1 and use them in the $\mathrm{C}_{3} \mathrm{M}$ code that may be called by MFIX. PCCL predicts the devolatilization, combustion, and gasification behavior of a wide variety of coals. The software can simulate two types of tests, namely, an electrically heated wire grid experiment and a laminar flow drop tube furnace experiment. The predictions give the yields of all major primary devolatilization products $-\mathrm{CO}_{2}$, $\mathrm{H}_{2} \mathrm{O}, \mathrm{CO}, \mathrm{CH}_{4}, \mathrm{C}_{2} \mathrm{H}_{4}, \mathrm{C}_{2} \mathrm{H}_{6}, \mathrm{C}_{3} \mathrm{H}_{6}, \mathrm{C}_{3} \mathrm{H}_{8}, \mathrm{H}_{2}, \mathrm{H}_{2} \mathrm{~S}, \mathrm{HCN}$, tar, and char - as well as the elemental compositions of tar and char and the tar molecular weight distribution. It also predicts the subsequent secondary pyrolysis of primary volatiles into $\mathrm{CO}_{2}, \mathrm{H}_{2} \mathrm{O}, \mathrm{CO}, \mathrm{H}_{2}, \mathrm{CH}_{4}, \mathrm{C}_{2} \mathrm{H}_{2}$, and soot.

PCCL v4.1 describes char combustion from ignition throughout the later stages of burnout based on the expanded version of Hurt's Carbon Burnout Kinetics (CBK) Model (Hurt, 2002). It also describes char gasification by $\mathrm{H}_{2} \mathrm{O}, \mathrm{CO}_{2}, \mathrm{H}_{2}$, and $\mathrm{CO}$ with a newly expanded version of CBK called CBK/G.

In order to run PCCL, the following procedure is followed:

a) The user selects up to five fuels for testing,

b) Proximate and ultimate analyses are input.

c) The method by which the simulation needs to be run is selected, either the wire grid or the drop tube method.

d) The reactor configuration is chosen, and up to five sets of operating conditions for a particular test series are specified.

e) Tests using the wire-grid require values for the initial and ultimate temperature, the heating rate, the reaction time at the ultimate temperature, and the pressure. 


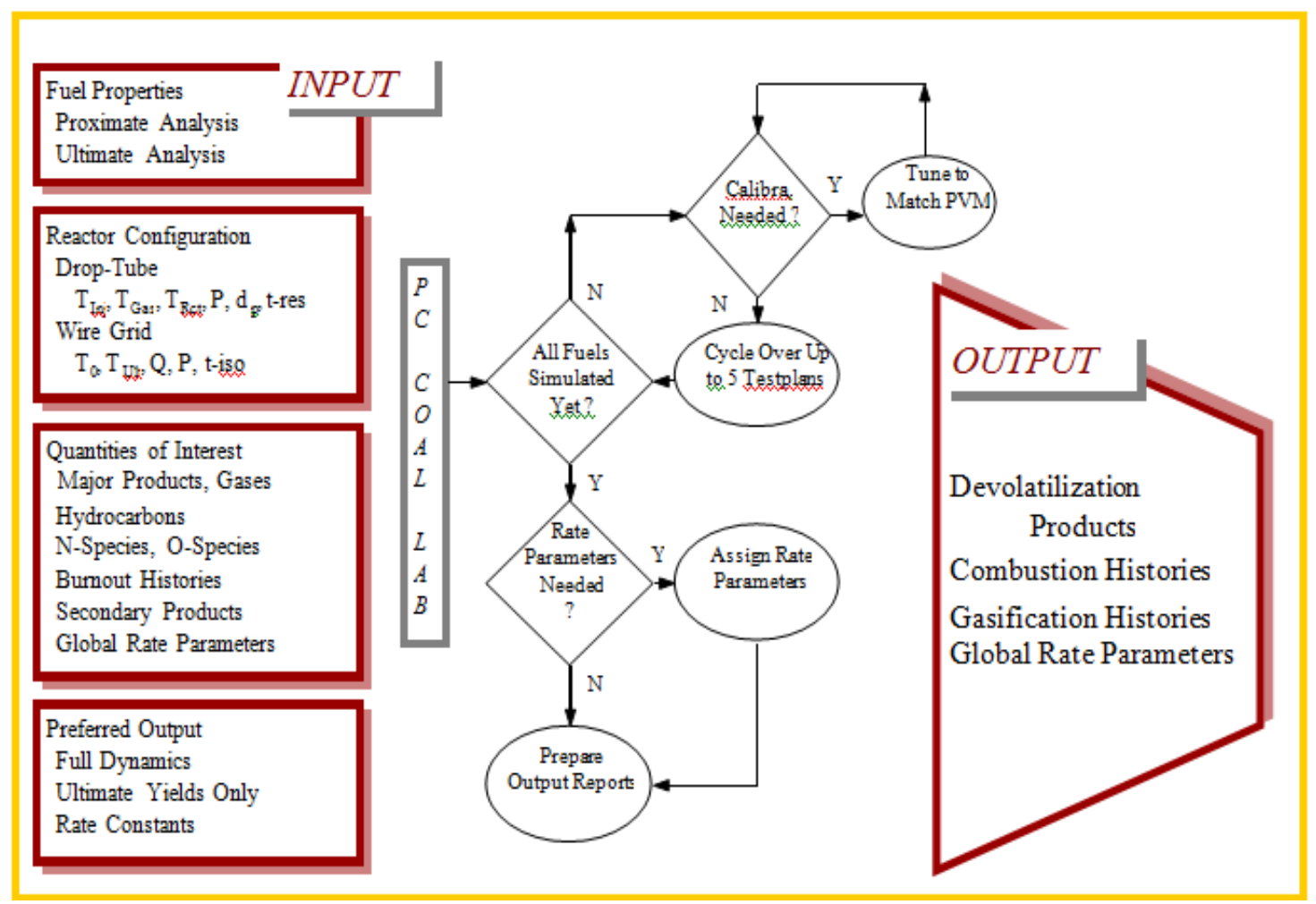

Figure 1.2: PCCL flow sheet (Niksa, 2008)

f) Tests with the drop tube furnace require values for the initial fuel temperature, temperatures of the gas stream and reactor wall, the gas composition the pressure, mean particle size, and the total residence time.

g) The desired results are selected and include: devolatilization behavior, the distribution of non condensable gases, the distributions of hydrocarbons with $\mathrm{H}_{2}$ and $\mathrm{H}_{2} \mathrm{~S}$, the $\mathrm{N}$-species distributions, the $\mathrm{O}$-species distributions, tar characteristics, char characteristics, and product distributions for secondary volatiles pyrolysis, char oxidation and char gasification characteristics, reaction kinetics parameters. Users select only the reports that interest them for each simulation.

h) After entering all input information a simulation is run to attain the required results. 


\subsection{Multiphase Flow with Interphase Exchange (MFIX)}

Currently, various CFD codes have been developed to simulate different gasifiers. The CFD code of most interest in the current study is called Multiphase Flow with Interphase Exchanges (MFIX). MFIX is a general-purpose computer code developed at The Department of Energy's National Energy Technology Laboratory (NETL) for describing the hydrodynamics, heat transfer and chemical reactions in fluid-solids systems. It has been used for describing bubbling and circulating fluidized beds and spouted beds. MFIX calculations yield transient data on the three-dimensional distribution of pressure, velocity, temperature, and species mass fractions. The MFIX code is based on a generally accepted set of multiphase flow equations. The following features of MFIX are relevant to the current work (https://mfix.netl.doe.gov/about_mfix.php)

1. MFIX has species mass, energy and momentum balance equations for gas and solid phases.

2. It can access a 3-dimensional coordinate system with either Cartesian or cylindrical coordinates.

3. The required inputs are very simple.

4. MFIX is written in Fortran that allows users to modify easily and enhance the code.

5. MFIX generates serial, shared-memory parallel (SMP) or distributed-memory parallel (DMP) executables from the same code base.

As specified previously, MFIX simulates the reaction kinetics for coals using a default subroutine named Carbonaceous Chemistry for Continuum Modeling $\left(\mathrm{C}_{3} \mathrm{M}\right)$. The MFIX model for coal chemistry $\left(\mathrm{C}_{3} \mathrm{M}\right.$ subroutine) is a modified version of the reaction scheme from the METC Gasifier Advanced Simulation (MGAS) (Syamlal and Bissett 1992) and is based on gasification kinetic equations proposed by Wen et al. (1982). The kinetics for coal gasification reactions other than devolatilization and tar cracking give fairly good predictions for the yield and evaluation of product gases. Figure 1.3 gives the pictorial representations of subroutines available in $\mathrm{C}_{3} \mathrm{M}$ module. 


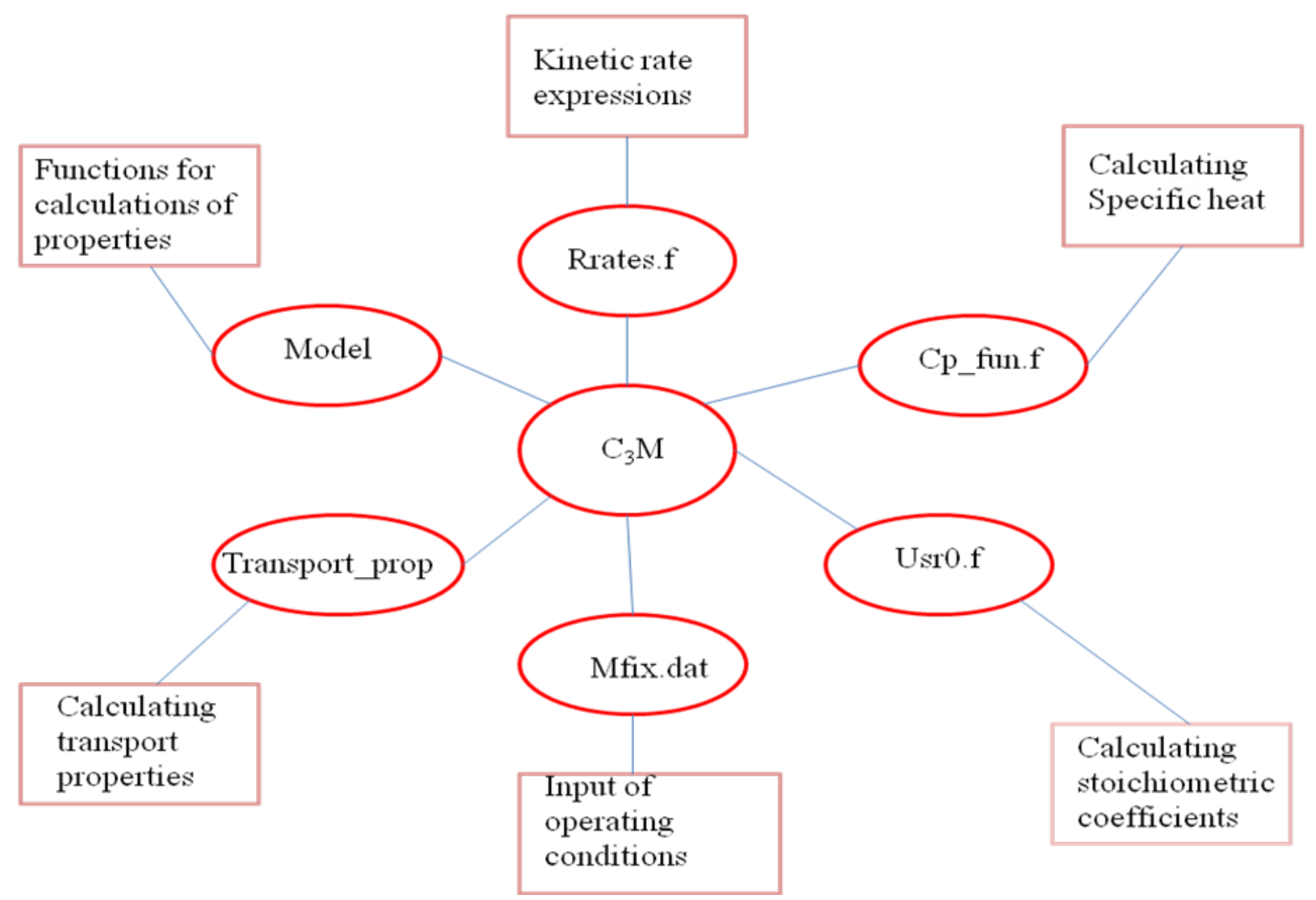

Figure 1.3: Schematic diagram of $\mathrm{C}_{3} \mathrm{M}$ subroutine in MFIX.

The default units used in MFIX code are grams, centimeters, seconds, calories and Kelvin.

The following table, Table 1.1, shows the one to one comparison between MFIX and PCCL regarding its functional form for gasification.

Table 1.1 Comparisons between PCCL and MFIX

\begin{tabular}{|l|l|l|}
\hline Number & MFIX & PCCL \\
\hline 1 & $\begin{array}{l}\text { MGAS tracks 14 gas species, while } \mathrm{C}_{3} \mathrm{M} \\
\text { module in MFIX considers only } 8 \text { it } \\
\text { lumps all other species as tar in MFIX }\end{array}$ & species during the whole coal gasification, \\
& & \\
\hline
\end{tabular}




\begin{tabular}{|c|c|c|}
\hline 2 & $\begin{array}{l}\mathrm{C}_{3} \mathrm{M} \text { module in MFIX does not consider } \\
\text { ash as an inert; from literature it supports } \\
\text { that mineral content of ash can act as } \\
\text { catalyst also for some reaction. }\end{array}$ & PCCL assumes ash to be inert. \\
\hline 3 & $\begin{array}{l}\text { For devolatilization MFIX uses the } \\
\text { reaction kinetics available in the literature } \\
\text { with some modified values of reaction } \\
\text { rate constant. }\end{array}$ & $\begin{array}{l}\text { PCCL uses the } 3 \text { methods to predict the } \\
\text { devolatilization reaction kinetics namely } \\
\text { SFOR, DAEM and C2SM methods }\end{array}$ \\
\hline 4 & $\mathrm{C}_{3} \mathrm{M}$ accounts for water gas shift reaction & $\begin{array}{l}\text { PCCL does not account for water gas shift } \\
\text { reaction }\end{array}$ \\
\hline 5 & $\begin{array}{l}\text { MFIX has first order reaction rate } \\
\text { equation for gasification reaction. }\end{array}$ & $\begin{array}{l}\text { PCCL uses simple } n^{\text {th }} \text { order rate } \\
\text { expression for } \mathrm{CO}_{2}, \mathrm{H}_{2} \mathrm{O} \text { and char } \\
\text { hydrogen gasification reactions. }\end{array}$ \\
\hline 6 & $\begin{array}{l}\text { MFIX has different reaction kinetics for } \\
\text { carbon, hydrogen, and tar combustion. }\end{array}$ & $\begin{array}{l}\text { PCCL has char and soot combustion } \\
\text { reaction kinetics. }\end{array}$ \\
\hline 7 & $\begin{array}{l}\text { Some gasification reaction rate equations } \\
\text { have temperature barrier, e.g. above } \\
1200^{\circ} \mathrm{C} \text { the rate equation for char steam } \\
\text { gasification reaction should not be used. } \\
\text { Similarly Char } \mathrm{CO}_{2} \text { reactions rate } \\
\text { equation should be used below } 1300^{\circ} \mathrm{C}\end{array}$ & $\begin{array}{l}\text { In PCCL the temperature effect is taken } \\
\text { into consideration by the SNOR model for } \\
\text { gasification reactions and by SFOR for } \\
\text { devolatilization reactions. }\end{array}$ \\
\hline 8 & $\begin{array}{l}\text { Shrinking core model is used for char } \\
\text { combustion in MFIX }\end{array}$ & $\begin{array}{l}\text { PCCL does not use the shrinking core } \\
\text { model for char combustion. }\end{array}$ \\
\hline
\end{tabular}


Gasification reaction rates are well studied compared to devolatilization. Devolatilization predictions given by PCCL using the FLASHCHAIN (Niksa (1991a, 1991b, 1991c, 1994b) ) mechanism are more accurate when compared to laboratory data. The amount of volatiles produced and the amount of char generated will affect the subsequent gasification reactions; hence, devolatilization should be studied in detail. 


\section{Chapter 2}

\section{GASIFICATION KINETICS}

In gasification, when coal is heated under pressure with steam and oxygen it gives out volatile matter, tar, and unburned char which further undergo several reactions that evolve gaseous products such as $\mathrm{CO}_{2}, \mathrm{CO}, \mathrm{H}_{2} \mathrm{O}, \mathrm{CH}_{4}$ along with some hydrocarbons and $\mathrm{H}_{2}$. The following sections outline a review of the reactions that take place in the gasification process and the reaction kinetics for them.

\subsection{Drying}

Coal consists of moisture and the evaporation of the moisture occurs during heating. When coal is heated at around atmospheric pressure uncombined water is evolved below $105^{\circ} \mathrm{C}$ and the remaining moisture is released when temperature approaches $300^{\circ} \mathrm{C}$. (Desai and Wen, 1978)

$$
\text { Moisture(in coal) } \rightarrow \text { steam }
$$

The rate of loss of moisture from a coal is given by an equation proposed by (Syamlal and Bisset 1992):

$$
\text { Rate }=1.1 \times 10^{5} \exp \left(\frac{-21,200}{R T_{s}}\right) \varepsilon_{\mathrm{s}} \rho_{\mathrm{s}} \mathrm{X}_{\mathrm{s}, \mathrm{H}_{2} \mathrm{O}} \quad\left(\mathrm{g} / \mathrm{cm}^{3} \cdot \mathrm{s}\right),
$$

This rate equation is used in MFIX to calculate moisture release.

Whitty (2003) suggests the volumetric evaporation rate for a black liquor droplet as

$$
m_{\text {vap }}=\frac{6 h_{w}}{d_{p} \lambda_{\text {vap }}}\left(T_{g}-T_{p}\right)
$$

PCCL gives the drying rate as water flux $\left(\mathrm{kg} / \mathrm{m}^{2} \mathrm{~s}\right)$ along with vapor enthalpy $(\mathrm{J} / \mathrm{kg})$ in the /output file $\mathrm{CFDC}_{\mathrm{i}} \mathrm{T}_{\mathrm{j}}$.rpt.

\subsection{Devolalitilzation}

When coal is heated to high temperatures it gives out volatiles that consist of the following component gases $\mathrm{CO}, \mathrm{CO}_{2}, \mathrm{CH}_{4}, \mathrm{H}_{2} \mathrm{O}, \mathrm{H}_{2}$, tar and higher hydrocarbons. This transformation can be simply represented as: 


$$
\begin{aligned}
\mathrm{VM} \rightarrow & \alpha_{d} \operatorname{tar}+\beta_{\mathrm{CO}}^{\mathrm{d}} \mathrm{CO}+\beta_{\mathrm{CO}_{2}}^{d} \mathrm{CO}_{2}+\beta_{\mathrm{CH}_{4}}^{d} \mathrm{CH}_{4}+\beta_{\mathrm{H}_{2}}^{d} \mathrm{H}_{2}+\beta_{\mathrm{H}_{2}}^{\mathrm{d}} \mathrm{H}_{2} \mathrm{O}+\beta_{C_{2} \mathrm{H}_{4}}^{d} \mathrm{C}_{2} \mathrm{H}_{4} \\
& +\beta_{\mathrm{C}_{2} \mathrm{H}_{6}}^{\mathrm{d}} \mathrm{C}_{2} \mathrm{H}_{6}+\beta_{\mathrm{C}_{3} \mathrm{H}_{8}}^{d} \mathrm{C}_{3} \mathrm{H}_{8}+\beta_{\mathrm{C}_{6} \mathrm{H}_{6}}^{\mathrm{d}} \mathrm{C}_{6} \mathrm{H}_{6}+\beta_{\mathrm{H}_{2} \mathrm{~S}}^{\mathrm{d}} \mathrm{H}_{2} \mathrm{~S}+\beta_{\mathrm{NH}_{3}}^{d} \mathrm{NH}_{3}
\end{aligned}
$$

$\beta$ and $\alpha$ are the respective stoichiometric coefficients for the products as mass fractions.

Devolatilization kinetics is a very complex area because of the structure variation within different types of coals. A few kinetic models treat devolatilization as a volatile release in a fractional distillation (Niksa ,1988) and others have concentrated on an analytical approach dealing with the different types of chemical bonds in a coal (Solomon, 1988). Badzioch and Hawksley (1970) proposed the devolatilization as a fist order reaction with respect to volatile matter remaining in coal:

$$
\text { rate }=k \exp (-E / R T)\left(V^{*}-V\right)
$$

Some authors reported that under varying conditions like time, temperature, pressure, a first order rate equation does not hold. Ubhayakar (1977) defined two types of volatiles, benzene and ethylene that are released at different rates and this lead to the following twin reaction rate expression:

$$
\text { rate } \left.=\left(a_{1} k_{1} e^{\frac{-E_{1}}{R T}}+a_{2} k_{2} e^{\frac{-E_{2}}{R T}}\right) m_{c} e^{-\int\left(k_{1} \frac{-E_{1}}{R T}\right.}+k_{2} \frac{-E_{2}}{R T}\right) d t
$$

Where $a_{1}$ and $a_{2}$ are the possible yield of the two volatile types, $m_{c}$ is mass of undevolatilised coal.

Models by Solomon (1988), van Heek (1990) and Niksa (1988) determine the rates of devolatilization of individual gases from volatile matter based on specific bond types in a coal in order to predict better accuracy. In general, more complex models are not necessary for devolatilization as this process occurs over a very short time period.

The devolatilization rate equation suggested by Wen et al. (1982) has the following simple form:

$$
\text { rate }=k_{d} \exp \left(-E_{d} / R_{g} T_{s}\right)(1-\varepsilon) \rho_{s} X_{V M}
$$

Values of frequency factor and activation energy are given according to coal type in Table 2.1. Syamlal and Bisset (1992) modified this rate form because volatile matter release depends on temperature. The modified form of the equation used in $\mathrm{C}_{3} \mathrm{M}$ as the devolatilization rate equation is:

$$
\begin{array}{ll}
\text { rate }=k_{d} \exp \left(-E_{d} / R_{g} T_{s}\right)(1-\varepsilon) \rho_{s}\left(X_{V M}-X^{*}\right) & ; X^{*} \leq X_{V M} \\
\text { rate }=0 & ; X_{V M}<X^{*}
\end{array}
$$


Where $X^{*}$ is minimum possible volatile fraction that is determined using a correlation given by Gregory and Little John (1965)

$$
\begin{array}{ll}
X_{0}^{*}=\frac{\left(\frac{867.2}{\left(T_{s}-273\right)}\right)^{3.914}}{100} T_{S}<1223 K \\
X_{0}^{*}=0 & T_{s}>1223 K
\end{array}
$$

$X_{0}{ }^{*}$ is the weight of remaining volatiles as a fraction of the original dry ash free coal

$$
X^{*}=\frac{\rho_{S 0}\left(X_{F C 0}+X_{V M 0}\right) X_{0}^{*}}{\rho_{s}}
$$

The values of $k_{d}$ and $E_{d}$ for different coals are given in Table 2.1

Table 2.1: Devolatilization kinetic rate constant for three types of coal

\begin{tabular}{|l|c|c|c|}
\hline $\begin{array}{l}\text { Reaction rate } \\
\text { constant }\end{array}$ & Bituminous coal & Sub bituminous coal & Lignite \\
\hline$k_{\mathrm{d}}[1 / \mathrm{sec}]$ & $1.1 \times 10^{5}$ & $7.5 \times 10^{4}$ & $5.1 \times 10^{4}$ \\
\hline$E_{\mathrm{d}}[\mathrm{cal} / \mathrm{g}-\mathrm{mole}]$ & $21.2 \times 10^{3}$ & $18.7 \times 10^{3}$ & $16.2 \times 10^{3}$ \\
\hline
\end{tabular}

Choi et al. (2001) used the following devolatilization model for an entrained flow coal gasifier;

$$
m_{v}=m_{c}\left[\alpha_{1} \beta_{v 1} \exp \left(\frac{-E_{V 1}}{R T_{p}}\right)+\alpha_{2} \beta_{v 2} \exp \left(-\frac{E_{v 2}}{R T_{P}}\right)\right]
$$

where,

$E_{V 1}$ and $E_{v 2}=$ activation energy of forward and backward reaction respectively, $\mathrm{J} / \mathrm{mol}$

$\beta_{v 1}$ and $\beta_{v 2}=$ equivalent frequency factor of forward and backward reaction , $\mathrm{s}^{-1}$

$\alpha_{1}=$ volatile constant based on combustible analysis

$\alpha_{2}=$ empirical constant between 0.8 and 1

$T_{P}=$ solid phase temperature

Chen et al. (2000) proposed the following rate equation for devolatilization in entrained flow gasifiers: 


$$
\begin{gathered}
\frac{d Y}{d t}=\frac{d\left(Y_{1}+Y_{2}\right)}{d t}=k_{1}\left(Y_{1}^{*}-Y_{1}\right)+k_{2}\left(Y_{2}^{*}-Y_{2}\right) \\
k_{1}=A_{1} \exp \left(-E_{1} / R T_{p}\right) \\
k_{2}=A_{2} \exp \left(-E_{2} / R T_{p}\right)
\end{gathered}
$$

Where, $A_{l}=3.7 \times 10^{5} \mathrm{~s}^{-1} ; A_{2}=1.5 \times 10^{13} \mathrm{~s}^{-1} ; E_{l}=7.4 \times 10^{4} \mathrm{~kJ} / \mathrm{mol} ; E_{2}=2.5 \times 10^{5} \mathrm{~kJ} / \mathrm{mol}$.

PCCL predicts the devolatilization species kinetics using the FLASHCHAIN mechanism. FLASHCHAIN represents a given coal's distinctive devolatilization behavior with very good accuracy. The FLASHCHAIN mechanism is described in detail by a series of papers by Niksa (1991a, 1991b, 1991c, 1994b)

According to this mechanism, the influences of thermal history, pressure, and particle size can be understood in terms of only four mechanisms: (1) coal macromolecules depolymerize into fragments with a broad size distribution; (2) a phase equilibrium establishes the mole fraction of tar fragments in a gas stream that are convected out of the particle with no transport resistance; (3) the conversion of labile bridges in the fragments into char links suppresses depolymerization and simultaneously generates non condensable gases; and (4) fragments also crosslink in the condensed phase to form nonvolatile components of char. However for simplicity, PCCL has only three different mechanisms to predict devolatilization such as single first-order reaction (SFOR), the competing two-step reactions model (C2SM) and the distributed activation energy model (DAEM).

The SFOR equation for devolatilization is

$$
\frac{d V(t)}{d t}=A \exp \left(\frac{-E_{a}}{R T}\right)\left(V^{\infty}-V(t)\right)
$$

where,

$V(t)=$ the instantaneous volatiles yield; \% dry ash free

$V^{\infty}=$ the hypothetical ultimate volatiles yield; \% dry ash free

$A=$ pseudo-frequency factor, $\mathrm{s}^{-1}$

$E_{a}=$ apparent activation energy, $\mathrm{kcal} / \mathrm{mol}$

$A, E_{a}$, and $V^{\infty}$ are adjustable parameters that vary with temperature, heating rate, pressure, and coal type. The weight loss rate, $d V(t) / d t$, is evaluated as the sum of the total rates of tar and gas release from FLASHCHAIN. $A$ and $E_{a}$ values can be obtained in the PCCL output file called 
$\mathrm{CFDC}_{\mathrm{i}} \mathrm{T}_{\mathrm{j}}$.rpt. The SFOR over predicts the weight loss in the initial stage of reaction with various heating rates. This is a universal flaw of SFOR.

DAEM rate equation:

The distributed activation energy model (DAEM) for devolatilization is,

$$
\frac{d V(t)}{d t}=V^{\infty} \int_{0}^{\infty} A \exp \left(\frac{-E}{R T}\right) \exp \left[-\int_{0}^{t} A \exp \left(\frac{-E}{R T}\right) d t^{\prime}\right] f(E) d E
$$

where

$V(t)$ is the instantaneous volatiles yield;

$V^{\infty}$ is the hypothetical ultimate volatiles yield;

$A$ is a pseudo-frequency factor,

$E$ is a particular activation energy in a continuous distribution function, $f(E)$.

and

$$
f(E)=\frac{1}{\sqrt{2 \pi \sigma}} \exp \left(-\frac{\left(E-E_{0}\right)^{2}}{2 \sigma^{2}}\right)
$$

$\sigma$ is the standard deviation about the mean energy.

DAEM represents the impact of temperature and heating rate variation better than SFOR and it is suited for moderate temperatures.

C2SM rate equation:

The C2SM model is discussed in detail by Kobayashi et al. (1977). The mechanism is represented as,

$$
\begin{gathered}
S \stackrel{k_{1}}{\longrightarrow} y_{1} V_{1}+\left(1-y_{1}\right) C_{1} \\
S \stackrel{k_{2}}{\longrightarrow} y_{2} V_{2}+\left(1-y_{2}\right) C_{2} \\
\frac{d V(t)}{d t}=\int_{0}^{t}\left(y_{1} k_{1}\left(t^{\prime}\right)+y_{2} k_{2}\left(t^{\prime}\right)\right) S\left(t^{\prime}\right) d t^{\prime}
\end{gathered}
$$

where 


$$
S=S_{0} \exp \left(-\int_{0}^{t}\left(k_{1}+k_{2}\right) d t^{\prime}\right)
$$

$S$ is the coal reactant; $S_{0}$ is initial coal reactant concentration;

$V_{1}(t)$ and $V_{2}(t)$ are instantaneous volatiles yields generated through channels 1 and 2, respectively;

$C_{1}(t)$ and $C_{2}(t)$ are instantaneous char yields; $k_{1}$ and $k_{2}$ are rate constants of Arrhenius form;

$y_{1}$ and $y_{2}$ are stoichiometric coefficients that are less than unity.

These six required parameters are assigned using PCCL. For simplicity the SFOR mechanism will be used when linking PCCL to MFIX.

The SFOR parameter for various operating conditions can be obtained from the output file named $\mathrm{CFDC}_{\mathrm{i}} \mathrm{T}_{\mathrm{j}}$.rpt under the section devolatilization parameters. PCCL generates SFOR parameters for individual species formation rate and can be obtained from the output file SFORT $_{\mathrm{i}} \mathrm{C}_{\mathrm{j}} \cdot \mathrm{rpt}$.

\subsection{Tar Cracking}

Tar formed during the devolatilization reaction undergoes pyrolysis producing higher hydrocarbons, non condensable gases, oil, PAH and soot along with some fixed carbon.

$$
\begin{aligned}
\operatorname{tar} \rightarrow & \alpha_{\mathrm{c}} \text { Fixed carbon }+\beta_{c}^{\mathrm{CO}} \mathrm{CO}+\beta_{c}^{\mathrm{CO}_{2}} \mathrm{CO}_{2}+\beta_{c}^{\mathrm{CH}_{4}} \mathrm{CH}_{4}+\beta_{c}^{\mathrm{H}_{2}} \mathrm{H}_{2} \\
& +\beta_{c}^{\mathrm{H}_{2} \mathrm{O}} \mathrm{H}_{2} \mathrm{O}+\mathrm{Oil}+\mathrm{PAH}
\end{aligned}
$$

The tar cracking rate is given by Wen et al. (1982):

$$
\text { tar } \rightarrow \text { product gases }
$$

Product gases consist of components lighter than $\mathrm{C}_{6}$, i.e., $\mathrm{CO}, \mathrm{CH}_{4}, \mathrm{CO}_{2}, \mathrm{C}_{2} \mathrm{H}_{6}, \mathrm{H}_{2} \mathrm{O}$ etc. The rate of tar cracking is given by,

$$
\text { rate }=k_{20} \exp \left(\frac{-E_{20}}{R_{g} T}\right) C_{t a r}
$$

and tar deposits as char :

$$
\begin{gathered}
\operatorname{tar} \rightarrow \text { char } \\
\text { rate }=k_{30} \exp \left(\frac{-E_{30}}{R_{g} T}\right) C_{t a r}
\end{gathered}
$$


Where $k_{20}$ and $k_{30}$ are rate constant, $\mathrm{s}^{-1}, E_{20}$ and $E_{30}$ are activation energies $(\mathrm{cal} / \mathrm{mol})$ and $C_{\text {tar }}$ is the concentration of tar $\left(\mathrm{gmole} / \mathrm{cm}^{3}\right)$

Rate constant for three coal types are given in Table 2.2

Table 2.2 Tar cracking kinetic data for three coals (Wen et al. 1982)

\begin{tabular}{|c|c|c|c|}
\hline $\begin{array}{c}\text { Reaction rate } \\
\text { constant }\end{array}$ & Bituminous coal & Sub bituminous coal & Lignite \\
\hline$k_{20}(\mathrm{sec})^{-1}$ & $9.7 \times 10^{9}$ & $3.5 \times 10^{10}$ & $8 \times 10^{10}$ \\
\hline$E_{20}(\mathrm{cal} / \mathrm{mol})$ & $29.0 \times 10^{3}$ & $27.75 \times 10^{3}$ & $26.50 \times 10^{3}$ \\
\hline$k_{30}(\mathrm{sec})^{-1}$ & $5.3 \times 10^{4}$ & $2.5 \times 10^{4}$ & $1.1 \times 10^{3}$ \\
\hline$E_{30}(\mathrm{cal} / \mathrm{mol})$ & $7.0 \times 10^{3}$ & $5.5 \times 10^{3}$ & $4.0 \times 10^{3}$ \\
\hline
\end{tabular}

Despite the problems with the simplest global rate expressions, it is always possible to identify the parameters in simple, global rate laws for tar decomposition that will match predictions closely to the predictions from the FLASHCHAI in PCCL.

The formulation follows a two-step, first-order, reaction model (Niksa, 2008)

$$
\begin{gathered}
\frac{d^{1} W_{T}}{d t}={ }^{1} R_{T}={ }^{1} k_{T}\left({ }^{1} W_{T}^{\infty}-{ }^{1} W_{T}(t)\right) \\
\frac{d \Delta W_{T}}{d t}={ }^{2} R_{T}=k_{T}\left(\Delta W_{T}^{\infty}-\Delta W_{T}(t)\right)
\end{gathered}
$$

The first rate equation describes the release of primary tar with a conventional SFOR; and the second describes the secondary conversion of tar in terms of the difference between the instantaneous primary and secondary tar yields, i.e., $\Delta \mathrm{W}_{\mathrm{T}}={ }^{1} \mathrm{~W}_{\mathrm{T}}(\mathrm{t})-\mathrm{W}_{\mathrm{T}}(\mathrm{t})$. Once ${ }^{1} \mathrm{~W}_{\mathrm{T}}$ and $\Delta \mathrm{W}_{\mathrm{T}}$ are evaluated, $\mathrm{W}_{\mathrm{T}}(\mathrm{t})$ is determined as ${ }^{1} \mathrm{~W}_{\mathrm{T}}-\Delta \mathrm{W}_{\mathrm{T}}$. These data are generated by PCCL.

In PCCL, when the temperature is above $1000^{\circ} \mathrm{C}$ in secondary pyrolysis it is advisable to consider tar conversion into soot and if the temperature is below $1000^{\circ} \mathrm{C}$ the $\mathrm{PAH}$ are the main products of tar decomposition. Depending on availability of hydrogen, PAH may get converted into gases such as higher hydrocarbons and methane.

Rate parameters for tar decomposition can be obtained in the output file $\mathrm{SFRT}_{\mathrm{i}} \mathrm{C}_{\mathrm{j}} \cdot \mathrm{rpt}$ 


\subsection{Secondary Pyrolysis}

Primary pyrolysis (devolatilization) products include light gases, char, and tar, which is a gas mixture of heavy-molecular-weight hydrocarbons at high temperatures and condensable at room temperature. Simultaneously, the volatile matter released in the gas phase may also undergo secondary reactions. Soot is believed to be one of the products of these secondary reactions. Primary devolatilization products are transformed into secondary pyrolysis products at high temperatures such as soot, $\mathrm{CO}, \mathrm{CO}_{2}, \mathrm{H}_{2} \mathrm{O}, \mathrm{H}_{2}, \mathrm{C}_{2} \mathrm{H}_{2}$ and $\mathrm{CH}_{4}$.

Soot is made up of small carbonaceous particles. Tar, oil and PAH generated from tar cracking cannot survive high temperatures. McLean, et al. (1981) first proposed that tar is a precursor of soot in coal flames. Tar gets transformed into a soot aerosol that grows and coalesces into sooty chain agglomerates similar to soot formed in gaseous hydrocarbon flames. At moderate temperatures, PAH like tars will survive but at temperatures above $900-1000^{\circ} \mathrm{C}$, PAH re-polymerize with non condensable unsaturated hydrocarbons to form soot (Niksa, 2008). A global mechanism for soot formation that was proposed by Chen et al. (1992) is shown below:

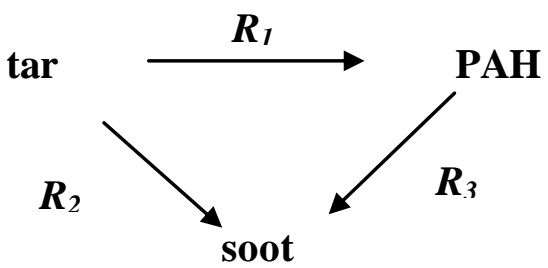

All reaction pathways shown above are irreversible. In the earlier stages, $R_{2}$ is the major pathway for soot formation, and nitrogen-containing compounds are incorporated in soot. Thereafter, substantial soot mass is added via $R_{3}$. Direct tar addition to soot in later stages is possible only if tars eliminate their nitrogen before getting added to the soot. Secondary pyrolysis occurs in the gas phase; hence it can also be affected by reactive gases, especially $\mathrm{H}_{2}$, steam, and $\mathrm{O}_{2} . \mathrm{H}_{2}$ shifts tar conversion from PAH and soot into BTX and non-condensable gaseous hydrocarbons while steam and $\mathrm{O}_{2}$ accelerate the rate of secondary pyrolysis.

Ruiz et al. (2007) studied the influence of temperature on the properties of soot formed from $\mathrm{C}_{2} \mathrm{H}_{2}$ pyrolysis. No soot was observed at low temperatures $\left(<1000{ }^{\circ} \mathrm{C}\right)$. However, with 
increase in temperature an increase of acetylene $\left(\mathrm{C}_{2} \mathrm{H}_{2}\right)$ conversion into soot and $\mathrm{H}_{2}$ was observed (Fletcher et al. 1997).

Currently the $\mathrm{C}_{3} \mathrm{M}$ module does not include a secondary pyrolysis stage. This reaction kinetics in MFIX is introduced by adding soot and $\mathrm{C}_{2} \mathrm{H}_{2}$ as the new gas species. PCCL generates secondary pyrolysis yields for the given operating condition in the output file called $\mathrm{FDC}_{\mathrm{i}} \mathrm{SP}_{\mathrm{j}}$.rpt. The ouput file consists of secondary pyrolysis product yields on a \% daf (dry-ash-free) basis.

Figure 2.1 shows the output file for secondary pyrolysis of PRB coal at $1325^{\circ} \mathrm{C}$.

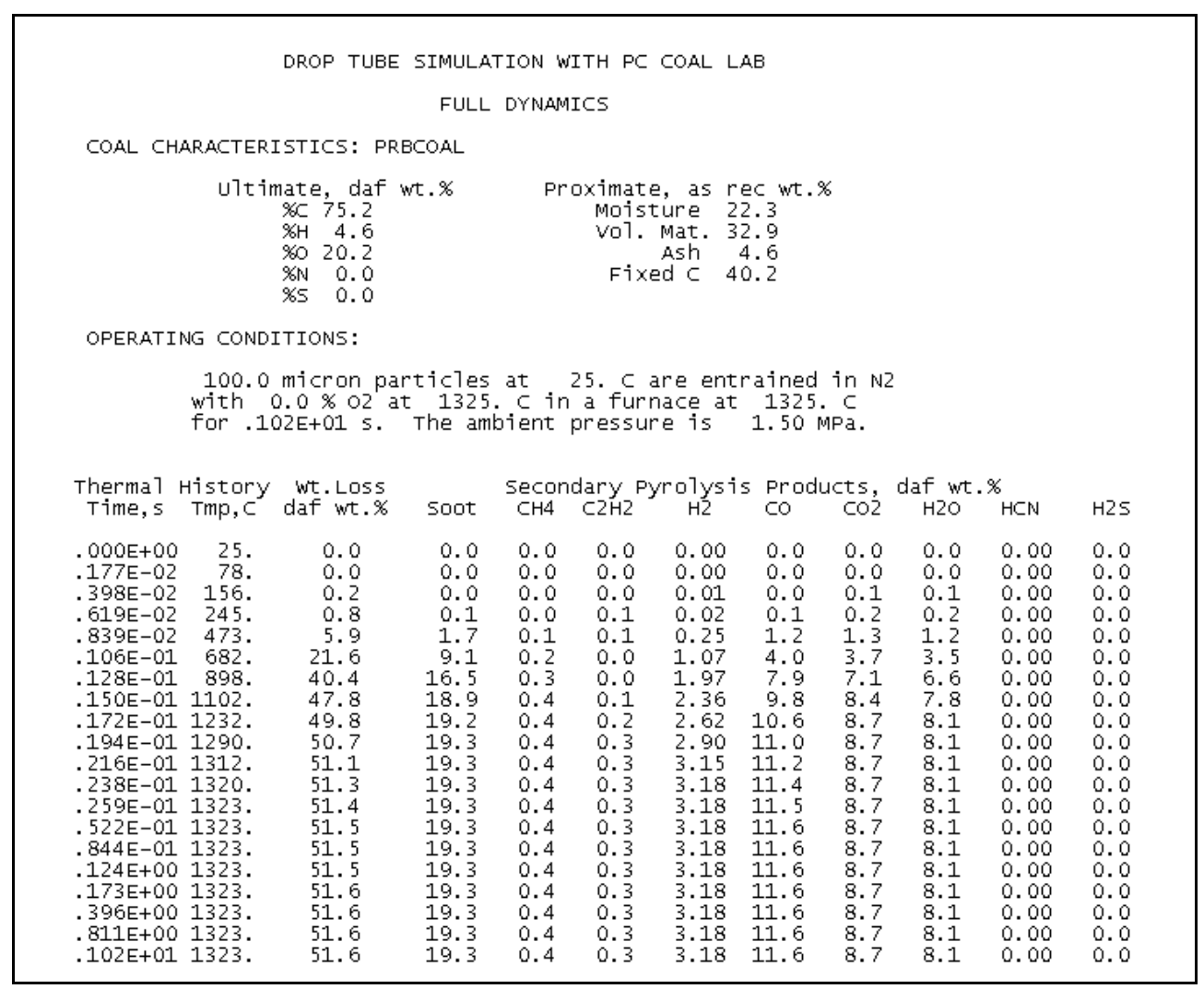

Figure 2.1: $\mathrm{FDC}_{\mathrm{i}} \mathrm{SP}_{\mathrm{j}} . \mathrm{rpt}$ file showing secondary pyrolysis yields for PRB coal.

PCCL predicts soot formation based on the mechanism described by Chen et al. (1992).

The current version of PCCL is not programmed to generate soot formation kinetics. Due to this limitation, no specific kinetics are available from PCCL for soot generation. 
In this research, we have lumped secondary pyrolysis and devolatilization together as a single devolatilization step. It has been assumed that secondary pyrolysis occurs only above $1000{ }^{\circ} \mathrm{C}$ so that when the reactor temperature is above $1000{ }^{\circ} \mathrm{C}$ the modified devolatilization reaction equation becomes,

$$
\mathrm{VM} \rightarrow \text { soot }+\mathrm{C}_{2} \mathrm{H}_{2}+\beta_{\mathrm{CO}}^{\mathrm{d}} \mathrm{CO}+\beta_{\mathrm{CO}_{2}}^{d} \mathrm{CO}_{2}+\beta_{\mathrm{CH}_{4}}^{d} \mathrm{CH}_{4}+\beta_{\mathrm{H}_{2}}^{d} \mathrm{H}_{2}+\beta_{\mathrm{H}_{2} \mathrm{O}}^{\mathrm{d}} \mathrm{H}_{2} \mathrm{O}
$$

This equation satisfies the mass balance. Stoichiometric coefficients are obtained from the ultimate yield predicted by PCCL. Soot formation is expressed using SFOR kinetics for devolatilization.

\subsection{Combustion and Gasification Reactions}

Char combustion reaction kinetics are proposed using the shrinking core model (Doraiswamy, 1986) in $\mathrm{C}_{3} \mathrm{M}$ module of MFIX. Reaction kinetics for other gasification reactions is well established and given in the $\mathrm{C}_{3} \mathrm{M}$ module. The predictions using this kinetics model compare well with the experimental data. Hence these gasification and combustion reaction kinetics will not be changed in MFIX during this research.

\subsection{Soot Oxidation}

Soot is generated via secondary pyrolysis but it can react simultaneously with steam, $\mathrm{O}_{2}$, $\mathrm{CO}_{2}$, and $\mathrm{H}_{2}$. Above $800{ }^{\circ} \mathrm{C}$ soot formation competes with oxidation (Stanmore et al., 2001). The soot reactivity is directly related to its structure and composition. Properties such as surface area, particle size, and crystallinity affect the reactivity of the soot particles. The soot nanostructure depends upon its formation conditions, like fuel identity, residence time, and temperature (Ruiz et al. 2007).

This research focuses only on soot oxidation. The oxidation of soot aerosol particles in a flame environment is difficult to examine experimentally. In the case of oxidation by $\mathrm{O}_{2}$, the semi- empirical formula of Nagle and Strickland-Constable (NSC) (1962) can be used to correlate the oxidation rate measurements for pyrolytic graphite, 


$$
\frac{\omega}{12}=\left(\frac{k_{A} P_{O_{2}}}{1+k_{z} P_{O_{2}}}\right) x+k_{B} P_{O_{2}}(1-x) \text { g-carbon } / \mathrm{cm}^{2}-\mathrm{s}(2.31)
$$

where $\omega$ is the reaction rate per surface area and $x$ is given by:

$$
x=\left(1+\frac{k_{T}}{k_{B} P_{O_{2}}}\right)^{-1}
$$

where,

$$
\begin{array}{cr}
k_{A}=20 \exp (-125 / R T) & \mathrm{g}-\mathrm{cm}^{-2} \mathrm{sec}^{-1} \mathrm{~atm}^{-1}(2.33) \\
k_{B}=4.46 \times 10^{-3} \exp (-63.6 / R T) & \mathrm{g}-\mathrm{cm}^{-2} \mathrm{sec}^{-1} \mathrm{~atm}^{-1}(2.34) \\
k_{T}=1.51 \times 10^{-5} \exp (-406 / R T) & \mathrm{g}-\mathrm{cm}^{-2} \mathrm{sec}^{-1}(2.35) \\
k_{Z}=21.3 \exp (17.2 / R T) & \mathrm{atm}(2.36) \\
R=0.00831 & \mathrm{MJ} / \mathrm{Kg} \text { mole }(2.37)
\end{array}
$$

This correlation was verified by Radcliffe and Appleton (1971) and Park and Appleton (1973) to be applicable to soot oxidation.

Puri, et al. (1994) studied the oxidation of soot in hydrocarbon diffusion flames. They found that the reactivity of soot (in terms of collision efficiency) decreased with increase in temperature, probably due to thermal annealing or radical site stabilization processes. It was also found that the $\mathrm{OH}$ radical was the dominant oxidizer of soot, with $\mathrm{O}_{2}$ making only a small contribution in diffusion flames.

John et al. (1997) studied uncatalysed oxidation of a flame soot and diesel soot. They used $n^{\text {th }}$ order model for the oxidation. The order in molecular oxygen concentration was found to be 1 for the flame soot and slightly lower than 1 for the diesel soot. The equation had the following form:

$$
\begin{gathered}
r=k_{0}{ }^{\prime} \exp \left(-E_{a} / R T\right) \\
k_{0}^{\prime}=c(1-\xi)^{n_{\xi}} \cdot P_{O_{2}}{ }^{n_{O_{2}}} \\
c=\lambda S_{a_{0}} k_{0}
\end{gathered}
$$

where,

$\xi=$ fraction of carbon that is oxidized

$\lambda=$ surface concentration of active sites $\left(\mathrm{cm}^{-2}\right)$ 
$k_{0}^{\prime}=$ overall pre exponential factor $\left(\mathrm{sec}^{-1}\right)$

$n_{\xi}=$ order of reaction

$P_{O_{2}}=$ partial pressure of $\mathrm{O}_{2}(\mathrm{~atm})$

$S_{a_{0}}=$ initial surface area $\left(\mathrm{cm}^{2}\right)$

$k_{0}=$ pre exponential factor $\left(\sec ^{-1}\right)$

Leung and Lindstedt (1991) assumed that CO is the only product of soot oxidation and used the reaction kinetics described below:

$$
\begin{gathered}
R=k_{3}(T) S\left[O_{2}\right] \\
k_{3}(T)=0.1 \times 10^{5} \times T^{1 / 2} \times e^{-19680 / T}
\end{gathered}
$$

where, $R$ is in $\mathrm{kmol} / \mathrm{m}^{3} \cdot \sec , k_{3}(T)$ is in $\mathrm{m}^{3} / \mathrm{m}^{2}$-soot.sec, $S$ local surface area of soot $\left(\mathrm{m}^{2}\right)$ and $\left[O_{2}\right]$ is partial pressure of oxygen in Pa.

PCCL predicts soot oxidation using the semi-empirical expression (equation 2.30-2.36) reported by Nagle and Strickland-Constable (NSC) (1962). PCCL has the following reaction chemistry for soot oxidation,

$$
\text { soot }+2.714 \mathrm{O}_{2} \rightarrow 3.618 \mathrm{CO}_{2}+0.089 \mathrm{H}_{2} \mathrm{O} \quad \text { (g/g basis) (2.43) }
$$

The rate expression implemented in PCCL assumes soot particle size of $0.8 \mu \mathrm{m}$ and a bulk soot density of $2.0 \mathrm{~g} / \mathrm{cm}^{3}$. $\mathrm{SNORC}_{\mathrm{i}} \mathrm{T}_{\mathrm{j}}$.rpt gives the output report for soot oxidation kinetics and the product yields. 


\section{Chapter 3}

\section{Biomass}

Biomass is biological material derived from living, or recently living organisms (www.biomassenergycentre.org.uk). It is a renewable source of energy and the use of renewable energy sources is increasing in an effort to reduce the effect of greenhouse gases production. It is recognized as the fourth largest primary energy source in the world (Li et al. 2004). Wood and biomass can be used in a variety of ways to provide energy:

1. Direct combustion can provide heat and steam production for electricity generation

2. Gasification of biomass provides fuel gas for combustion and hence is useful as fuel for engines or turbines for electricity generation

3. Fast pyrolysis can provide a liquid fuel substitute for fuel oil (Bridgewater et al. 1999)

As with coal the proximate analysis of biomass gives the ash, moisture, volatile matter and fixed carbon content while the ultimate analysis gives the carbon, oxygen, hydrogen, nitrogen and sulfur content of the biomass. Biomass has a high percentage of volatile matter content (Biagini et al. 2002). Biomass contents can also be characterized using the chemical composition of hemicelluloses, cellulose, lignin and xylan.

Biomass pyrolysis causes thermal conversion of organics to produce liquids as the primary products. Biomass gasification means incomplete combustion of biomass resulting in production of combustible gases consisting of $\mathrm{CO}, \mathrm{H}_{2}$ and traces of $\mathrm{CH}_{4}$. This mixture is called producer gas (Goswami, 1986). Biomass devolatilization is different from coal devolatilization because of 3 major reasons:

1. Biomass characterization is based on hemicelluloses, cellulose, lignin and xylan

2. The macromolecular structure of biomass consists of few condensed polyaromatic compounds

3. Product yields and release rates are highly affected by ash catalysis (Niksa et al., 2000) The focus of this research is on biomass devolatilization.

\subsection{Biomass Devolatilization}

Devolatilization plays a significant role in biomass combustion processes, and it depends on the biomass form and composition. Biomass devolatilization releases light gas products such 
as $\mathrm{CO}, \mathrm{CO}_{2}, \mathrm{CH}_{4}, \mathrm{H}_{2} \mathrm{O}, \mathrm{CH}_{3} \mathrm{COOH}$, and $\mathrm{HCOOH}$ along with complex organic compounds (Biagini et al. 2006). PCCL predicts biomass devolatilization with the following products:

$$
\begin{aligned}
V M \rightarrow & \mathrm{CO}+\mathrm{CO}_{2}+\mathrm{H}_{2} \mathrm{O}+\mathrm{H}_{2}+\mathrm{CH}_{4}+\mathrm{C}_{2} \mathrm{H}_{2}+\mathrm{C}_{2} \mathrm{H}_{4}+\mathrm{C}_{2} \mathrm{H}_{6}+\mathrm{C}_{3} \mathrm{H}_{8}+\text { tar } \\
& +\mathrm{CH}_{3} \mathrm{OH}+\mathrm{CH}_{3} \mathrm{CO}+\text { Acetaldehyde }+\mathrm{CH}_{2} \mathrm{O}+\mathrm{C}_{2} \mathrm{H}_{5} \mathrm{O}+\mathrm{NH}_{3}+\mathrm{H}_{2} \mathrm{~S}
\end{aligned}
$$

Thermal decomposition kinetics of biomass is complicated as it involves a large number of reactions. Xiu et al. (2006) and Zhao et al. (2009) described devolatilization of biomass in terms of a simple first order reaction model as follows:

$$
\begin{gathered}
\frac{d \alpha}{d t}=A e^{-E / R T}(1-\alpha) \\
\alpha=\frac{W}{W_{\infty}}
\end{gathered}
$$

where,

$\alpha=$ ratio of volatile mass fraction at time $t$ to maximum volatile mass fraction

$W=$ volatile mass fraction at time $t$

$W_{\infty}=$ maximum volatile mass fraction

$A=$ Arrhenius constant

$E=$ Activation Energy

$t=$ residence time

Table 3.1 gives the kinetic parameters for 4 types of biomass reported by Xiu et al., 2006.

Table 3.1 Kinetic parameters for biomass devolatilization

\begin{tabular}{|c|c|c|}
\hline Raw materials & $A\left(\mathrm{~s}^{-1}\right)$ & $E(\mathrm{~kJ} / \mathrm{mol})$ \\
\hline Wheat straw & $1.05 \times 10^{3}$ & 31.65 \\
\hline Coconut shell & $6.84 \times 10^{3}$ & 48.73 \\
\hline Rice Husk & $1.19 \times 10^{3}$ & 39.30 \\
\hline Cotton stalk & $2.44 \times 10^{3}$ & 40.84 \\
\hline
\end{tabular}

Table 3.2 gives the kinetic parameters for rice husk and sawdust pyrolysis in entrained flow reactor reported by Sun et al. (2010) using equation (3.2) and (3.3). 
Table 3.2 kinetic parameters for rice husk and wheat straw pyrolysis.

\begin{tabular}{|c|c|c|}
\hline Raw Material & $A\left(\mathrm{~s}^{-1}\right)$ & $E(\mathrm{~kJ} / \mathrm{mol})$ \\
\hline Rice husk & 92.76 & 35.67 \\
\hline Sawdust & 80.64 & 32.59 \\
\hline
\end{tabular}

E. Biagini et al. (2002) defined single first order biomass devolatilization rate using a global mass balance as,

$$
\begin{aligned}
-\frac{d W}{d t} & =k\left(W-W_{\infty}\right) \\
k & =A e^{\frac{-E}{R T}}
\end{aligned}
$$

$W=$ mass of the sample

$W_{\infty}=$ final solid residue of sample i.e $W_{\infty}=W_{\text {ash }}+W_{\text {char }}$

$A=$ Arrhenius constant

$E$ = Activation Energy

$t=$ residence time

The kinetic parameters obtained are reported in Table 3.3

Table 3.3: Kinetic parameters for Biogran and Pine sawdust ( $E$ in $\mathrm{kcal} / \mathrm{mol} ; A$ in s${ }^{-1}$ )

\begin{tabular}{|c|c|c|}
\hline Sample & $\begin{array}{c}\text { Isothermal run conversion } \\
50 \%\end{array}$ & $\begin{array}{c}\text { Isothermal run conversion } \\
90 \%\end{array}$ \\
\hline Biogran & $E=21.2, A=2.2 \times 10^{3}$ & $E=18.1, A=12$ \\
\hline Pine sawdust & $E=29.1, A=3.9 \times 10^{3}$ & $E=24.4, A=5.7 \times 10^{3}$ \\
\hline
\end{tabular}

Blasi and Branca(2001) studied primary wood degradation with three parallel reactions for the formation of the main products (char, liquid, gas). The schematic of mechanism is shown below,

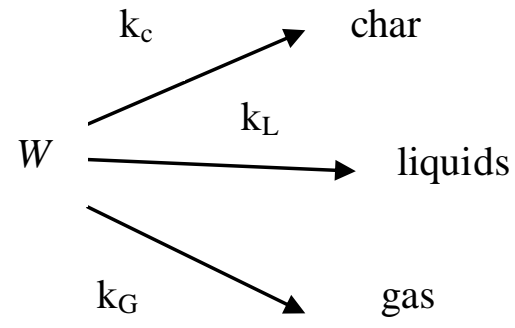




$$
\begin{aligned}
& k=k_{G}+k_{L}+k_{C} \\
& k_{j}=A e^{-E_{j} / R T}, j=G, L, C
\end{aligned}
$$

Table 3.4 gives estimated values for kinetic parameters of wood pyrolysis.

Table 3.4 Kinetic constants for wood pyrolysis

\begin{tabular}{|c|c|c|}
\hline & $E(\mathrm{~kJ} / \mathrm{mol})$ & $\ln A\left[\mathrm{~s}^{-1}\right]$ \\
\hline$k_{G}$ & $152.7 \pm 18.2$ & $22.2 \pm 3.4$ \\
\hline$k_{L}$ & $148.0 \pm 17.2$ & $23.1 \pm 3.2$ \\
\hline$k_{C}$ & $111.7 \pm 14.3$ & $15,0 \pm 2.7$ \\
\hline
\end{tabular}

PC Coal Lab predicts biomass devolatilization kinetics and product yields using the bioFLASHCHAIN (bio-FC) mechanism (Niksa, 2000). Bio-FC predicts primary devolatilziation products along with tar and major gas species yields based on proximate and ultimate analyses of biomass. PC Coal Lab can predict the devolatilization behavior for any form of wood, grass, agricultural residue and paper. Bio-FC treats biomass as a chain copolymer of cellulose and lignin-like components. Figure 3.1 gives the schematic diagram of the bio-FC mechanism. 


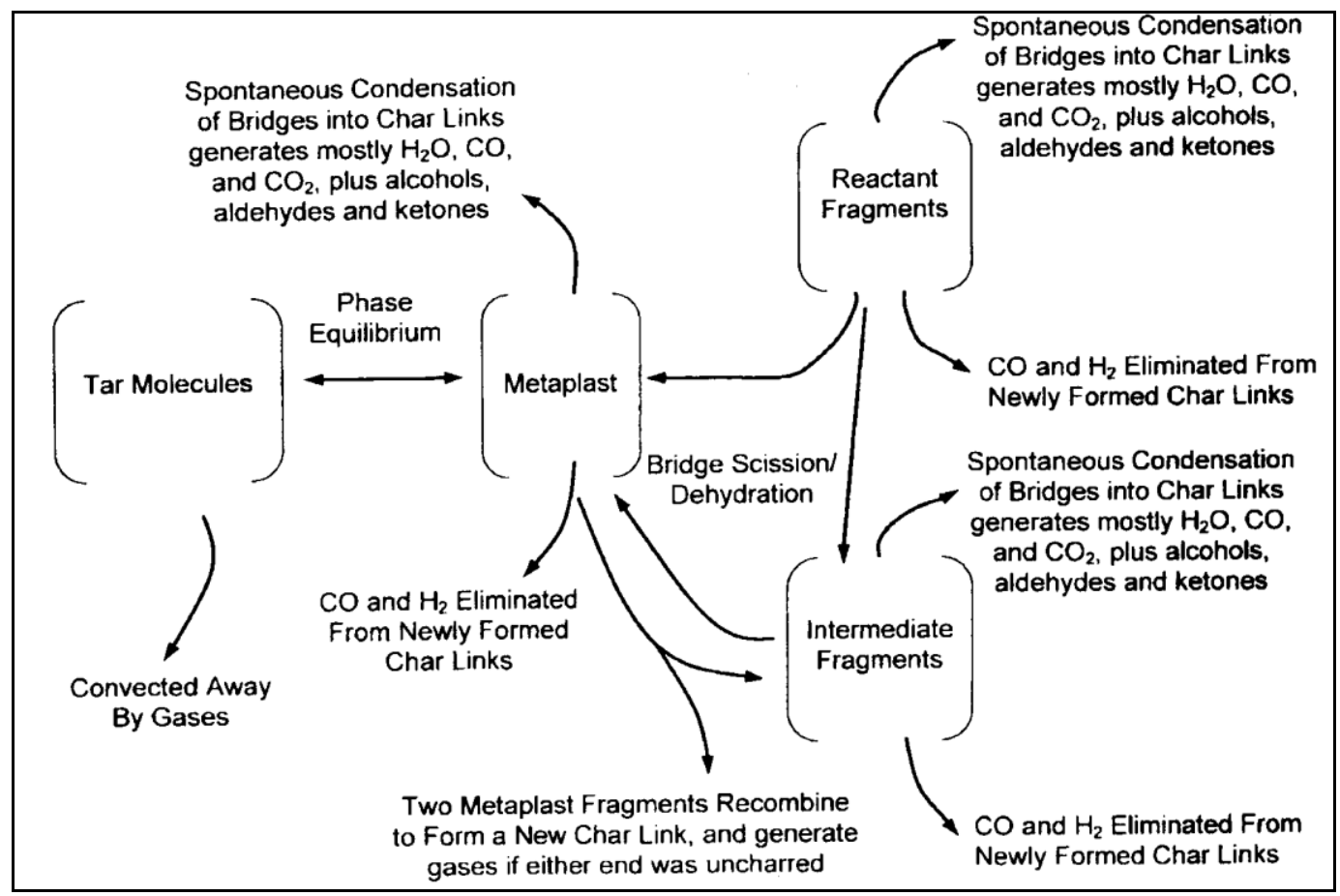

Figure 3.1: Reaction mechanism in bio-FLASHCHAIN (Niksa, 2000).

Similar to coal PCCL predicts biomass devolatilization using single first-order reaction (SFOR), the competing two-step reactions model (C2SM) and the distributed activation energy model (DAEM).

In this research only the SFOR model will be considered.

The SFOR equation for devolatilization of biomass is

$$
\frac{d V(t)}{d t}=A \exp \left(\frac{-E_{a}}{R T}\right)\left(V^{\infty}-V(t)\right)
$$

Where,

$V(t)=$ the instantaneous volatiles yield; \% dry ash free

$V^{\infty}=$ the hypothetical ultimate volatiles yield; \% dry ash free

$A=$ pseudo-frequency factor, $\mathrm{s}^{-1}$

$E_{a}=$ apparent activation energy, $\mathrm{kcal} / \mathrm{mol}$

$A, E_{a}$, and $V^{\infty}$ are adjustable parameters that vary with temperature, heating rate, pressure, and coal type. The weight loss rate, $d V(t) / d t$, is evaluated as the sum of the total rates of tar and gas release from bio-FC. $A$ and $E_{a}$ values can be obtained in the PCCL output file called $\mathrm{CFDC}_{\mathrm{i}} \mathrm{T}_{\mathrm{j}} . \mathrm{rpt}$. 
Currently the $\mathrm{C}_{3} \mathrm{M}$ module does not have kinetics for biomass devolatilization. Similar to coal we can modify SFOR kinetics in $\mathrm{C}_{3} \mathrm{M}$ for biomass devolatilization. New gas species including acetaldehyde, $\mathrm{CH}_{3} \mathrm{OH}, \mathrm{CH}_{3} \mathrm{CHO}, \mathrm{CH}_{2} \mathrm{O}, \mathrm{C}_{2} \mathrm{H}_{5} \mathrm{O}, \mathrm{NH}_{3}$ need to be added in $\mathrm{C}_{3} \mathrm{M}$. Reaction kinetics for the added gas species must be introduced in $\mathrm{C}_{3} \mathrm{M}$ module. 


\section{Chapter 4}

\section{Methodology}

The main aim of this research is to build a connecting bridge between PCCL and MFIX via $\mathrm{C}_{3} \mathrm{M}$.An interface between PCCL and $\mathrm{C}_{3} \mathrm{M}$ that allows two-way communication between the programs is being created. The interface is designed to allow MFIX to transfer information through $\mathrm{C}_{3} \mathrm{M}$ and PCCL, then run PCCL with input data from MFIX, and then send kinetic information back to $\mathrm{C}_{3} \mathrm{M}$ in a form that allows $\mathrm{C}_{3} \mathrm{M}$ to update and continue to run the MFIX simulation using the updated parameters from PCCL. Coal types whose proximate and ultimate analyses are known will be used for verification of the results. The MFIX simulation will be run initially for transport flow gasifiers. However, it is expected that all forms of gasifier will be able to be handled using the PCCL/C 3 M interface in MFIX. A full description of the methodology to be used is best illustrated by examining the type and form of the results that PCCL generates. This is illustrated in the following section.

All the different protocols used in both PCCL and $\mathrm{C}_{3} \mathrm{M}$ subroutine for describing the devolatilization and tar chemistry reactions will be studied. The differences between the reaction kinetics predicted by PCCL and MFIX via $\mathrm{C}_{3} \mathrm{M}$ subroutines will then be determined. The parameters that are necessary to be substituted in $\mathrm{C}_{3} \mathrm{M}$ subroutine will be noted. Powder River Basin (PRB) a sub bituminous coal has been chosen as a sample coal.

Input file Coalpc.dat and Testplan.dat will be set up in PCCL according to the operating conditions (which includes proximate and ultimate analysis of coal, temperature and pressure of gasifier, diameter of coal particle, heating rate) specified in MFIX. Wire grid/drop tube method will be chosen accordingly. Output files of interest generated by PCCL are $\mathrm{CFDC}_{\mathrm{i}} \mathrm{T}_{\mathrm{j}}$.rpt, $\mathrm{FDC}_{\mathrm{i}} \mathrm{HC}_{\mathrm{j}} \cdot \mathrm{rpt}, \mathrm{FDC}_{\mathrm{i}} \mathrm{NG}_{\mathrm{j}} \cdot \mathrm{rpt}, \mathrm{FDC}_{\mathrm{i}} \mathrm{SP}_{\mathrm{j}} \cdot \mathrm{rpt}, \mathrm{SFORC}_{\mathrm{i}} \mathrm{T}_{\mathrm{j}} \cdot \mathrm{rpt}, \mathrm{SFR}_{\mathrm{i}} \mathrm{TC}_{\mathrm{j}} \cdot \mathrm{rpt}, \mathrm{TDC}_{\mathrm{i}} \mathrm{PR}_{\mathrm{j}} \cdot \mathrm{rpt}, \mathrm{TDC}_{\mathrm{i}} \mathrm{TC}_{\mathrm{j}} \cdot \mathrm{rpt}$ and $\mathrm{TDC}_{\mathrm{i}} \mathrm{HC}_{\mathrm{j}} \cdot \mathrm{rpt}$ ( $\mathrm{i}=$ Coal number, $\mathrm{j}=$ Number of operating condition).

$\mathrm{CFDC}_{\mathrm{i}} \mathrm{T}_{\mathrm{j}}$.rpt gives devolatilization reaction kinetic parameters. $\mathrm{FDC}_{\mathrm{i}} \mathrm{HC}_{\mathrm{j}}$.rpt contains the yield of hydrocarbons generated in devolatilization. $\mathrm{FDC}_{\mathrm{i}} \mathrm{NG}_{\mathrm{j}}$.rpt contains the yield of noncondensables gases like $\mathrm{H}_{2} \mathrm{O}, \mathrm{CO}_{2}$ and $\mathrm{CO}$ produced in devolatilization. $\mathrm{SFORC}_{\mathrm{i}} \mathrm{T}_{\mathrm{j}}$.rpt gives the single first order reaction kinetic parameters for the formation of devolatilization product species. $\mathrm{SFR}_{\mathrm{i}} \mathrm{TC}_{\mathrm{j}} \cdot \mathrm{rpt}$ contains kinetic parameter for tar cracking. $\mathrm{TDC}_{\mathrm{i}} \mathrm{PR}_{\mathrm{j}} \cdot \mathrm{rpt}, \mathrm{TDC}_{\mathrm{i}} \mathrm{TC}_{\mathrm{j}} \cdot \mathrm{rpt}$ and $\mathrm{TDC}_{\mathrm{i}} \mathrm{HC}_{\mathrm{j}}$.rpt output files generate the yield of output products in the tar cracking reaction. PCCL 
predicts PAH and oil as the product gas species generated from tar cracking and soot and $\mathrm{C}_{2} \mathrm{H}_{2}$ as the product gas species in secondary pyrolysis.

All the percentage yields of output products generated by PCCL are in dry ash free basis; hence they will be converted into gram basis. $\mathrm{PAH}$, oil, soot and $\mathrm{C}_{2} \mathrm{H}_{2}$ will be added as new gas species in MFIX. An algorithm will be developed to transfer kinetic data generated by PCCL to MFIX in its format. Simulations similar to those described in Section 4.4 are run to verify the connecting bridge validity.

For Biomass new gas species like acetaldehyde, $\mathrm{CH}_{3} \mathrm{OH}, \mathrm{CH}_{3} \mathrm{CHO}, \mathrm{CH}_{2} \mathrm{O}, \mathrm{C}_{2} \mathrm{H}_{5} \mathrm{O}, \mathrm{NH}_{3}$ will be added in $\mathrm{C}_{3} \mathrm{M}$. SFOR kinetics will be used for biomass devolatilization.

\subsection{Assumptions}

1. The hydrocarbons $\left(\mathrm{C}_{2} \mathrm{H}_{4}, \mathrm{C}_{2} \mathrm{H}_{6}, \mathrm{C}_{3} \mathrm{H}_{6}, \mathrm{C}_{3} \mathrm{H}_{8}\right)$ higher than $\mathrm{CH}_{4}$ will be treated as $\mathrm{CH}_{4}$. This will simplify the simulations. Current $\mathrm{C}_{3} \mathrm{M}$ module in MFIX does not have higher hydrocarbons other than $\mathrm{CH}_{4}$ also in addition it does not have any reaction chemistry for these gas species.

Treating the gas species individually will increase simulation time.

Table 4.1 and Table 4.2 shows the comparison of $\%$ carbon in coal when the hydrocarbons are treated as $\mathrm{CH}_{4}$ or accounted as individual gas species for PRB and Lignite coal respectively.

PRB Coal:

Ultimate analysis (\%): $\mathrm{C}=75.2, \mathrm{H}=4.6, \mathrm{O}=20.2$

Basis: 100gm

Table 4.1 Comparison of \% of $\mathrm{C}$ in devolatilization product yield for PRB coal

\begin{tabular}{|c|c|c|c|c|}
\hline Products & $\begin{array}{c}\text { \% daf yield as } \\
\text { individual } \\
\text { species }\end{array}$ & $\begin{array}{c}\text { \%daf yield } \\
\text { when higher } \\
\text { hydrocarbon } \\
\text { treated as } \mathrm{CH}_{4}\end{array}$ & $\begin{array}{c}\% \mathrm{C} \text { as individual } \\
\text { gas species }\end{array}$ & $\begin{array}{c}\% \mathrm{C} \text { when higher } \\
\text { hydrocarbon } \\
\text { treated as } \mathrm{CH}_{4}\end{array}$ \\
\hline $\mathrm{CO}_{2}$ & 9.1 & 9.1 & 2.48 & 2.48 \\
\hline $\mathrm{CO}$ & 5.6 & 5.6 & 2.40 & 2.40 \\
\hline $\mathrm{H}_{2} \mathrm{O}$ & 8.5 & 8.5 & 0 & 0 \\
\hline $\mathrm{CH}_{4}$ & 3.8 & 6.68 & 2.85 & 4.95 \\
\hline
\end{tabular}




\begin{tabular}{|c|c|c|c|c|}
\hline $\mathrm{C}_{2} \mathrm{H}_{4}$ & 1.5 & 0 & 1.29 & 0 \\
\hline $\mathrm{C}_{2} \mathrm{H}_{6}$ & 0.24 & 0 & 0.19 & 0 \\
\hline $\mathrm{C}_{3} \mathrm{H}_{6}$ & 1.14 & 0 & 0.98 & 0 \\
\hline $\mathrm{H}_{2}$ & 0.4 & 0.4 & 0 & 0 \\
\hline Tar ( 79.5\% C) & 13.4 & 13.4 & 10.65 & 10.65 \\
\hline Char & 56.4 & 56.4 & 56.4 & 56.4 \\
\hline Total & & & 77.24 & 76.88 \\
\hline
\end{tabular}

\section{Lignite Coal}

Ultimate analysis (\%): $\mathrm{C}=73.2, \mathrm{H}=5.3, \mathrm{O}=20.7, \mathrm{~N}=0.8, \mathrm{~S}=0.1$

Basis: $100 \mathrm{gm}$

Table 4.2 Comparison of $\%$ of $\mathrm{C}$ in devolatilization product yield for Lignite coal

\begin{tabular}{|c|c|c|c|c|}
\hline Products & \% dry ash free & $\begin{array}{c}\text { \%daf yield } \\
\text { when higher } \\
\text { hydrocarbons } \\
\text { treated as } \mathrm{CH}_{4}\end{array}$ & $\begin{array}{c}\text { \% of } \mathrm{C} \text { as } \\
\text { individual gas } \\
\text { species }\end{array}$ & $\begin{array}{c}\text { \% of } \mathrm{C} \text { when } \\
\text { higher } \\
\text { hydrocarbons } \\
\text { treated as } \mathrm{CH}_{4}\end{array}$ \\
\hline $\mathrm{CO}_{2}$ & 8.3 & 8.3 & 2.26 & 2.26 \\
\hline $\mathrm{CO}$ & 7.7 & 7.7 & 3.30 & 3.30 \\
\hline $\mathrm{H}_{2} \mathrm{O}$ & 8.5 & 8.5 & 0 & 0 \\
\hline $\mathrm{CH}_{4}$ & 5.8 & 10.78 & 4.35 & 8.03 \\
\hline $\mathrm{C}_{2} \mathrm{H}_{4}$ & 2.42 & 0 & 2.07 & 0 \\
\hline $\mathrm{C}_{2} \mathrm{H}_{6}$ & 0.55 & 0 & 0.44 & 0 \\
\hline $\mathrm{C}_{3} \mathrm{H}_{6}$ & 1.91 & 0 & 1.64 & 0 \\
\hline $\mathrm{H}_{2}$ & 0.97 & 0.97 & 0 & 11.73 \\
\hline Tar $(77.2 \% \mathrm{C})$ & 15.2 & 15.2 & 11.73 & 0.26 \\
\hline $\mathrm{HCN}^{2}$ & 0.58 & 0.58 & 0.26 & 0 \\
\hline $\mathrm{H}_{2} \mathrm{~S}$ & 0.09 & 0.09 & 0 & 73.98 \\
\hline $\mathrm{Char}$ & 48.4 & 48.4 & 48.4 & 74.45 \\
\hline Total & & & & 0 \\
\hline
\end{tabular}


It can be seen that $\%$ of carbon in coal is in good argument with $\%$ of carbon in product species when higher hydrocarbons are treated as $\mathrm{CH}_{4}$

1. Molecular weight of soot is assumed to be $300 \mathrm{gm} / \mathrm{mole}$.

3. PAH and soot has almost over $95 \%$ of carbon content. Specific heat of PAH and soot are assumed to be the same as fixed carbon.

CPPAH $=-0.1315+1.341 \mathrm{E}-03 * \mathrm{XXX}-1.087 \mathrm{E}-06 * \mathrm{XXX} * \mathrm{XXX}+3.06 \mathrm{E}-10 * \mathrm{XXX} * \mathrm{XXX} * \mathrm{XXX}$

CPSOOT $=-0.1315+1.341 \mathrm{E}-03 * \mathrm{XXX}-1.087 \mathrm{E}-06 * \mathrm{XXX} * \mathrm{XXX}+3.06 \mathrm{E}-10 * \mathrm{XXX} * \mathrm{XXX} * \mathrm{XXX}$

(Where XXX is the temperature in Kelvin)(MFIX document)

4. Oil is a mixture of benzene, toluene, xylene (BTX). Average molecular weight of the mixture is $92 \mathrm{gm} / \mathrm{mol}$. In addition it is assumed that the specific heat of oil is the same as toluene which has same molecular weight as oil.

$\mathrm{CPOIL}=(1.4014 \mathrm{E}+05-1.5230 \mathrm{E}+02 * \mathrm{XXX}+6.9500 \mathrm{E}-01 * \mathrm{XXX} * * 2) / 92 \quad($ Perry, 1997)

5. Version 4.1 of PCCL is not programmed to give kinetics of soot generation in secondary pyrolysis. In this research, it is assumed that when temperature is above $1000^{\circ} \mathrm{C}$, soot and $\mathrm{C}_{2} \mathrm{H}_{2}$ will be products in the devolatilization step. 


\section{Chapter 5}

\section{Results and Discussion}

Devolatilization and tar cracking are the main reactions that have to be modified in MFIX. PCCL takes into consideration the effect of different operating conditions for coal gasification; hence it is necessary to check the effects of operating conditions on coal devolatilization and tar cracking. Initially the differences in yields of devolatilization products given by MFIX and PCCL operating with the same input conditions were investigated. The parameters that must be replaced in the $\mathrm{C}_{3} \mathrm{M}$ module for MFIX were identified.

\subsection{Effect of Variations in Operating Conditions on pyrolysis of coal}

\subsubsection{Effect of Pressure}

The devolatilization rate decreases as pressure increases according to a number of researchers. (Oh et al.1989, Niksa et al. 2003, Lee et al. 1991, Van Heek 1990).

The PCCL wire grid method was used to study the effect of varying operating pressure.

The effect of pressure on devolatilization and tar cracking is expressed through the yield of products from those reactions. Powder River Basin (PRB) sub-bituminous coal was used as the sample coal.

PCCL results predict that:

1. Increase in pressure has significant effect on yields of tar and volatile matter at the same heating rate and temperature.

2. Yields of tar and volatile matter decrease as pressure increases at constant temperature and heating rate.

3. Yield of $\mathrm{H}_{2}$ is affected by pressure only at higher temperatures; namely, it increases with an increase in pressure at constant temperature and heating rate.

4. Pressure has no significant effect on the yields of $\mathrm{CO}_{2}, \mathrm{CO}, \mathrm{H}_{2} \mathrm{O}$ and $\mathrm{CH}_{4}$. These results are illustrated in Figure 5.1 


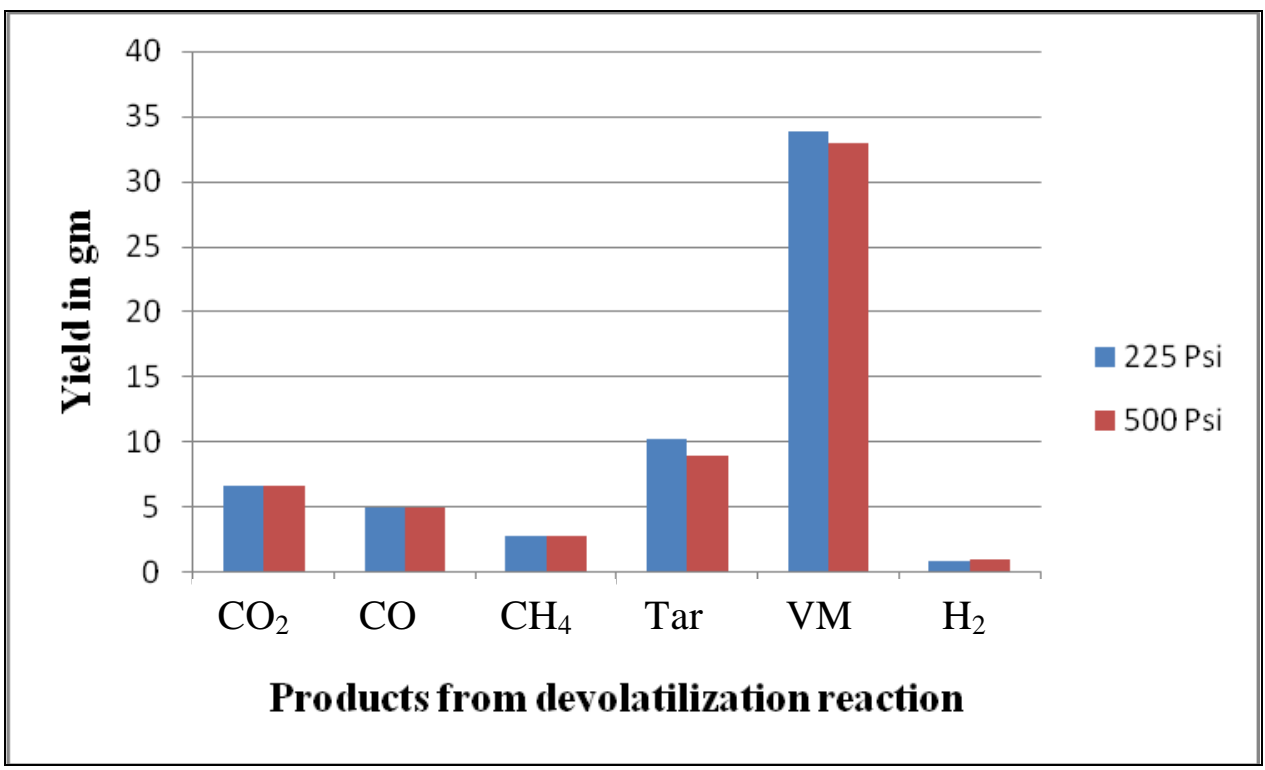

Figure 5.1 Effect of pressure on the yields of $\mathrm{CO}_{2}, \mathrm{CO}, \mathrm{CH}_{4}, \operatorname{tar}, \mathrm{H}_{2}$ and total volatile matter with heating rate of $1500{ }^{\circ} \mathrm{C} / \mathrm{s}$ at $1316^{\circ} \mathrm{C}$

\subsubsection{Effect of Temperature}

PCCL results show that:

1. As temperature increases at constant heating rate and pressure, the yields of $\mathrm{CO}, \mathrm{H}_{2}$ and total volatile matter increase as shown in Figure 5.2.

2. An increase in temperature has practically has no effect on the yields of $\mathrm{CO}_{2}, \mathrm{H}_{2} \mathrm{O}$, tar and $\mathrm{CH}_{4}$ at constant heating rate and pressure.

\subsubsection{Effect of heating rate}

Gibbins (1989) recorded an increase in yield of devolatilization products with an increase in heating rate.

PCCL results show:

1. As heating rate is increased at fixed temperature and pressure the yield of $\mathrm{CO}_{2}, \mathrm{H}_{2}, \mathrm{CH}_{4}$, $\mathrm{H}_{2} \mathrm{O}, \mathrm{CO}$ decreases as shown in Figure 5.3.

2. Yield of tar and total volatile matter increases as heating rate is increased at constant temperature and pressure.

The effects of heating rate and temperature on predictions from PCCL are shown in Figure 5.2 


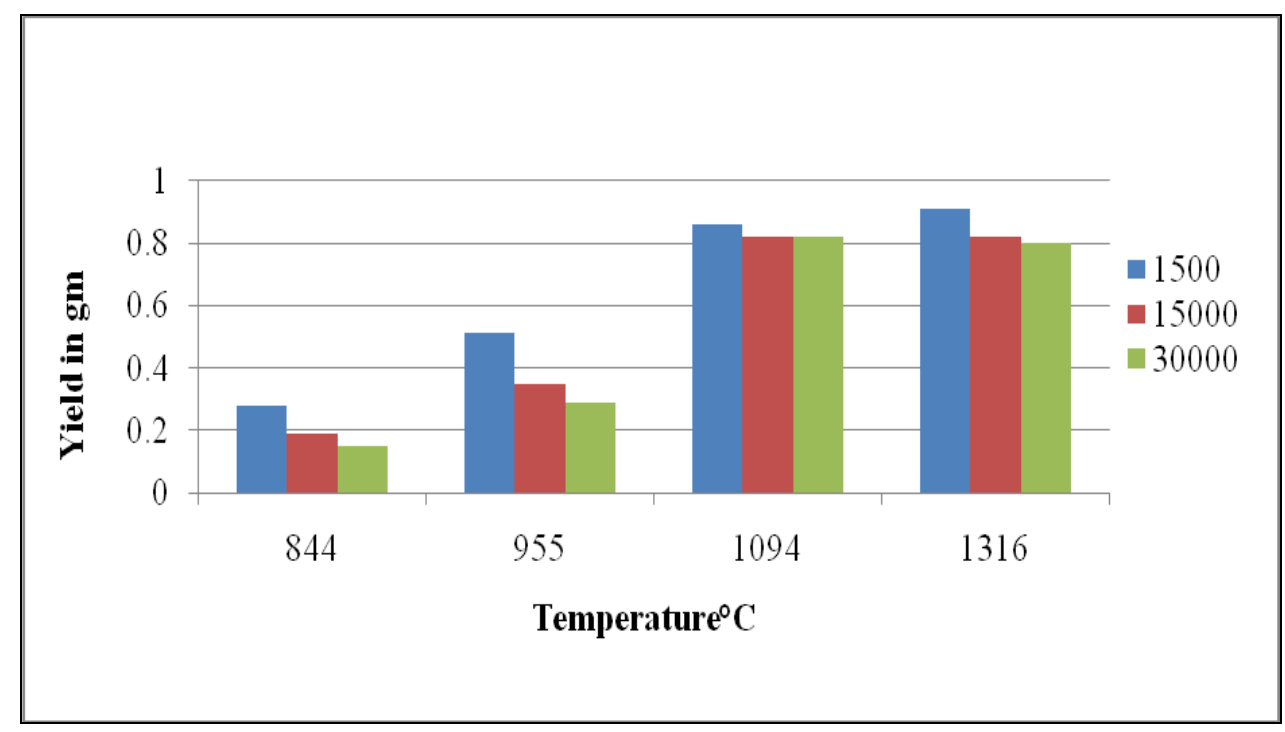

Figure 5.2. Graph showing effect of temperature and heating rate on yield of $\mathrm{H}_{2}$ at heating rate of $1500^{\circ} \mathrm{C} / \mathrm{s}, 15000^{\circ} \mathrm{C} / \mathrm{s}$ and $30000^{\circ} \mathrm{C} / \mathrm{s}$.

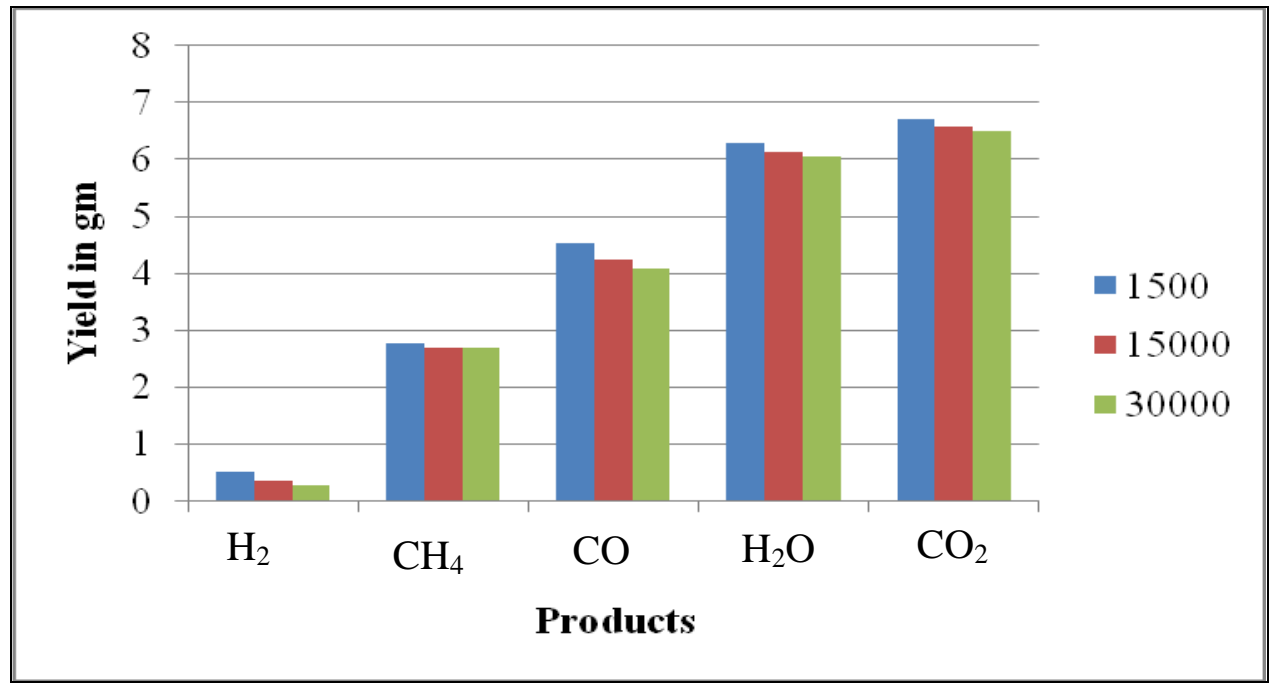

Figure5.3. Graph showing effect of heating rates on the yields of $\mathrm{H}_{2}, \mathrm{CH}_{4}, \mathrm{CO}, \mathrm{H}_{2} \mathrm{O}$ and $\mathrm{CO}_{2}$ at operating temperature of $955^{\circ} \mathrm{C}$ at 500 psi.

It can be seen that the effects of operating conditions predicted by PCCL are in agreement with experimental data available in the literature.

\subsection{Comparison of devolatilization kinetic parameters}

As discussed earlier MFIX has fixed devolatilization reaction kinetic parameters for 5 different types of coals. PCCL generates devolatilization reaction kinetic parameters considering all the operating conditions. Figure 5.4 shows the variation in devolatilization reaction rate 
parameters obtained from MFIX and PCCL operated at the same operating conditions. Figure 5.4 shows that MFIX overpredicts the kinetic parameters for devolatilization reaction.

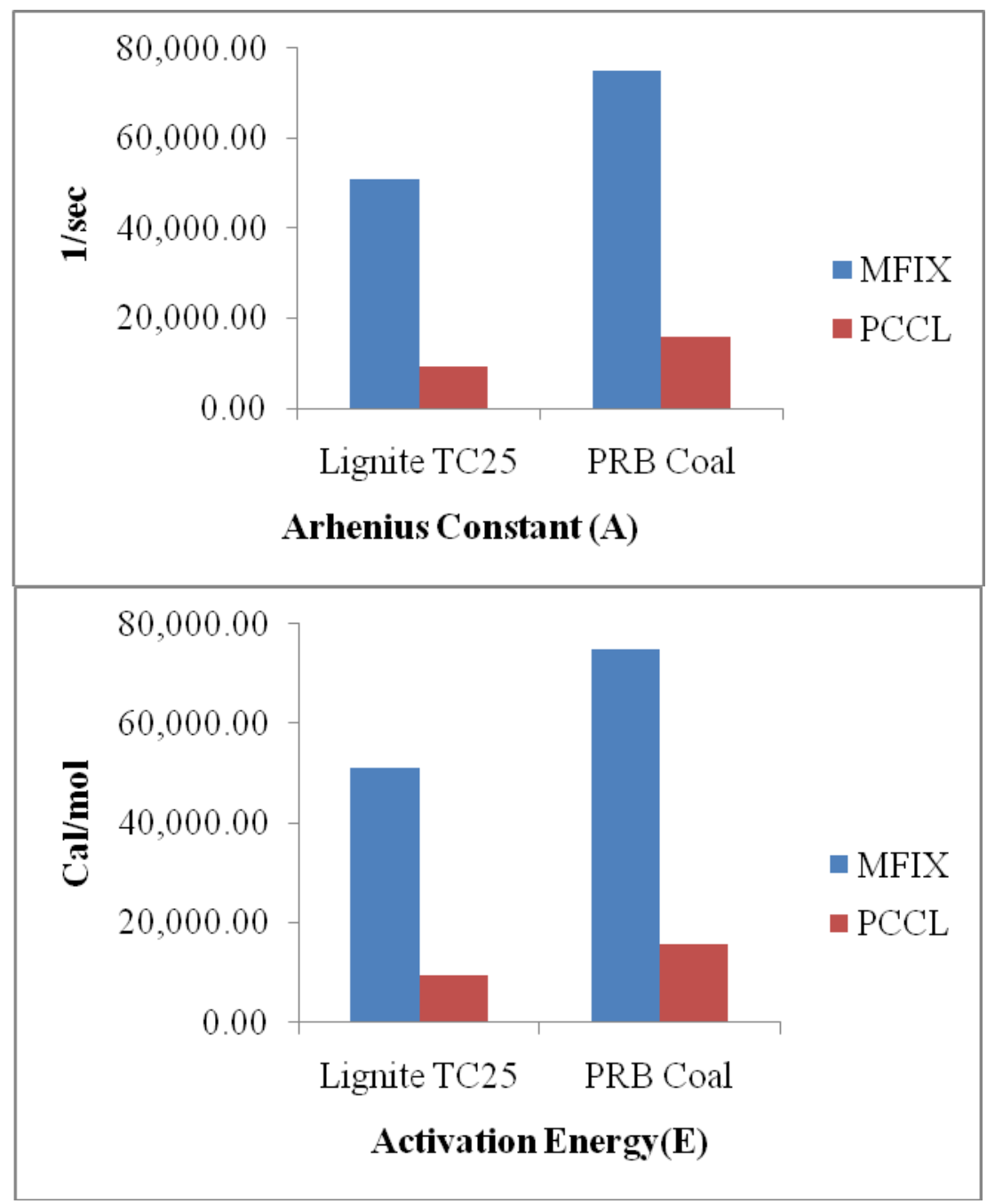

Figure 5.4 Figure showing comparison between devolatilization reaction parameters obtained from MFIX and PCCL at $844{ }^{\circ} \mathrm{C}$ for lignite TC 25 and PRB coal.

\subsection{Comparison of stoichiometric coefficients}

MFIX calculates the stoichiometric coefficients for devolatilization and tar cracking reactions via the $\mathrm{C}_{3} \mathrm{M}$ subroutine. Stoichiometric coefficients for devolatilization and tar cracking reactions can be generated using the output data obtained from PCCL. Stoichiometric coefficients calculated using PCCL data for $\mathrm{CO}_{2}, \mathrm{H}_{2}, \mathrm{H}_{2} \mathrm{O}, \mathrm{CO}$ and $\mathrm{CH}_{4}$ show much greater variations compared to those obtained from MFIX. The PCCL stoichiometric coefficients will 
be substituted in the subroutine rrates.f of MFIX. Figure 5.5 shows the comparison of stoichiometric coefficients obtained from MFIX and PCCL for Powder River Basin (PRB) and TC 25 lignite coals.

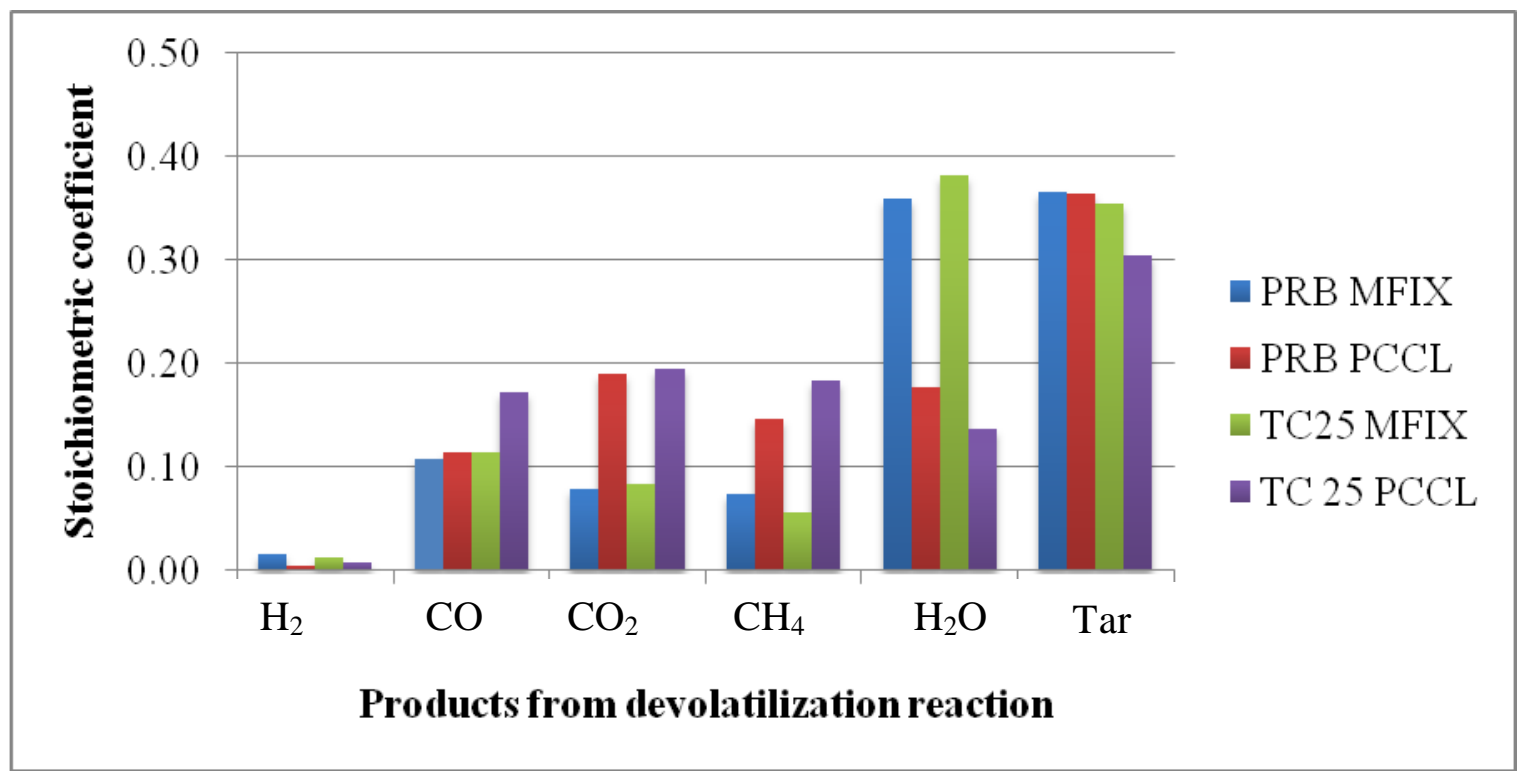

Figure 5.5 Comparison of Stoichiometric coefficients for devolatilization reaction generated from MFIX and PCCL for PRB and Lignite TC25 coal.

\subsection{Comparison of PCCL coal devolatilization predictions with experimental results}

Gibbons et al. (1989) studied the time temperature variation on coal pyrolysis. Experiments were carried out on Linby coal at $700^{\circ} \mathrm{C}$ with a heating rate of $1{ }^{\circ} \mathrm{C} / \mathrm{s}$ and $1000{ }^{\circ} \mathrm{C} / \mathrm{s}$. Figure 5.6 shows the yield of total volatile matter obtained via experiments and PCCL using same operating conditions. Fletcher et al. (2005) studied effects of pressure on coal pyrolysis and char morphology. Total volatile matter yield was reported for Pittsburgh \# 8 and Illinois \# 6 at 2.5, 6, 10 and 15 atm pressures. Figure 5.7 represents the effects of pressure on total volatile matter yield obtained via experiment and PCCL. Neoh and Gannon (1984) observed rapid pyrolysis of Pittsburgh \# 8 and Illinois \# 6. They reported total volatile matter yield at $1600 \mathrm{~K}$ and $2400 \mathrm{~K}$. Figure 5.8 shows a comparison of total volatile yield between experiments and PCCL using same operating conditions. 


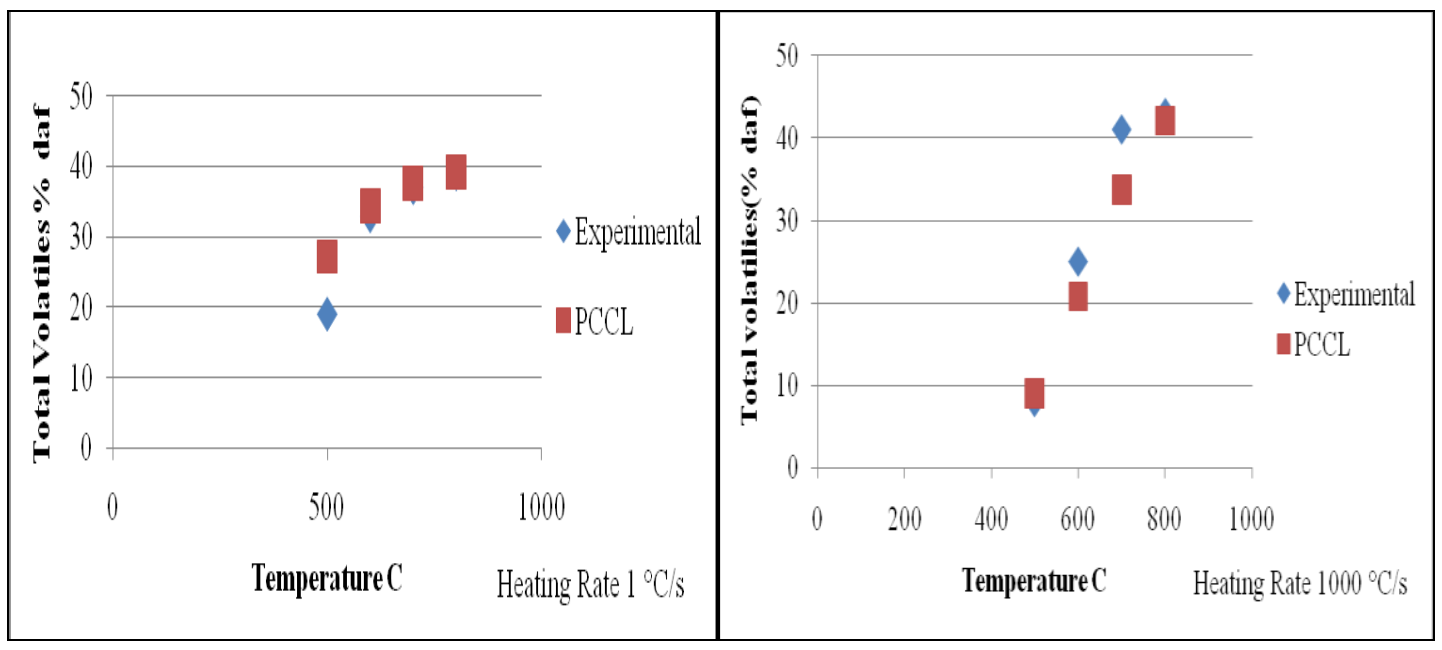

Figure 5.6 : Graph showing total volatile yield obtained for Linby coal via PCCL and experiments at same operating conditions.

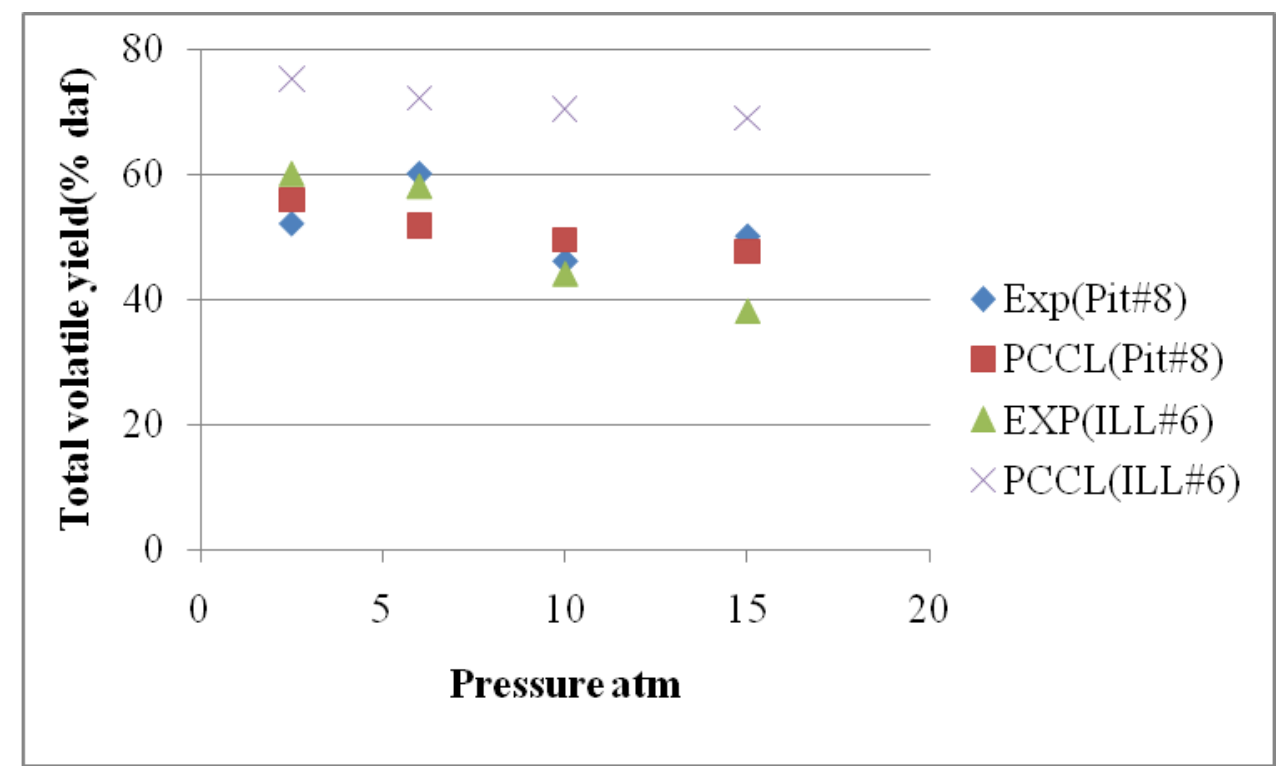

Figure 5.7 : Graph showing total volatile yield obtained for Pittsburgh \# 8 and Illinois \# 6 via PCCL and experiment(EXP) at same operating conditions. 

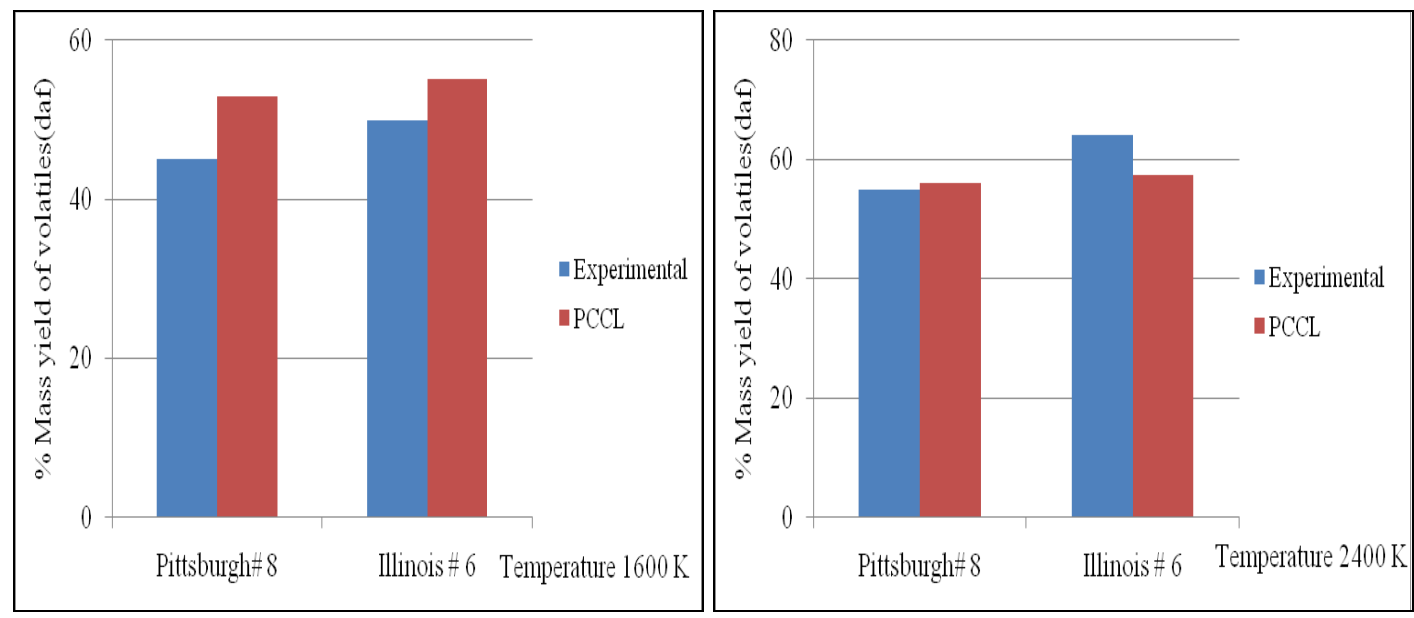

Figure 5.8 : Graph showing total volatile yield obtained for Pittsburgh \# 8 and Illinois \# 6 via PCCL and experiment at $1600 \mathrm{~K}$ and $2400 \mathrm{~K}$.

Looking at Figures 5.6-5.8 it can be concluded that devolatilization predictions of PCCL are reasonably accurate and in good argument with the experimental results. Hence the results give confidence in using PCCL kinetics for modyfying coal gasification kinetics in MFIX.

\subsection{Comparison of yields of devolatilization products}

A one-to-one comparison between PCCL and MFIX output was made to see the differences between yields of devolatilization products from the two programs. The wire grid method in PCCL was chosen as per the suggestion of Dr.Niksa. PCCL generates higher hydrocarbons other than $\mathrm{CH}_{4}$ during devolatilization while MFIX does not report these gas species as output, in order to allow a comparison between the two methods, these higher hydrocarbons can be adjusted in one of two ways. The first way is to add them in to the tar and modify the tar molecular weight and the other way is simply to lump them with $\mathrm{CH}_{4}$. Heating rates obtained from MFIX were used as input to the wire grid method. PCCL output was collected and stoichiometric coefficients in MFIX were substituted along with rate parameters. The higher hydrocarbons were lumped into $\mathrm{CH}_{4}$ and the calculation for this is shown in Appendix I.

In MFIX, a transport flow gasifier was chosen for simulation. Dimensions of the grid for the gasifier are $10 \mathrm{~cm} \times 100 \mathrm{~cm}$. The set up is shown in Figure 5.9 and a brief description of the gasifier that was simulated is given below: 
In this model coal feed is at cells 33-36 in the y direction, the pressure outlet is along cells 92-95 in the y direction. In this gasifier model, a hot air stream passes over a bed of coal that is coming in along with the recycled char. A hot nitrogen stream was also added above the feed inlet to maintain the temperature. Hence, throughout the channel the coal undergoes a gasification process and all the product gases leave via the pressure outlet. The output yields of all the gases were taken at the pressure outlet exit.

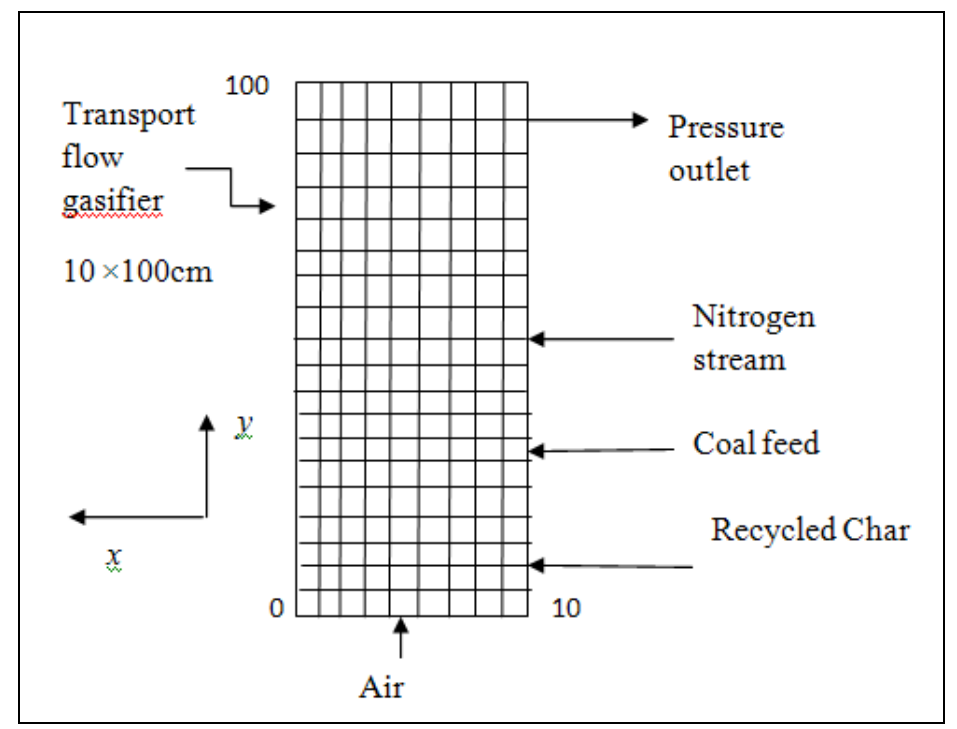

Figure 5.9 Transport flow gasifier for MFIX simulation

The following parameters were used in the simulation runs:

1. Temperatures: $844^{\circ} \mathrm{C}$ and $1316^{\circ} \mathrm{C}$

2. Sample Coal: PRB

3. Heating rate $1000^{\circ} \mathrm{C} / \mathrm{s}$

4. The simulation was run for $20 \mathrm{sec}$.

5. The following output cells in MFIX were used to obtain yields of product gases at the pressure exit: 
I cell: 11, 11; J cell: 92, 95; (which was the location of pressure outlet.)

Time span for which the output yield was obtained, $\mathrm{T}=15,20 \mathrm{sec}$ and it was averaged.

6. Rate parameters obtained from PCCL data for the specified temperature and heating rate:

Table 5.1 Kinetic parameters obtained from PCCL

\begin{tabular}{|c|c|c|}
\hline Temperature $^{\circ} \mathrm{C}$ & 844 & 1316 \\
\hline$A(1 / \mathrm{s})$ & 15,720 & 2315 \\
\hline$E(\mathrm{cal} / \mathrm{gmol})$ & 9320 & 6370 \\
\hline
\end{tabular}

7. When running the simulation in MFIX, only devolatilization rate was on while all other rates were turned off. Two simulations were run using the above mentioned conditions. One MFIX trial was simulated using the original $\mathrm{C}_{3} \mathrm{M}$ subroutine parameters for the devolatilization reaction (these are designated by MC in following figures) and the other simulation used the $\mathrm{C}_{3} \mathrm{M}$ subroutine rate parameters (like devolatilization rate parameters and stoichiometric coefficients for product gases) modified from data obtained via PCCL (which is designated as PC in the following figures)

A summary of the results are shown in Figures 5.10 and 5.11. From these figures the following observations can be made:

1. $\mathrm{O}_{2}, \mathrm{~N}_{2}$, moisture and ash yields in both MFIX and PCCL correction trial are about same.

2. $\mathrm{CO}, \mathrm{CO}_{2}, \mathrm{CH}_{4}$ and tar yields predicted by PCCL corrections are much higher than those from the original subroutine $\mathrm{C}_{3} \mathrm{M}$ in MFIX.

3. $\mathrm{H}_{2}$ yields predicted by MFIX are higher than those obtained from PCCL at low temperature but at higher temperature this trend reverses.

4. Fixed carbon (FC) yield from PCCL is higher than in the original MFIX run.

5. Volatile matter (VM) yield in the PCCL correction trial is lower than in the original MFI 


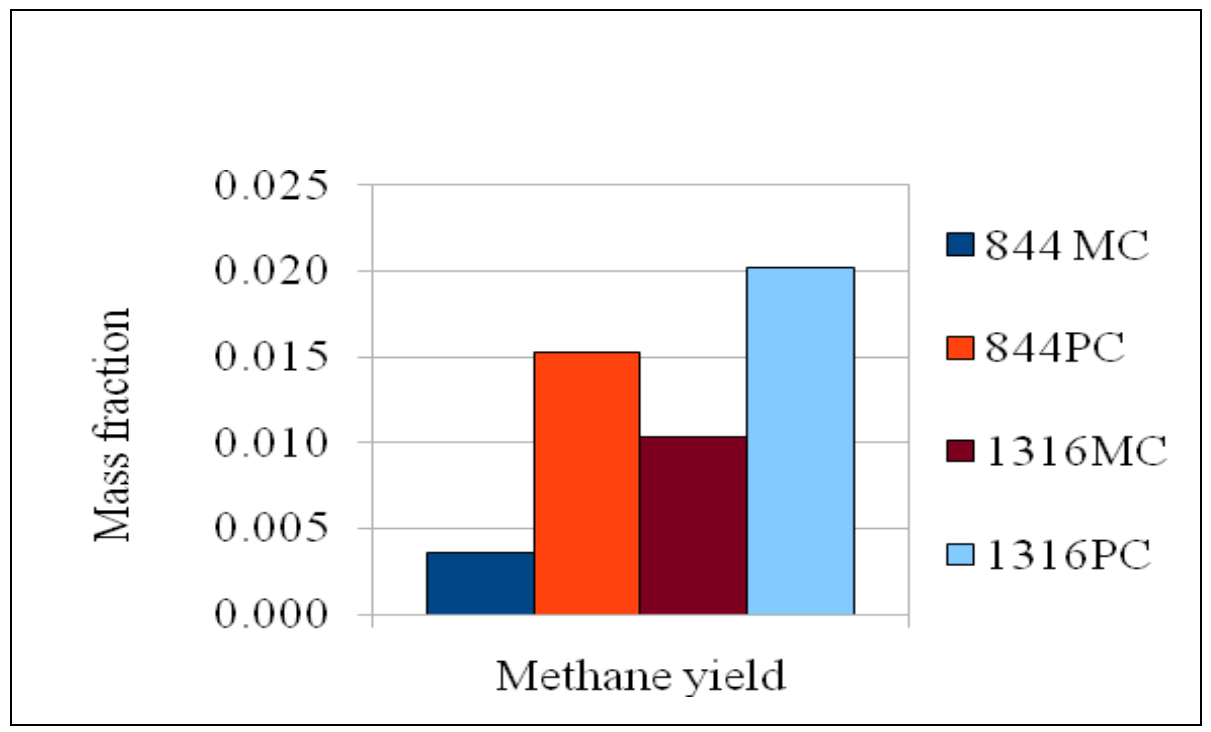

Figure 5.10 Comparison of PCCL( PC) and MFIX(MC) simulations for $\mathrm{CH}_{4}$ yield at same operating conditions(Temperatures $844^{\circ} \mathrm{C}$ and $1316^{\circ} \mathrm{C}$ ) .

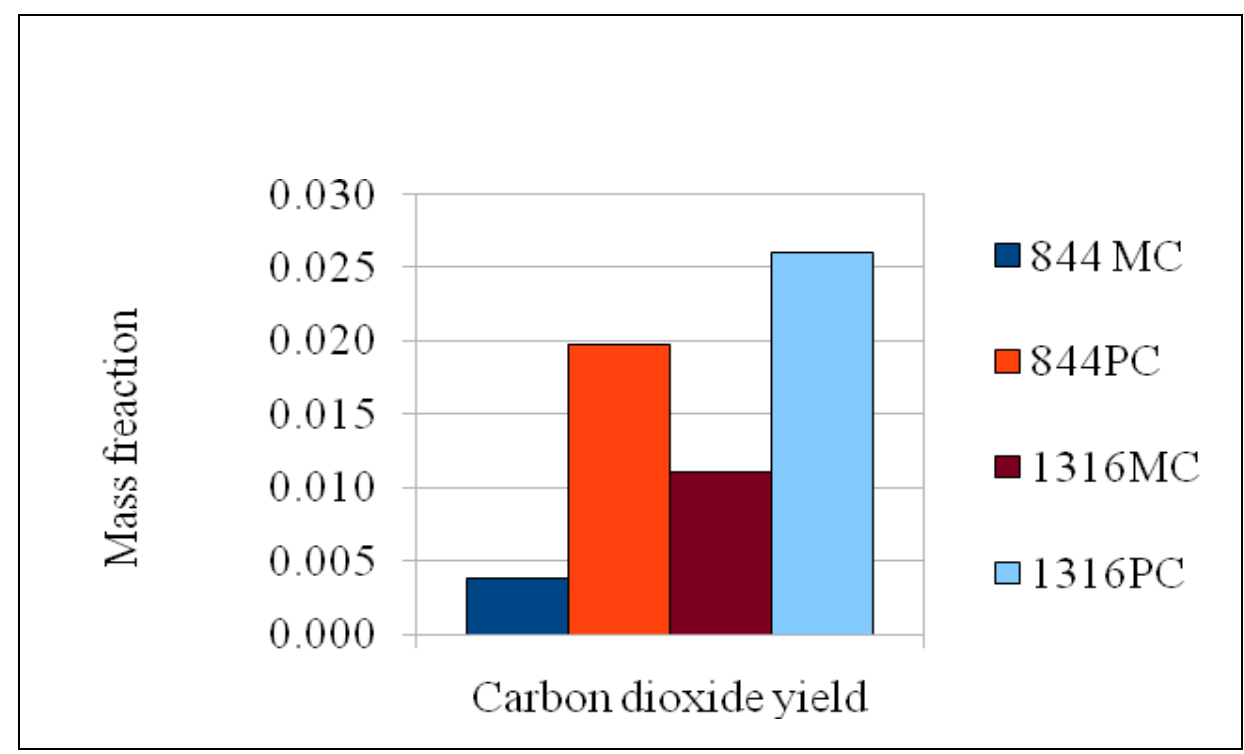

Figure 5.11 Comparison of PCCL( $\mathrm{PC})$ and $\mathrm{MFIX}(\mathrm{MC})$ simulations for $\mathrm{CO}_{2}$ yield at same operating conditions(Temperatures $844^{\circ} \mathrm{C}$ and $1316^{\circ} \mathrm{C}$ ) . 


\subsection{Substitution for MFIX parameters using PCCL output}

Before going further it was necessary to check that the parameters replaced in MFIX give the same output yield for devolatilization products as PCCL for the same operating conditions. For this comparison the moisture rate option was turned off. For the initial run, only the devolatilization reaction was modified. Parameters that needed to be changed in MFIX were:

1. In the subroutine rrates.f the devolatilization reaction parameter activation energy and Arrhenius constant are replaced by SFOR parameters obtained from PCCL.

2. In the subroutine rrates.f the stoichiometric coefficients for devolatilization reactions are replaced with stoichiometric coefficients obtained from PCCL output.

3. The tar molecular weight is modified in mfix.dat

Table 5.2 Comparison of devolatilization products obtained from PCCL and MFIX.

\begin{tabular}{|c|c|c|c|c|}
\hline Products & $\begin{array}{c}\text { Mass Fraction } \\
\text { by MFIX }\end{array}$ & $\begin{array}{c}\text { Mass fraction } \\
\text { on N and O free } \\
\text { basis by MFIX }\end{array}$ & $\begin{array}{c}\text { PCCL yield in } \\
\text { gm }\end{array}$ & $\begin{array}{c}\text { PCCL yield in } \\
\text { Mass fraction }\end{array}$ \\
\hline $\mathrm{O}_{2}$ & 0.108 & $\mathbf{0}$ & 0 & $\mathbf{0}$ \\
\hline $\mathrm{CO}$ & 0.0122 & $\mathbf{0 . 1 1 4 9}$ & 3.869 & $\mathbf{0 . 1 1 4 9}$ \\
\hline $\mathrm{CO}_{2}$ & 0.0202 & $\mathbf{0 . 1 9 0 8}$ & 6.424 & $\mathbf{0 . 1 9 0 8}$ \\
\hline $\mathrm{CH}_{4}$ & 0.0155 & $\mathbf{0 . 1 4 6 8}$ & 4.9424 & $\mathbf{0 . 1 4 6 8}$ \\
\hline $\mathrm{H}_{2}$ & 0.00053 & $\mathbf{0 . 0 0 5}$ & 0.1679 & $\mathbf{0 . 0 0 5}$ \\
\hline $\mathrm{H}_{2} \mathrm{O}$ & 0.0188 & $\mathbf{0 . 1 7 7 8}$ & 5.986 & $\mathbf{0 . 1 7 7 8}$ \\
\hline $\mathrm{N}_{2}$ & 0.786 & $\mathbf{0}$ & 0 & $\mathbf{0}$ \\
\hline $\mathrm{Tar}$ & 0.032 & $\mathbf{0 . 3 6 4 7}$ & 12.2778 & $\mathbf{0 . 3 6 4 7}$ \\
\hline
\end{tabular}


By comparing the second and last column of Table 5.2, it can be concluded that the parameters that are modified in MFIX are in good agreement with PCCL and hence the two models can be linked together.

\subsection{Moisture Release}

MFIX has single first order reaction kinetics for moisture release with a fixed Arrhenius constant and activation energy for 5 specific types of coals. PCCL generates moisture release flux based on the heating rate and temperature history. Simulation was run using the transport flow gasifier reactor set up described earlier in Section 5.5 with the operating conditions as follows:

1) Reactor temperature $1000^{\circ} \mathrm{C}$.

2) Pressure $1.5 \mathrm{MPa}$

3) Coal Feed: Lignite and PRB

4) Only the moisture release rate was switched on, others were turned off.

5) Moisture release rate was modified in MFIX using moisture release flux given by PCCL.

Figure 5.12 and Figure 5.13 shows the moisture release along the reactor length using the original MFIX kinetics compared to modified PCCL kinetics for the Lignite and PRB coals respectively. It can be seen that, as the heating rate increases the PCCL moisture release curve shifts upward. It shows that PCCL takes into consideration the effect of heating rate while MFIX does not. 


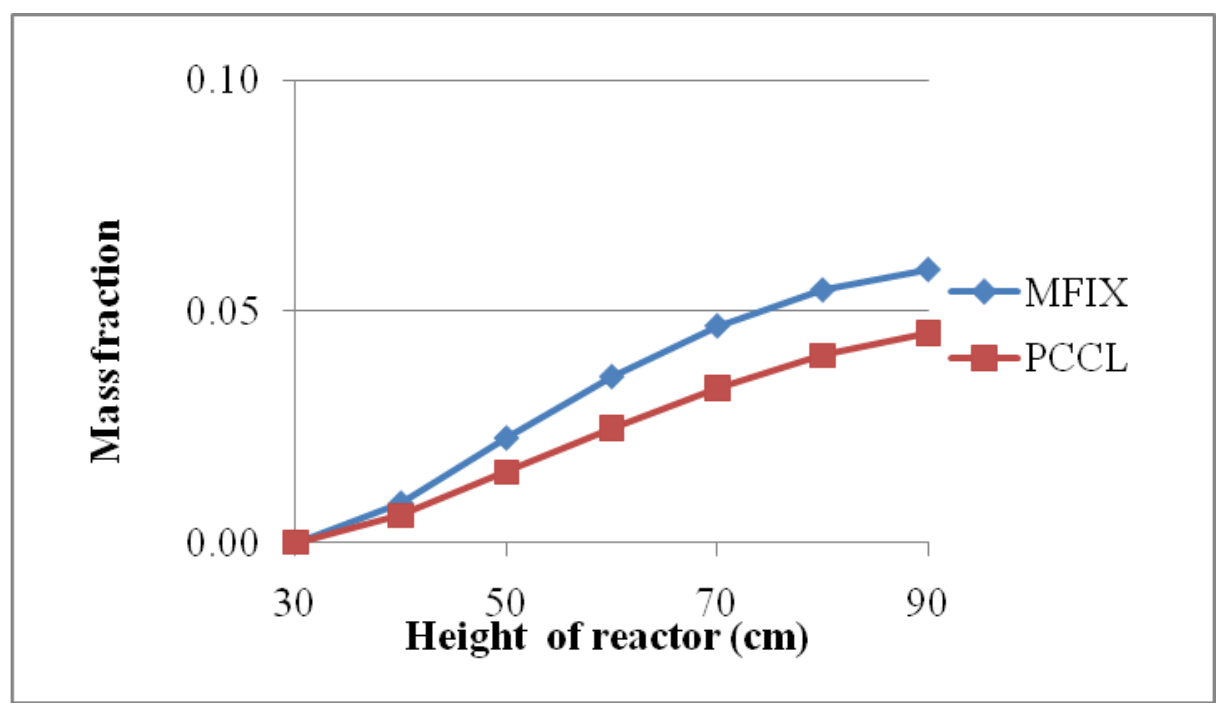

Figure 5.12 TheFigure showing moisture release along reactor length for Lignite coal at $900{ }^{\circ} \mathrm{C}$ and a heating rate of $1000^{\circ} \mathrm{C} / \mathrm{s}$ in PCCL.

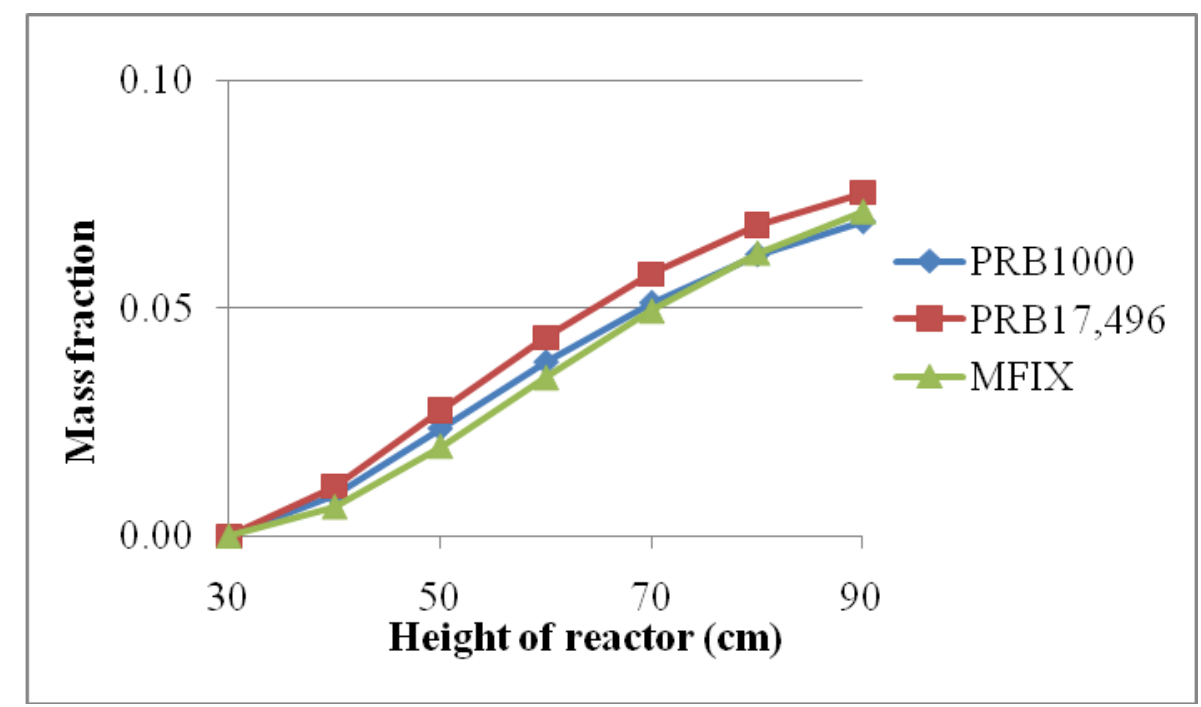

Figure 5.13 The moisture release along reactor length for PRB coal at $900{ }^{\circ} \mathrm{C}$ and heating rates of $1000^{\circ} \mathrm{C} / \mathrm{s}$ and $17,496^{\circ} \mathrm{C} / \mathrm{s}$ in PCCL.

\subsection{Tar Cracking}

MFIX uses single first order reaction (SFOR) kinetics for tar cracking. The kinetic parameters are fixed for the 5 types of coal. PCCL also gives tar cracking in SFOR kinetics but considers the effects of heating rate and operating temperature. In addition PCCL predicts PAH 
and oil as additional product gas species for tar cracking. PAH and oil cannot survive over $1000^{\circ} \mathrm{C}$. In this research, the tar cracking reaction is assumed to take place at temperatures below or equal to $1000^{\circ} \mathrm{C}$ otherwise the secondary pyrolysis reaction starts to take place.

The tar cracking simulation was run using the transport flow gasifier reactor set up described earlier in Section 5.5 with the operating conditions as follows:

1) Reactor temperature $900^{\circ} \mathrm{C}$.

2) Pressure $1.5 \mathrm{MPa}$

3) Coal Feed: PRB coal

4) Heating rate used for PCCL $1000^{\circ} \mathrm{C} / \mathrm{s}$

5) Only moisture release, devolatilization and tar cracking reaction rates were turned on while all other gasification reactions were turned off.

6) Moisture release rate was modified in MFIX using the moisture release flux given by PCCL while devolatilization and tar cracking kinetic parameter were updated using SFOR parameters generated by PCCL.

7) PAH and oil were added as new gas species.

8) There was no fixed carbon generated via tar cracking.

Figure 5.14 shows the evolution of tar cracking products along the reactor length. It can be seen that the products show the expected evolution trend for all gas species. From this figure it can be concluded that tar cracking reaction kinetics in MFIX can be modified using PCCL predicted SFOR kinetics. 

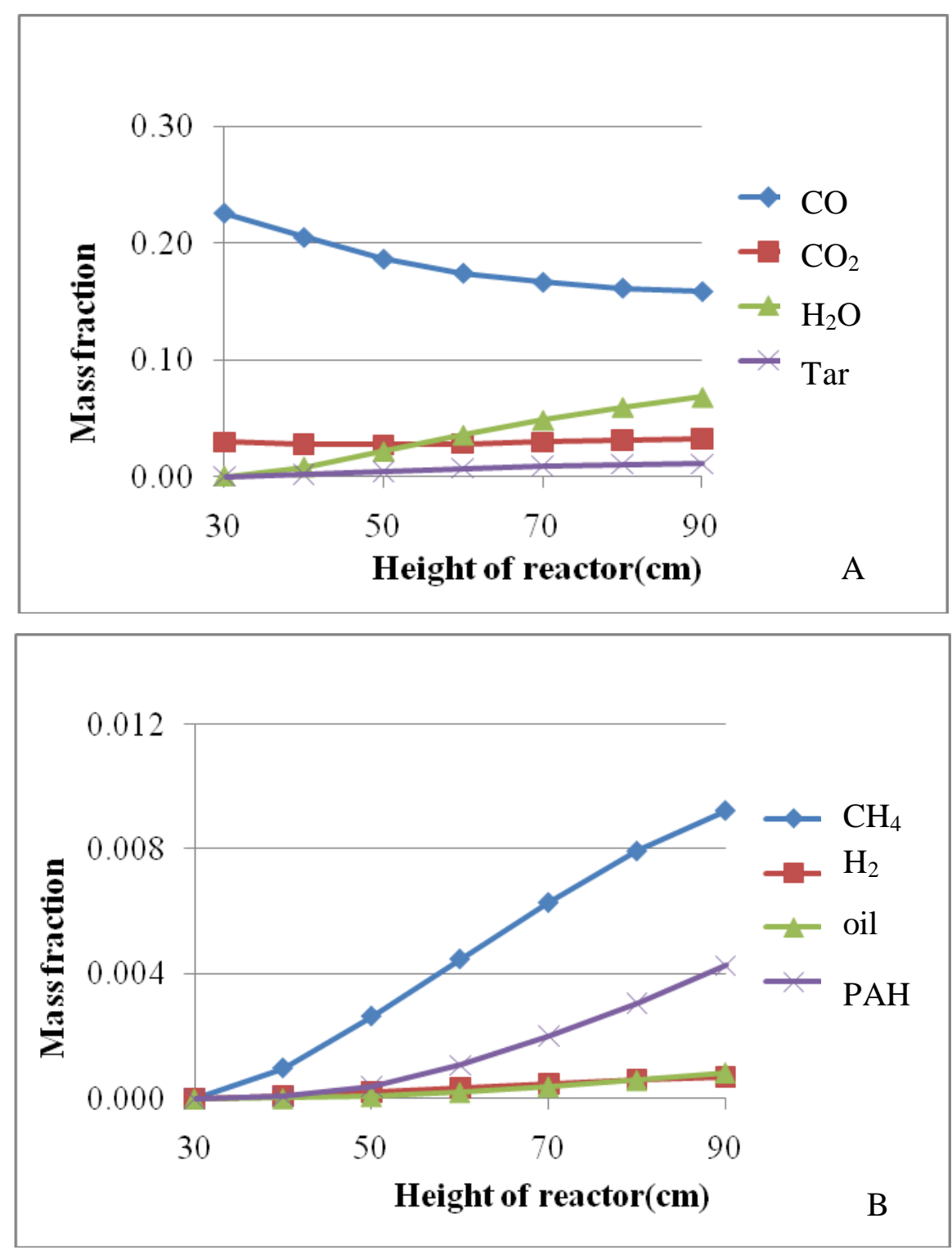

Figure 5.14 The evolution of gas species during tar cracking along reactor length for PRB coal at $900{ }^{\circ} \mathrm{C}$.

\subsection{Secondary Pyrolysis with soot oxidation}

$\mathrm{PAH}$ and oil become unstable at temperatures above $1000{ }^{\circ} \mathrm{C}$ and react with secondary hydrocarbons to form soot and $\mathrm{C}_{2} \mathrm{H}_{2}$. Version 4.1 of PCCL does not give soot formation kinetics from PAH and oil but gives the total yield of soot and $\mathrm{C}_{2} \mathrm{H}_{2}$ formed in secondary pyrolysis. We have assumed for this work that only above $1000^{\circ} \mathrm{C}$ will secondary pyrolysis take place and for 
this case the devolatilization reaction kinetics will be used to simulate the secondary pyrolysis reactions but with the yields adjusted to give the correct make of soot and $\mathrm{C}_{2} \mathrm{H}_{2}$ along with other gas species. Soot will also get oxidized in this process. Soot oxidation kinetics are given by Nagle and Strickland-Constable (NSC) (1962). Figures 5.15 and 5.16 show the simulation results for secondary pyrolysis and soot oxidation in transport flow gasifier. The operating conditions are as follows:

1) Reactor temperature $1000^{\circ} \mathrm{C}$ and $1200^{\circ} \mathrm{C}$.

2) Pressure $1.5 \mathrm{MPa}$

3) Coal Feed: Lignite

4) Heating rate used for PCCL $1000^{\circ} \mathrm{C} / \mathrm{s}$

5) Only moisture release, devolatilization and soot oxidation reaction rates were turned on all other gasification reaction were turned off.

6) Soot oxidation rate was introduced in MFIX using the NSC model given by PCCL while devolatilization kinetic parameters were updated using SFOR parameters generated by PCCL.

7) Soot and $\mathrm{C}_{2} \mathrm{H}_{2}$ were added as new gas species. 

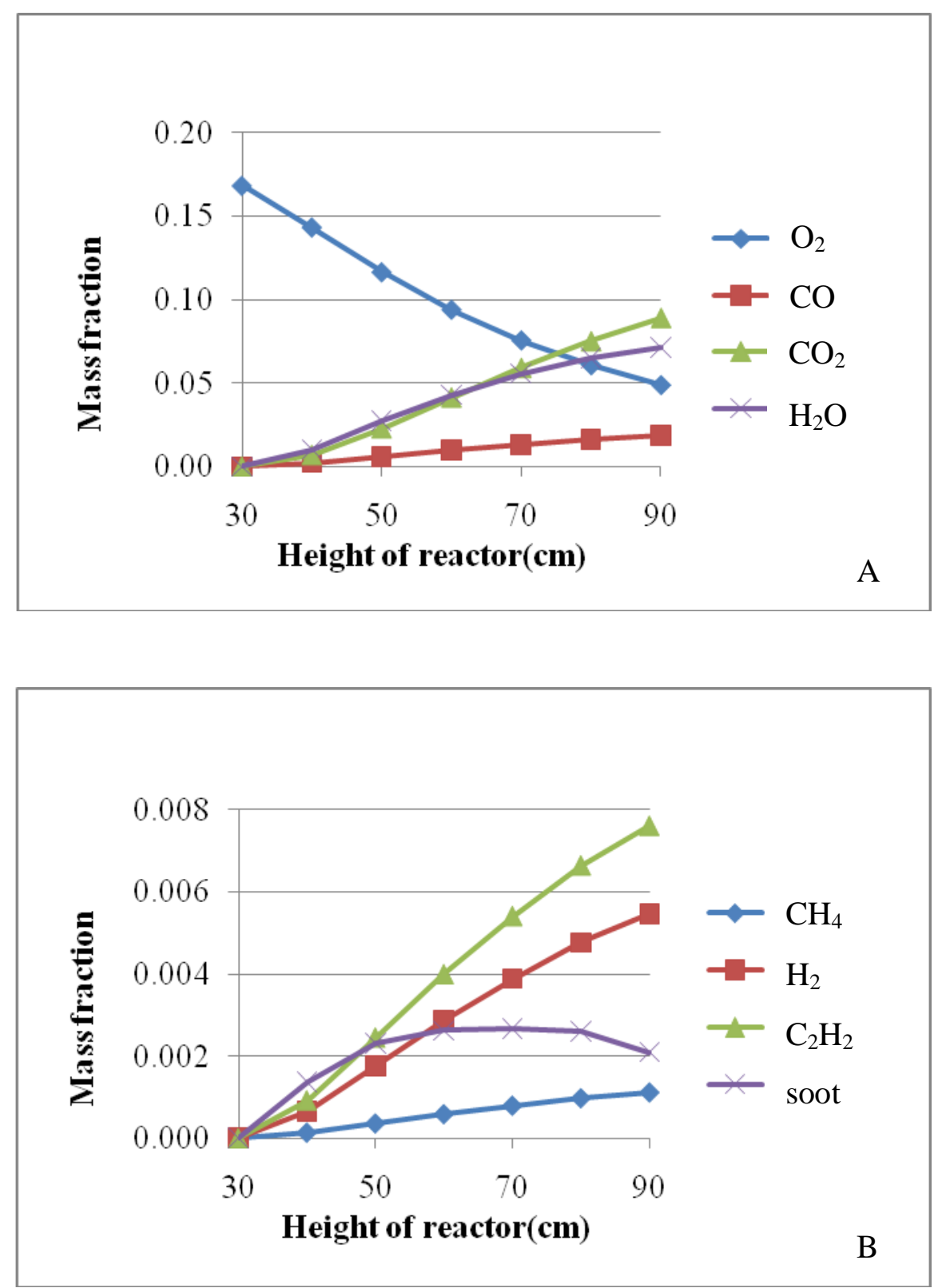

Figure 5.15 The evolution of gas species during secondary pyrolysis along the reactor length for Lignite coal at $1000^{\circ} \mathrm{C}$. 

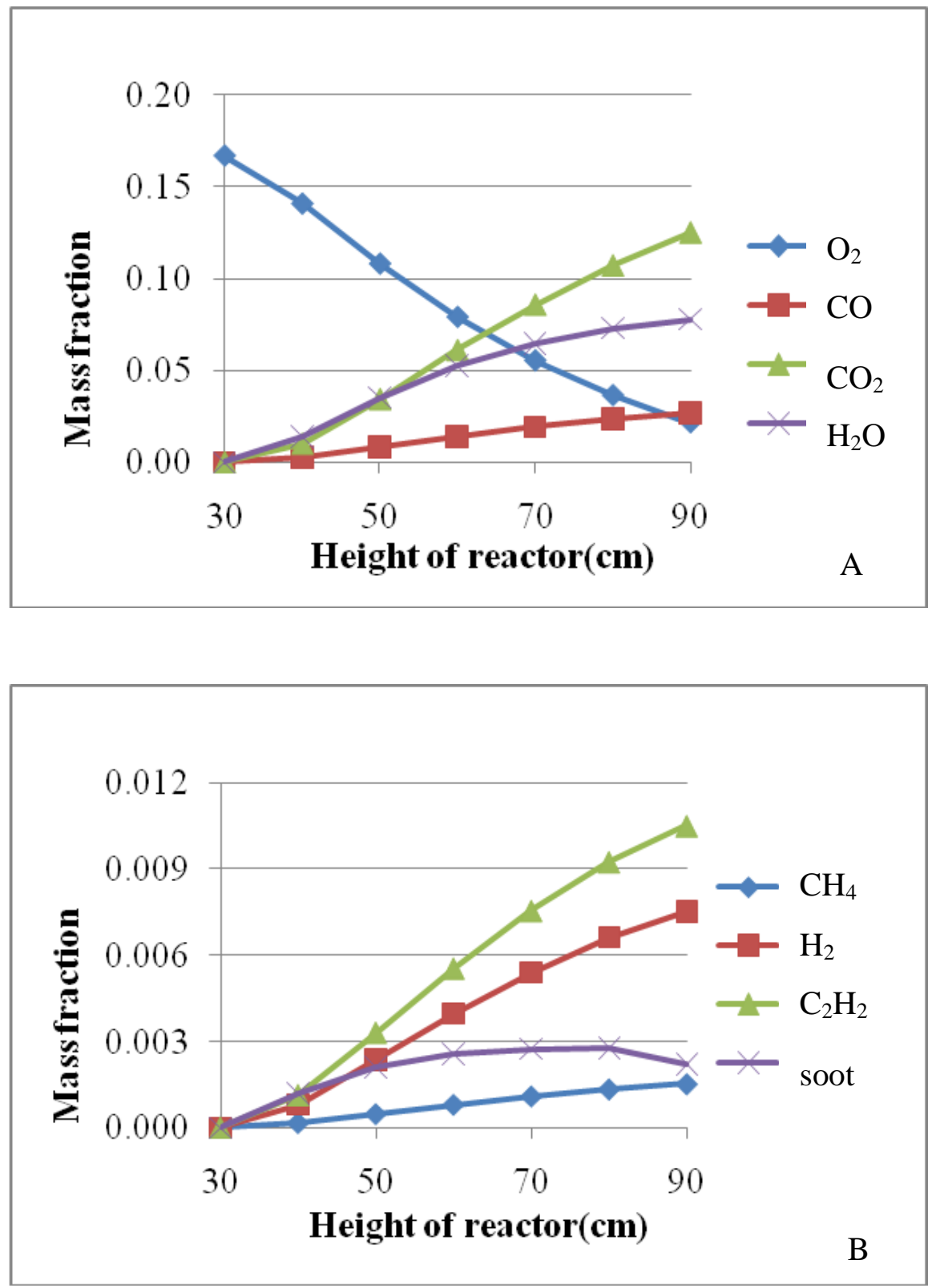

Figure 5.16 The evolution of gas species during secondary pyrolysis along the reactor length for Lignite coal at $1200^{\circ} \mathrm{C}$. 


\subsection{Biomass Devolatilization}

The yield for biomass devolatilization predicted by PCCL was compared with experimental results available in the literature.

Perez et al. (2008) reported the affect of temperature on the yield and quality of pyrolysis products of pine wood and oil malee. Figure 5.17 shows the comparison of char yield and water released generated by PCCL with experiments for oil malee pyrolysis at temperatures ranging from $350-500^{\circ} \mathrm{C}$.

Couhert et al.(2009) observed the failure of the component additively rule to predict gas yields of biomass in flash pyrolysis at $950^{\circ} \mathrm{C}$. Experiments were carried out on beechwood (BW), mix spruce (MS) and rice husk (RH). Figure 5.18 shows the secondary pyrolysis product yield obtained for BW, MS and RH at $950{ }^{\circ} \mathrm{C}$ from experiments (EXP) and PCCL. Yields of CO and $\mathrm{CO}_{2}$ obtained from PCCL are considerably different from the experimental results while yields for the other gas products are comparable.

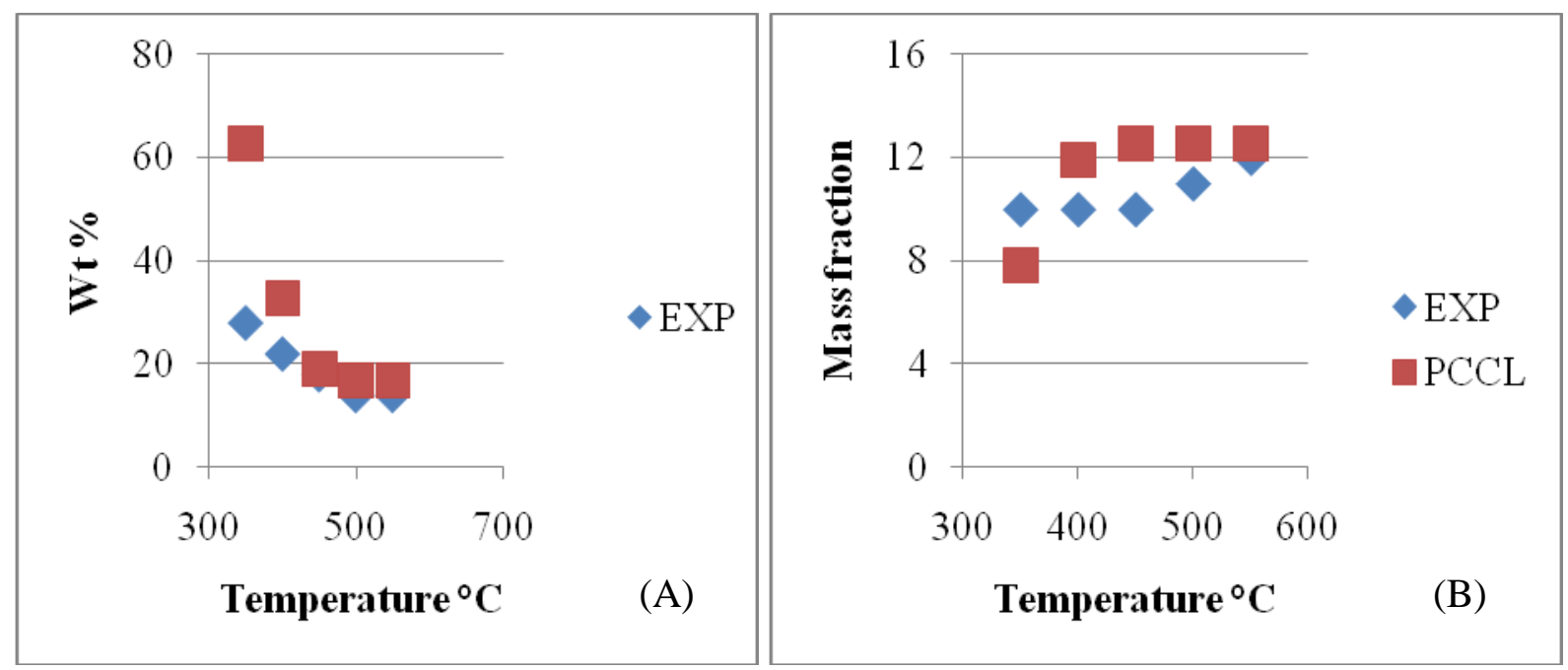

Figure 5.17 The evolution of char( A) and water (B) during oil malee pyrolysis 


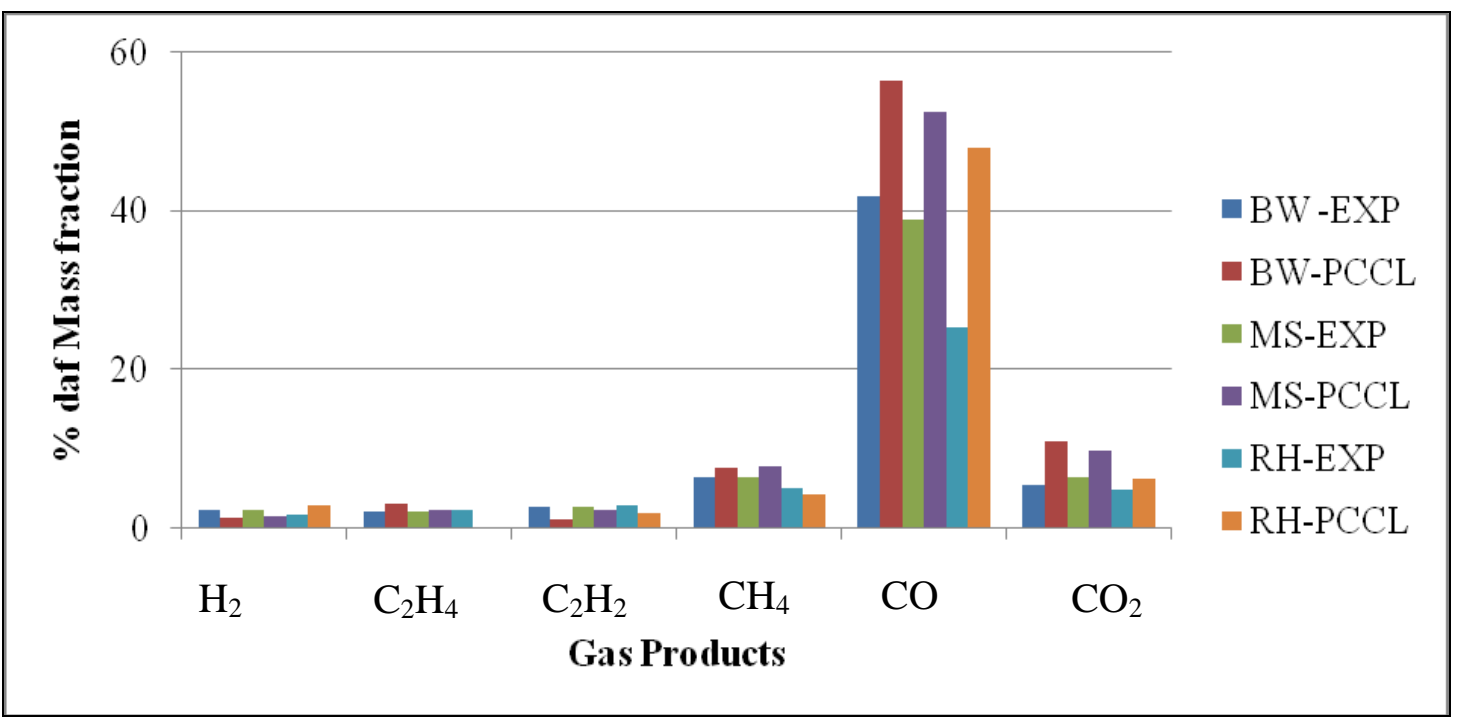

Figure 5.18 A comparison of secondary pyrolysis prodcut yields obtained from experiments and PCCL for beechwood(BW), mix spruce( MS) and rice husk $(\mathrm{RH})$ at $950^{\circ} \mathrm{C}$.

Du pont et al. (2008) modeled the pyrolysis kinetics of beechwood and softwood. Figures 5.19 and 5.20 give the comparison between pyrolysis product yields generated by PCCL and experiments at 800 and $1000^{\circ} \mathrm{C}$ for beechwood and softwood. 


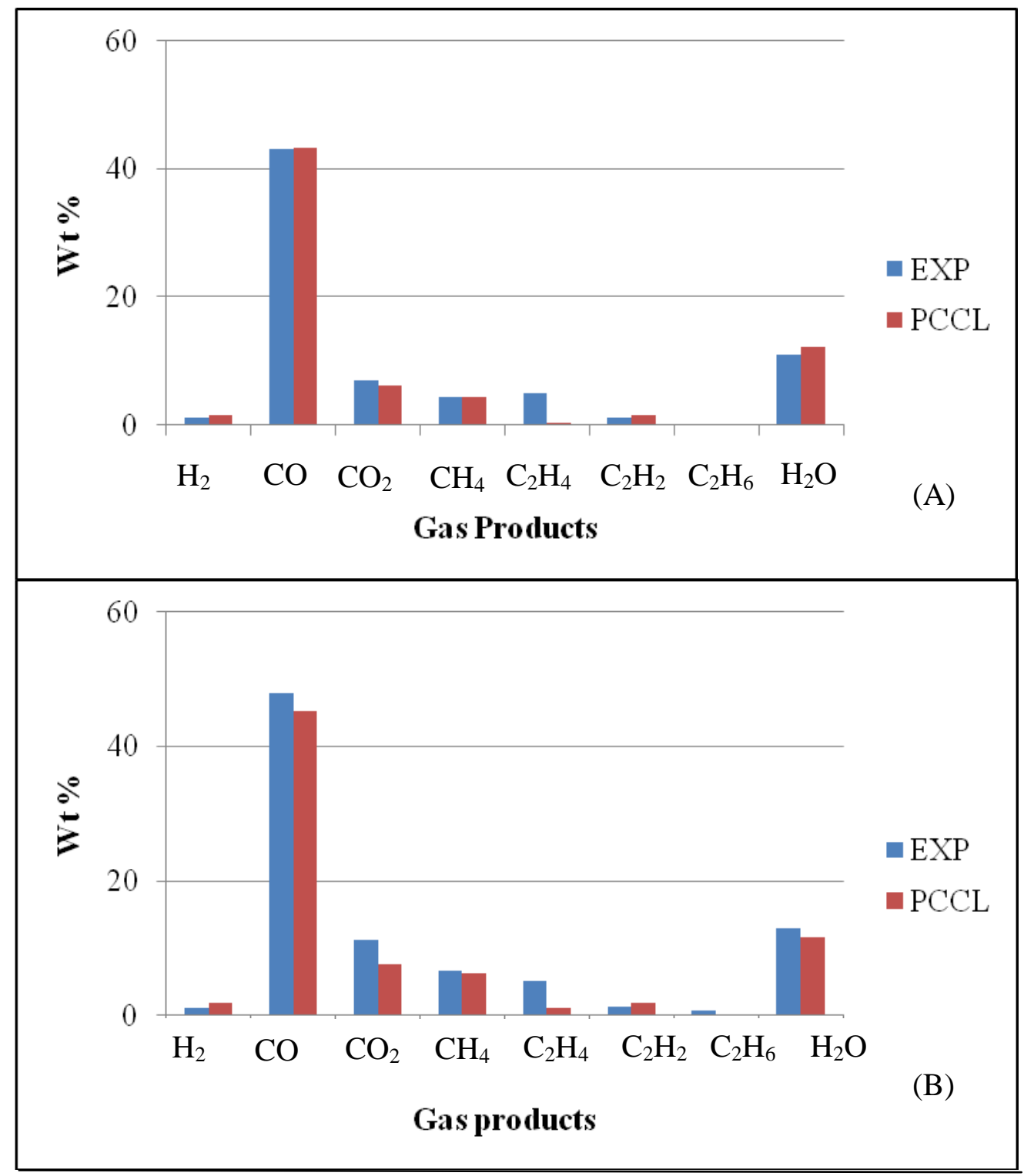

Figure 5.19 A comparison of pyrolysis prodcut yields obtained from experiments and PCCL for beechwood (A), softwood (B) at $800^{\circ} \mathrm{C}$. 

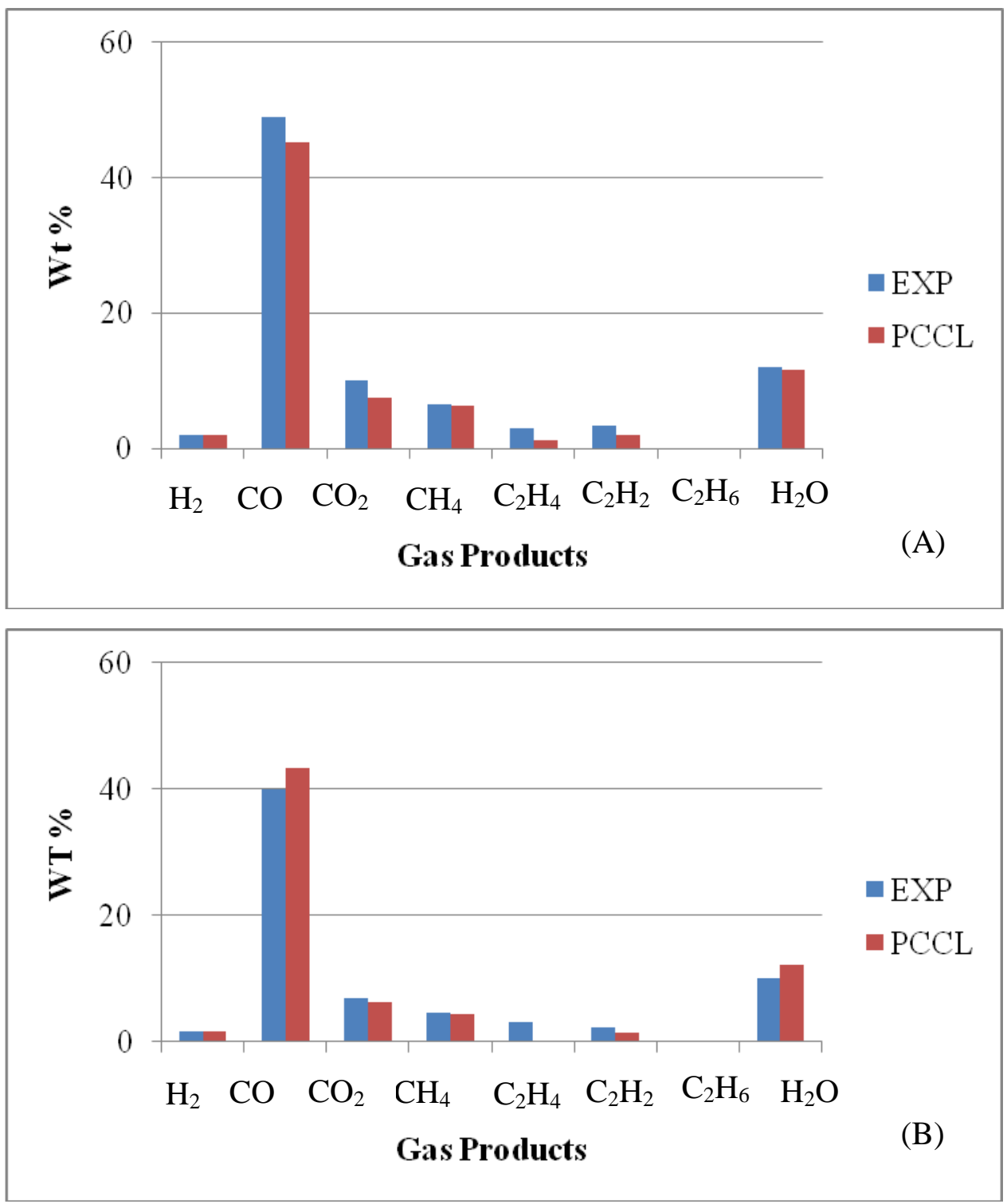

Figure 5.20 A comparison of pyrolysis prodcut yields obtained from experiments and PCCL for beechwood (A), softwood (B) at $1000{ }^{\circ} \mathrm{C}$.

Compairing Figures 5.17-5.20, it can be concluded that devolatilization predictions of PCCL are reasonably accurate and in good agreement with the experimental results for biomass pyrolysis. Hence the results give confidence in using PCCL kinetics for modyfying biomass devolatilization kinetics in MFIX. 


\subsection{Algorithm}

The basic idea behind the algorithm is to obtain the required kinetic parameters from PCCL to update $\mathrm{C}_{3} \mathrm{M}$. A seamless connection between PC Coal Lab and the $\mathrm{C}_{3} \mathrm{M}$ is created. The interface is designed to allow MFIX to transfer information through $\mathrm{C}_{3} \mathrm{M}$ to PC Coal Lab, run PC Coal Lab with the input data from MFIX and then sends kinetic information back to $\mathrm{C}_{3} \mathrm{M}$ in a form that allows $\mathrm{C}_{3} \mathrm{M}$ to update and continue the MFIX simulation using updated parameters from PC Coal Lab.

The output files generated from PCCL consists of product yields and reaction kinetics parameters for devolatilization, tar cracking and secondary pyrolysis. These results need to be converted into an acceptable format for $\mathrm{C}_{3} \mathrm{M}$. SFOR parameters for moisture release and devolatilization were obtained from $\mathrm{CFDC}_{\mathrm{i}} \mathrm{T}_{\mathrm{j}}$.rpt while product gas species yields were obtained from $\mathrm{FDC}_{\mathrm{i}} \mathrm{HC}_{\mathrm{j}}$.rpt, $\mathrm{FDC}_{\mathrm{i}} \mathrm{NG}_{\mathrm{j}}$.rpt and $\mathrm{FDC}_{\mathrm{i}} \mathrm{TC}_{\mathrm{j}}$.rpt. For tar cracking the $\mathrm{SFOR}$ and devolatilization parameters were obtained from $\mathrm{SFTRC}_{\mathrm{i}} \mathrm{T}_{\mathrm{j}}$.rpt. Secondary pyrolysis product yields were derived from $\mathrm{FDC}_{\mathrm{i}} \mathrm{SP}_{\mathrm{j}} . \mathrm{rpt}$.

The detail mechanism of conversion is explained in appendix I. A Graphical User Interface (GUI) to link MFIX to PCCL via C3M will be developed which will automatically do all the conversions.

The following steps illustrate how the process will work:

1. User will have to enter the coal proximate and ultimate analysis in the GUI.

2. GUI will run PCCL with same operating conditions used in MFIX.

3. GUI will update the $\mathrm{C}_{3} \mathrm{M}$ using the new parameters obtained from PCCL.

4. MFIX simulations will be run using the updated $\mathrm{C}_{3} \mathrm{M}$ parameters. 


\section{Chapter 6}

\section{Conclusions}

The effects of temperature, pressure and heating rate on devolatilization yield predicted by PCCL was studied. PCCL predictions for devolatilization were compared to experimental measured yields and were found in good agreement with experimetal data for the same operating condintions.Detailed kinetic expressions using PC Coal Lab (PCCL) were implemented for the devolatilization, tar cracking and secondary pyrolysis of a wide variety of coals in existing CFD code Multiphase Flow with Interphase Exchanges (MFIX) developed by NETL.

The $\mathrm{C}_{3} \mathrm{M}$ code was studied in detail and the parameters in need of change were identified. An algorithm to link MFIX to PCCL via $\mathrm{C}_{3} \mathrm{M}$ was developed. The parameters obtained from PCCL were converted into an acceptable format to update the fortran code in $\mathrm{C}_{3} \mathrm{M}$. The algorithm was tested using a simulation of a transport flow gasifier with the current $\mathrm{C}_{3} \mathrm{M}$ kinetics and compared with results using modified kinetics obtanied from PCCL. The algorithm is being used to develop a GUI at NETL site Morgantown by Phil Nicolletti.

PCCL predictions for biomass devolatilization were compared with experimental results and they show good agreement with experimental results. 


\section{Chapter 7}

\section{Future Work}

Version 4.1 of PCCL is not programmed to give soot formation kinetics. The algorithm will be updated when suitable soot formation kinetics become available.

Future work will concentrate on developing algorithms for implementing homogeneous and heterogeneous reactions in $\mathrm{C}_{3} \mathrm{M} / \mathrm{MFIX}$. The focus of this portion of the work will be on analyzing PCCL data for these reactions and to develop rate and appropriate yield equations to describe the reaction kinetics.

Furthermore, gasification reactions of soot that will occur in the gasifier must also be modeled. The heterogeneous oxidation and gasification reactions of the soot will therefore have to be modeled on an equivalent cell concentration basis and suitable algorithms to keep track of the conversion of the soot particles will be developed.

The current work considers steady state conditions in gasifier; future work will focus on unsteady state temperature profile across the reactor.

The $\mathrm{C}_{3} \mathrm{M}$ module does not have biomass pyrolysis kinetics. Biomass pyrolysis will be studied in detail and PCCL data will be used to provide suitable kinetic parameters to $\mathrm{C}_{3} \mathrm{M}$ Finally the effect of ash and hetero-atoms ( $\mathrm{N}$ and $\mathrm{S}$ ) on devolatilization will be studied. 


\section{References}

1. A.V. Bridgwater, D. Meier , D. Radlein, "An overview of fast pyrolysis of biomass", Organic Geochemistry V 30 (1999) 1479-1493.

2. Badzioch S, Hawksley P.G. W. 1970, "Kinetics of thermal Decomposition of Pulverised Coal Particles” Ind Eng Chem Process Des Dev V9 pp 521-530.

3. Campbell, J.H. , 1978. The Kinetics of Decomposition of Colorado Oil Shale: II. Carbonate Minerals. Lawrence Livermore Laboratory Report,

4. Capucine Dupont ,Jean-Michel Commandre, Paola Gauther, Guillaurne Boissonnet Sylvain Salvador and Daniel Schweich, "Biomass pyrolysis experiments in an analytical entrained flow reactor between 1073 and 1273 K”, Fuel V87(2008),1155-1164.

5. Capucine Dupont, Li Chen, Junlien Cances Jean -Michel Commadre. Alberto cuoci, Sauro Pierucci, Eliso Ranzi, "Biomass Pyrolysis :kinetic modelling and experimental validation under high temperature and flash heating rate conditions", Journal of analytical and applied pyrolysis, V85(2008),260-267.

6. Carole Couhert, Jean -Michel Commandre and Sylvain Salvador, "Failure of the componenet additivity rule to predict gas yields of biomass in flash pyrolysis at $950^{\circ} \mathrm{C} "$, biomass and bioenergy V33(2009),316-326.

Chemical Engineering Journal V127(2007)1-9.

7. Chen Caixia, Horio Masayuki, Kojima Toshinori "Numerical simulation of entrained flow coal gasifiers.Part.I: Modeling of coal gasification in an entrained flow gasifier", Chemical Engineering Science 55 (2000) 3861-3874.

8. Chen J C., Castangoli C., "Coal Devolatilization during Rapid Transient Heating-2 Secondary Pyrolysis", Energy Fuels vol1(1992) 264:271.

9. Choi Y.C., Li X. Y., Park T. J., Kim J. H., Lee J. G. , "Numerical Study on the coal gasification characteristics in an entrained flow coal gasifier” FUEL 802001 2193-2201

10. Chul Park and John Appleton, "Shock tube measurement of soot oxidation rates", Cobsution and flame V20(1973),369-379. 
11. Coal Chemistry document for MFIX

12. Desai, P.R., and Wen, C.Y., 1978, "Computer Modeling of the MERC Fixed Bed Gasifier," MERC/CR-78/3.

13. Desai, P.R., and Wen, C.Y., 1978, "Computer Modeling of the MERC Fixed Bed Gasifier," MERC/CR-78/3

14. Di Blasi, C.; Branca, C.; Santoro, A.; Gonzalez Hernandez, E, “ Pyrolytic behaviour and products of some wood varieties",Combust. Flame V124(2001), 165.

15. Doraiswamy L K and Sharma M M “Heterogeneous Reactions" Vol 1 Chapter 19,pp 460-474.1984 John Wiley \& sons Inc

16. Enrico Biagini, Federica Barontini, and Leonardo Tognotti, "Devolatilization of Biomass Fuels and Biomass Components Studied by TG/FTIR Technique”, Ind. Eng. Chem. Res. 2006, 45, 4486-4493.

17. Enrico Biagini, Federica Lippi, Luigi Petarca, Leonardo Tognotti, “ Devolatilization rate of biomass and coal biomass blends: an experimental investigation”, Fuel V81(2002),1041-1050.

18. Gregory D.R and R.F Littlejohn The BWRA Monthly Bulletin, 29(6) ,173 (1965)

19. Gunn, D.J., 1978, "Transfer of Heat or Mass to Particles in Fixed and Fluidized Beds," Int. J. Heat Mass Transfer, 21, 467-476

20. H. Kobayashi, J.B. Howard and A.F. Sarofim. In: Sixteenth Symposium (International) on Combustion (1977), pp. 411-425.

21. J.R. Gibbins \& R. Kandiyoti, The effect of variations in time-temperature history on product distribution from the pyrolysisof coal in a wire-mesh reactor, Fuel, 68, 1989, 895

22. John C. Chen, Craig Castagnoli and Stephen Niksa , "Coal Devolatilization during Rapid Transient Heating- Secondary Pyrolysis”, Energy and Fuel V6(1992),264-271.

23. John P A Neeft,T Xander Nijhuis, Erik Smakman, Michiel Makkee, "Kinetics of the oxidation of diesel soot", Fuel V76(1997),1129-1136. 
24. Jon R Gibbons,Rafael Kandiyoti, "The effect of variation in time temperature history on product distribution from coal pyrolysis", Fuel V68(1989), 895-903.

25. K M Leung ,Libdstedt, W P Jones, “ A simplified reaction mechanism for soot formation in nonpremixed flames", Combustion and flame V87(1991),289-305.

26. Koon Gee Neoh and Richard E Gannon , "Coal Volatile yield and element partition in rapid pyrolysis" Fuel V63 (1984), 1347-1352.

27. Lee C W Scaroni A W Jenkins R G 1991 "Effect of pressure on the devolatilization and swelling behavior of a softening coal during rapid heating", FUEL V70 pp 957-965.

28. Li S G, Xu S P, Liu S Q, “ Fast pyrolysis of biomass in free fall reactor for hydrogen rich gas." Fuel processing Tech V85(2001),1201-1211.

29. M.P. Ruiz, R. Guzm’an de Villoria, A. Millera, M.U. Alzueta, R. Bilbao, "Influence of the temperature on the properties of the soot formed from $\mathrm{C}_{2} \mathrm{H}_{2}$ pyrolysis",

30. Mannuel Garcia Perez, Xiao Shan Wang ,Jun Shen Mratin J Rhodes Fujun Tian Woo-jin lee, Hongwei Wu and Chun Zhu Li, "Fast Pyrolysis of oil malee woody biomass:Effect of temperature on the yield and quality of pyrolysis products" Ind Eng Chem V47(2008), 1846-1854.

31. McLean, W. J., D. R. Hardesty and J. H. Pohl, "Direct Observations of Devolatilizing Pulverized Coal Particles in a Combustion Environment," Eighteenth Symposium (International) on Combustion, 1239 (1981).

32. Nagle, J. and R. F. Strickland-Constable, "Oxidation of Carbon Between 1000-2000 oC," Proceedings of the Fifth Carbon Conference, V1 (1962),154.

33. Naik Chitralkumar and Niksa Stephen In: $5^{\text {th }}$ US combustion meeting, paper \# G23,March 25-28,2006.

34. Niksa Stephen, PCCL version 4.1 User Guide and Tutorial,2008 
35. Niksa S., Liu Giu, Hurt Robert H., "Coal conversion submodels for designs applications at elevated pressures.Part I.devolatilization and char oxidation",Progress in Energy and Combustion Science 29(2003) 425-477.

36. Niksa S., "Rapid coal devolatilization as an equilibrium flash distillation" AIChE J. V34, (1988)pp 790-802.

37. Oh M. S., Peters W. A., Howard J. B., "An experimental and modeling study of softening coal pyrolysis", AIChE, V 35(1989) pp 775-792.

38. Park, C. and J. P. Appleton, "Shock-Tube Measurements of Soot Oxidation Rates," Combustion and Flames, V20 (1973), 369.

39. Puri, R., R. J. Santoro and K. C. Smyth, "The Oxidation of Soot and Carbon Monoxide in Hydrocarbon Diffusion Flames," Combustion and Flames, V97 (1994), 129.

40. Qizhi Ni and Alan Williams, Department of Fuel and Energy, The University of Leeds, Leeds LS2 9JT, UK, February 1994.

41. Radcliffe, S. W. and J. P. Appleton, "Soot Oxidation Rates in Gas Turbine Engines," Combustion Science and Technology, V4 (1971), 171.

42. S Niksa, "Predicting the rapid devolatilization of diverse forms of biomass with bio flashchain", Proceeding of combustion institute V28(2000), 2727-2733.

43. Seeker, W. R., G. S. Samuelson, M. P. Heap, and J. D. Trolinger, "Thermal Decomposition of Pulverized Coal Particles," Eighteenth Symposium (International) on Combustion, The Combustion Institute, Pittsburgh, PA, p. 1213 (1981).

44. Shaozeng Sun, Hongming Tian, Yijun Zhao, “Experimental and numerical study of biomass flash pyrolysis in an entrained flow reactor", Bioresource technology V101(2010),3678-3684.

45. Solomon P.R, Hamblen D.G, Carangelo R.M, Serio M.A, Deshpande G.Y., "General Model of Coal Devolatilization" Energy and Fuels, V2(1988), pp 405-420.

46. Stillman R ,"Simulation of a Moving bed Gasifier for a Western Coal” IBM J. Res Dev. V23(1979), pp 240-252 
47. Syamlal, M., and Bissett, L.A., "METC Gasifier Advanced Simulation (MGAS) Model," Technical Note, NTIS report No. DOE/METC-92/4108 (DE92001111) (1992).

48. T. Lang and R.H. Hurt, "Char Combustion Reactivities for a Suite of Diverse Solid Fuels and Char-Forming Organic Model Compounds." Proc. Combust. Inst., 29:423-31 (2002).

49. Thomas S Fletcher, Jinliang Ma. , James R Rigby, Alexander A Brown, “ Soot in coal combustion system", Progress in Energy and Combustion Science, V23, issue3, (1997), 283-301.

50. Ubhayakar S. K., Stickler D. B., Gannon R. E., "Modeling of entrained bed pulverized coal gasifiers", Fuel, V-56(1977), pp 281-291.

51. Van Heek K H, “ Advanced Coal conversion by Pyrolysis and Hydrogenation”, Third Flame Research Course, IFRF, sept 1990, Netherlands.

52. Wen and Lee, "Coal Conversion Technology," Addison Wesley Publishing Co., 1978

53. Wen C.Y. and Chaung T.Z. Entrainment Coal Gasification Modeling Ind.Engg. Chem.Process Des.Dev vol 18 (1979),684-695

54. Wen, C.Y., Chen, H., and Onozaki, M., "User's Manual for Computer Simulation and Design of the Moving Bed Coal Gasifier," DOE/MC/16474-1390(1982), NTIS/DE83009533.

55. Xiu Shuangning, Li Zhihe, Li Baoming, Yi Weiming, Bai Xueyuam, “ Devolatilization characteristic of biomass at flash heating rate", Fuel V85(2006),664-670.

56. Yogi Goswami, “ Alternative Energy in Agriculture”, Vol. II, Ed. D. CRC Press,1986,83102.

57. Zeng D., Thomas Fletcher, "Effects of pressure on coal pyrolysis and char morphology", Energy and Fuel V19 (2005), 1828-38. 


\section{Notation}

$d_{p} \quad$ Diameter of droplet

(m)

$E_{d} \quad$ Activation energy

(cal/gmol)

$\rho_{s} \quad$ Density of coal particle

$(\mathrm{gm} / \mathrm{cc})$

$k_{d} \quad$ Frequency factor

$h_{w} \quad$ Heat transfer coefficient of water

(watt $\left./ \mathrm{m}^{2} \mathrm{~K}\right)$

$\lambda_{\text {vap }} \quad$ Latent heat of vaporization

$(\mathrm{J} / \mathrm{mol})$

$\mathrm{X}_{\mathrm{sH}_{2} \mathrm{O}}$ Mass fraction of moisture content in coal

$T_{p} \quad$ Temperature of droplet

$T_{s} \quad$ Temperature of solid phase

$\varepsilon_{s} \quad$ Volume fraction of solid phase

$m_{\text {vap }} \quad$ Volumetric evaporation rate of black liquor droplet

$\left(\mathrm{kg} / \mathrm{m}^{3} \mathrm{~s}\right)$

$T_{\mathrm{g}} \quad$ Local gas temperature

$m_{c} \quad$ Mass of raw coal

$m_{v} \quad$ Rate of devolatilization

$(\mathrm{gm} / \mathrm{s})$

$R_{g} \quad$ Gas constant

(cal/K.mol)

$V \quad$ Volatile yield at any time

(\% daf)

$V^{*} \quad$ Ultimate volatile yield

(Kg or daf \%)

$X_{V M} \quad$ Mass fraction of volatile matter

$Y \quad$ Volatile yield

$Y_{I} \quad$ Volatile yield for low activation devolatilization reaction

$Y_{1}^{*} \quad$ Maximum of $Y_{I}$

$Y_{2} \quad$ Volatile yield for high activation devolatilization reaction

$Y_{2}{ }^{*} \quad$ Maximum of $Y_{2}$

$C_{\text {tar }}$ Concentration of tar

$\left(\mathrm{gmole} / \mathrm{cm}^{3}\right)$

$\omega \quad$ Rate of soot oxidation

(g carbon $/ \mathrm{cm}^{3} \mathrm{sec}$ )

$\xi \quad$ Fraction of carbon oxidized 
$\lambda \quad$ Surface concentration of active sites $\quad\left(\mathrm{cm}^{-2}\right)$

$S_{a_{0}} \quad$ Initial surface area

$\left(\mathrm{cm}^{2}\right)$

$\left[\mathrm{O}_{2}\right]$ Partial pressure of oxygen 


\section{Appendix I}

\section{Algorithm to couple PCCL and MFIX:}

I.1. The reaction schemes considered in this algorithm are as follows,

\section{Devolatilization only:}

$$
\begin{gathered}
\text { Moisture (incoal) } \rightarrow \mathrm{H}_{2} \mathrm{O} \\
\mathrm{VM} \rightarrow \alpha_{d} \operatorname{tar}+\beta_{\mathrm{CO}}^{\mathrm{d}} \mathrm{CO}+\beta_{\mathrm{CO}_{2}}^{d} \mathrm{CO}_{2}+\beta_{\mathrm{CH}_{4}}^{d} \mathrm{CH}_{4}+\beta_{\mathrm{H}_{2}}^{d} \mathrm{H}_{2}+\beta_{\mathrm{H}_{2} O}^{\mathrm{d}} \mathrm{H}_{2} \mathrm{O}
\end{gathered}
$$

Devolatilization with tar cracking:

$$
\begin{gathered}
\text { Moisture(incoal) } \rightarrow \mathrm{H}_{2} \mathrm{O} \\
\mathrm{VM} \rightarrow \alpha_{d} \operatorname{tar}+\beta_{\mathrm{CO}}^{\mathrm{d}} \mathrm{CO}+\beta_{\mathrm{CO}_{2}}^{d} \mathrm{CO}_{2}+\beta_{\mathrm{CH}_{4}}^{d} \mathrm{CH}_{4}+\beta_{\mathrm{H}_{2}}^{d} \mathrm{H}_{2}+\beta_{\mathrm{H}_{2} \mathrm{O}}^{\mathrm{d}} \mathrm{H}_{2} \mathrm{O} \\
\operatorname{tar} \rightarrow P A H+\mathrm{Oil}+\beta_{\mathrm{CO}}^{\mathrm{c}} \mathrm{CO}+\beta_{\mathrm{CO}_{2}}^{c} \mathrm{CO}_{2}+\beta_{\mathrm{CH}_{4}}^{c} \mathrm{CH}_{4}+\beta_{\mathrm{H}_{2}}^{c} \mathrm{H}_{2}+\beta_{\mathrm{H}_{2} O}^{\mathrm{c}} \mathrm{H}_{2} \mathrm{O}
\end{gathered}
$$

Devolatilization with soot formation or secondary pyrolysis:

$$
\text { Moisture(in coal) } \rightarrow \mathrm{H}_{2} \mathrm{O}
$$

$$
\begin{gathered}
\mathrm{VM} \rightarrow \text { soot }+\mathrm{C}_{2} \mathrm{H}_{2}+\beta_{\mathrm{CO}}^{\mathrm{d}} \mathrm{CO}+\beta_{\mathrm{CO}_{2}}^{d} \mathrm{CO}_{2}+\beta_{\mathrm{CH}_{4}}^{d} \mathrm{CH}_{4}+\beta_{\mathrm{H}_{2}}^{d} \mathrm{H}_{2}+\beta_{\mathrm{H}_{2} O}^{\mathrm{d}} \mathrm{H}_{2} \mathrm{O} \\
\text { soot }+2.714 \mathrm{O}_{2} \rightarrow 3.618 \mathrm{CO}_{2}+0.089 \mathrm{H}_{2} \mathrm{O}
\end{gathered}
$$

Stoichiometric coefficients for PAH, oil, soot, and $\mathrm{C}_{2} \mathrm{H}_{2}$ are obtained from PCCL.

I .1.1. User has to select the reaction for which PCCL data will be extracted:

1. Devolatilization

2. Devolatilization with Tar Cracking (PAH and oil formation)

3. Devolatilization with soot formation /secondary pyrolysis (soot and $\mathrm{C}_{2} \mathrm{H}_{2}$ formation) $\left\{\right.$ soot is seen above $\left.1000^{\circ} \mathrm{C}\right\}$ 


\section{I.1.2 Primary changes to be made in MFIX}

Add oil, $\mathrm{PAH}$, soot and $\mathrm{C}_{2} \mathrm{H}_{2}$ as new gas species in MFIX.

I.1.2.1. Specific heats for all these new gas species are added in CP_FUN1.inc

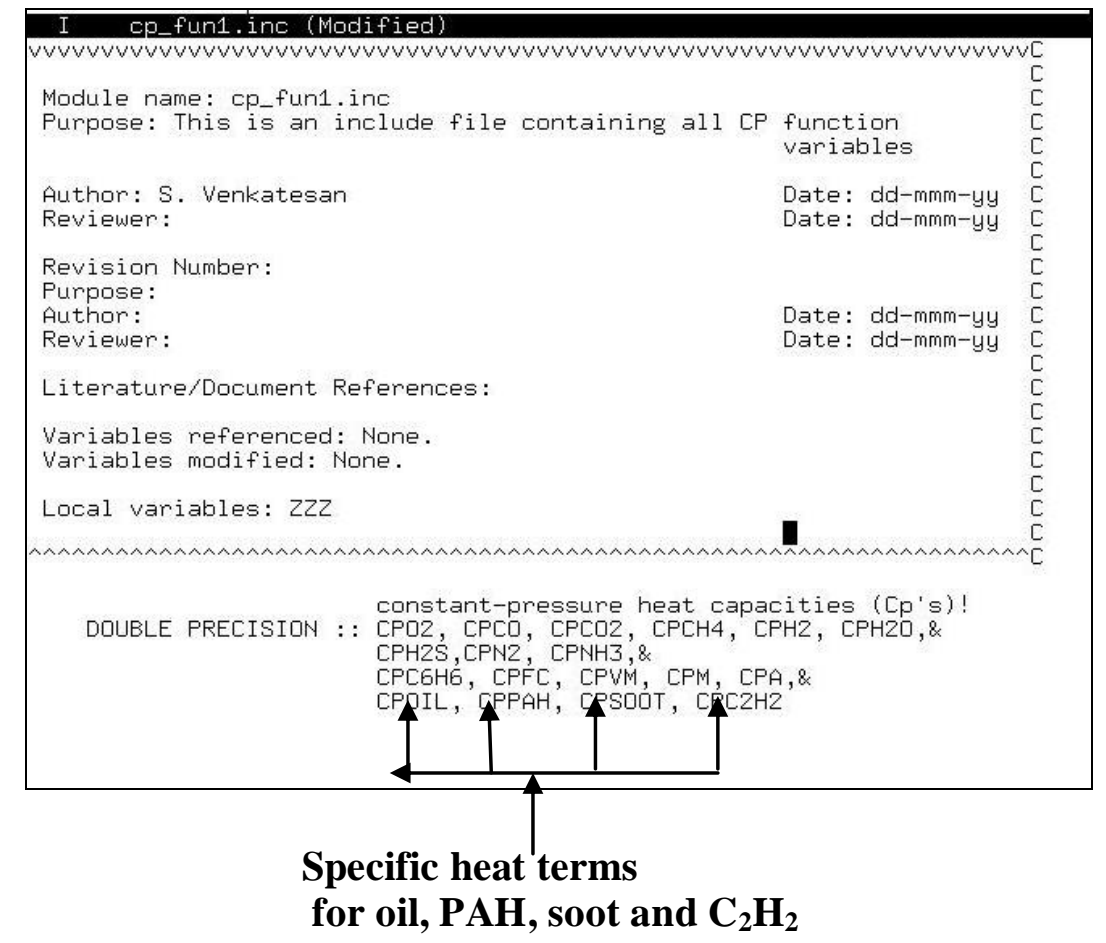

I.1.2.2. Equations to calculate specific heat of added gas species at any temperatures were added in CP_FUN2.inc

$\mathrm{CPOIL}=(1.4014 \mathrm{E}+05-1.5230 \mathrm{E}+02 * \mathrm{XXX}+6.9500 \mathrm{E}-01 * \mathrm{XXX} * 2) / 92$

$\mathrm{CPC} 2 \mathrm{H} 2=(2.0011 \mathrm{E}+05-1.1988 \mathrm{E}+03 * \mathrm{XXX}+3.0027 * \mathrm{XXX} * * 2) / 26$

СРPAH $=-0.1315+1.341 \mathrm{E}-03 * \mathrm{XXX}-1.087 \mathrm{E}-06 * \mathrm{XXX}^{*} \mathrm{XXX}$

$+3.06 \mathrm{E}-10 * \mathrm{XXX} * \mathrm{XXX} * \mathrm{XXX}$

CPSOOT $=-0.1315+1.341 \mathrm{E}-03 * \mathrm{XXX}-1.087 \mathrm{E}-06 * \mathrm{XXX} * \mathrm{XXX}$

$+3.06 \mathrm{E}-10 * \mathrm{XXX}^{*} \mathrm{XXX} * \mathrm{XXX}$ 


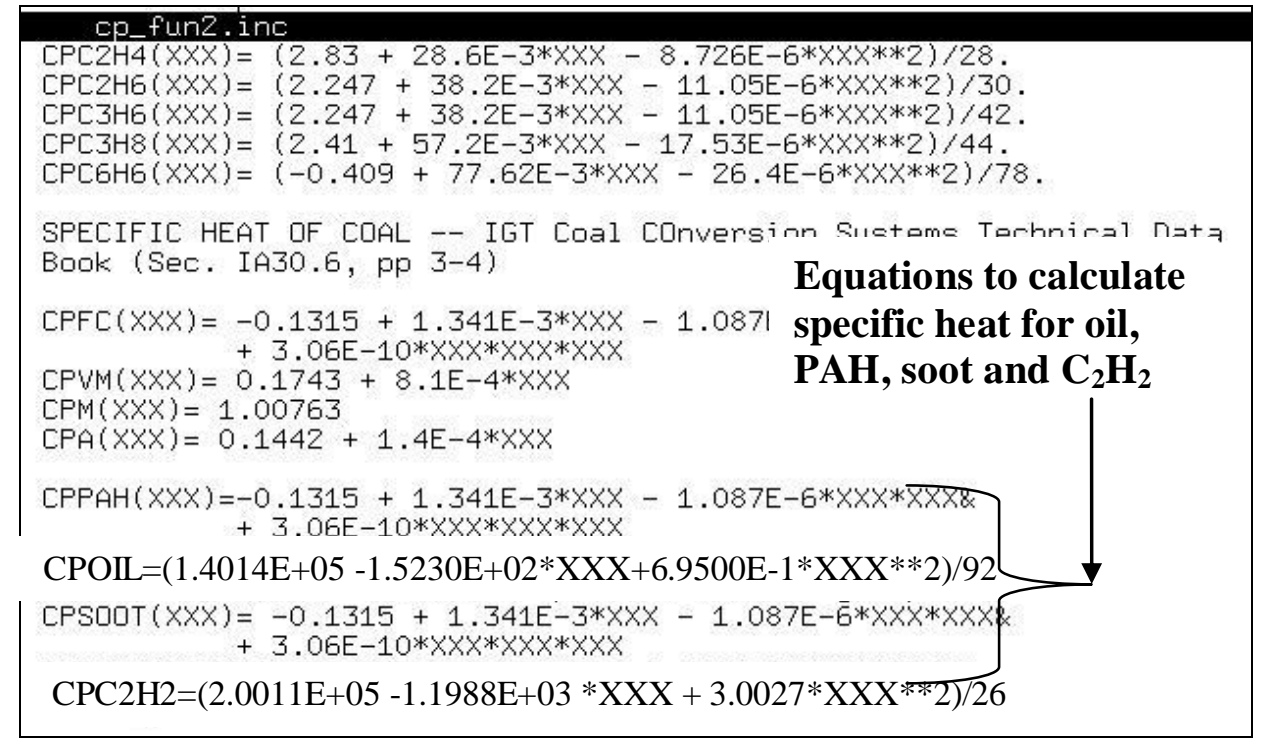

I.1.2.3. Modify the constant pressure specific heat of air calculation (C_pg(IJK)) equation with addition of new gas species in physical_prop.f

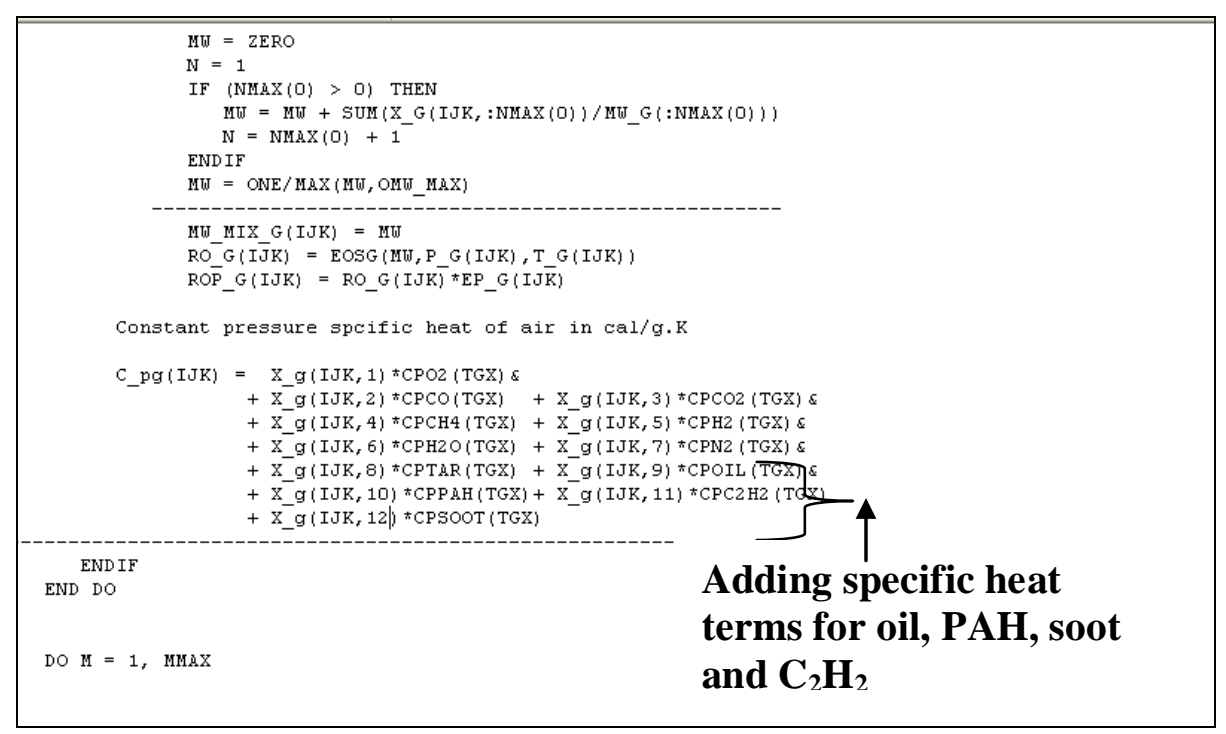


I.1.2.4. Total number of gas species and their molecular weight need to be modify in mfix.dat

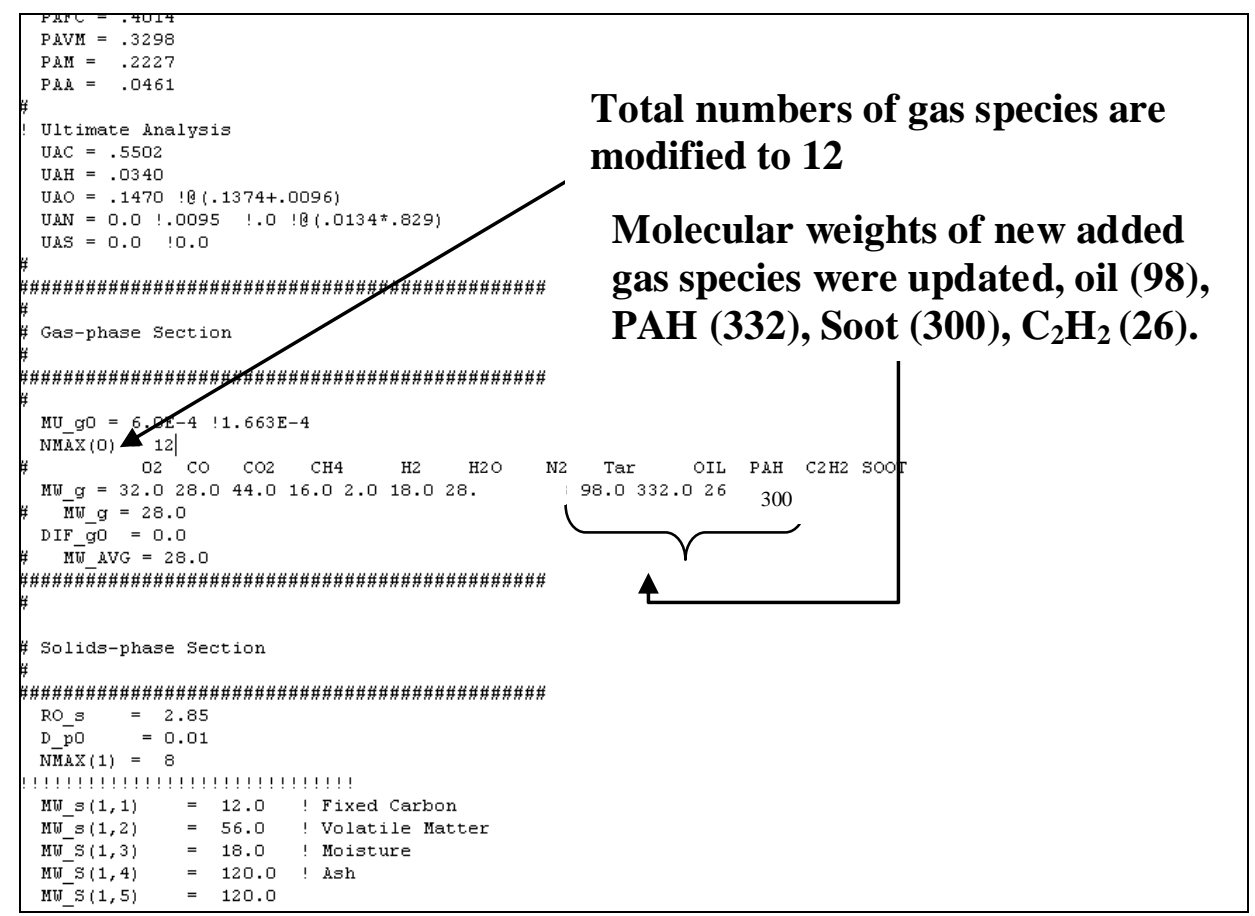

I.1.2.5. Modify rrates.f with following variables :

Pressure term for new gas species: PPAH, PSOOT, PC2H2, POIL.

Soot oxidation kinetics variables: XYZ, TAN, KPC, TANN, KPCC, XYZZ, TANC, RXNWF.

Partial pressure calculation equation for PPAH, PSOOT, PC2H2, POIL. 

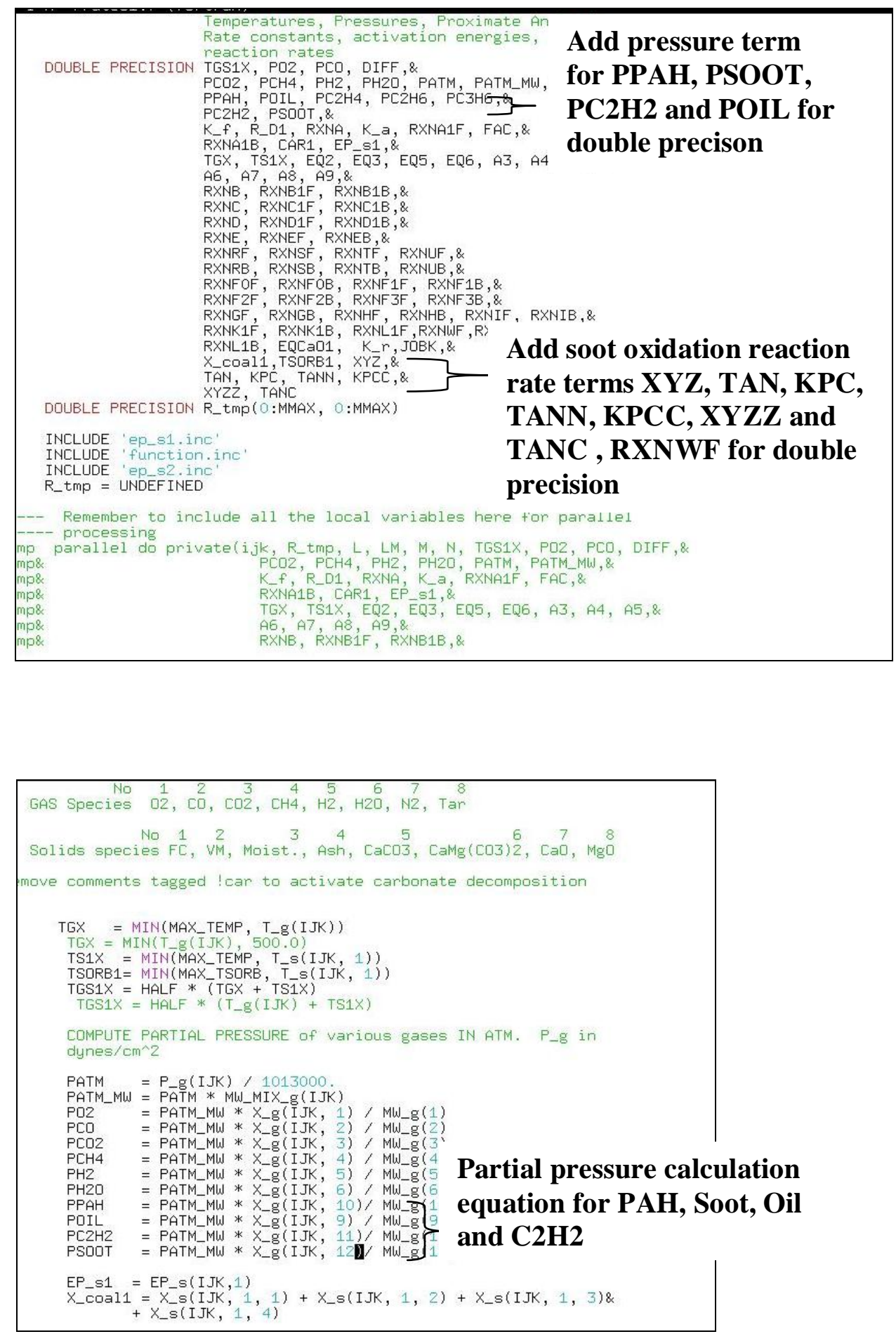

I.1.2.6. Modify rrates.f for soot oxidation reaction:

Soot oxidation equation given by PCCL need to be introduced in MFIX.

(When there is only devolatilization or devolatilization with tar cracking this rate will be multiplied by zero.) 


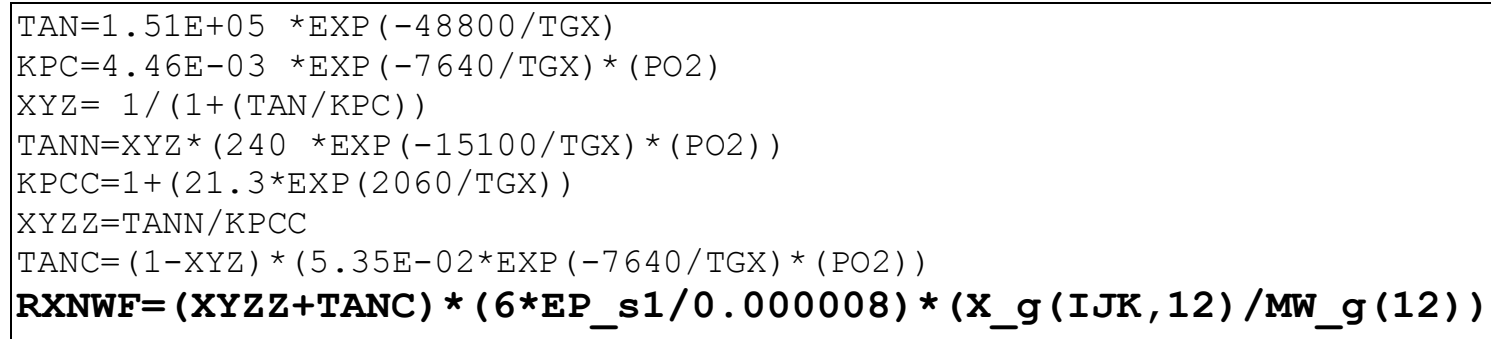




\section{I.2. Input Specification for PCCL:}

- Proximate analysis as received basis:

Fixed Carbon: 40.2

Volatile matter: 32.9

Moisture: 22.3

Ash: 4.6

- Ultimate analysis dry ash free basis:

C: 75.2

\}

Coal properties to be specified in coalpac.dat as shown in figure1

H: 4.6

O: 20.2

$\mathrm{N}: 0$

S: 0

- Heating rate for wire grid method

- Pressure in MPascal

- Temperature in ${ }^{0} \mathrm{C}$

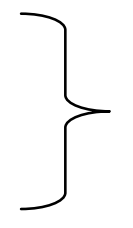

Operating conditions to be specified in testplan.dat as shown in figure 2

- Particle diameter in microns

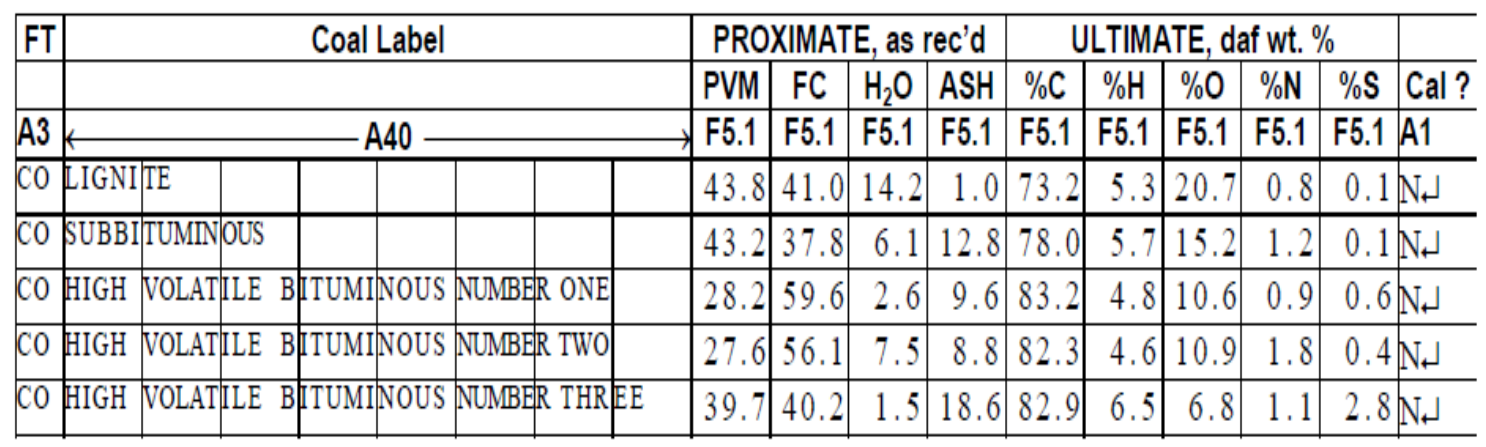

Figure1: Input file for coal types coalpac.dat 


\begin{tabular}{|c|c|c|c|c|c|c|c|c|c|c|c|}
\hline CF & TR & TS & OR & Gas & $T_{\text {initial }}$ & $\mathbf{T}_{\text {ultimate }}$ & $\mathrm{Q},{ }^{\circ} \mathrm{C} / \mathrm{s}$ & $\% \mathrm{O}_{2}$ & $\mathrm{P}, \mathrm{MPa}$ & $t^{I R P}, s$ & $\mathrm{D}_{\mathrm{p}}, \mu \mathrm{m}$ \\
\hline $\mathrm{A} 2$ & A3 & A5 & A3 & A3 & F6.0 & F6.0 & F7.0 & F6.1 & F6.2 & F8.3 & F6.1 \\
\hline 01 & WG & FFDP & FD & N2 & 25 & 1025 & 00000 . & 0.0 & 0.10 & 0.022 & 63.0 \\
\hline 02 & WG & FFDP & FD & N2 & 25 & 1025 & 10000 & 0.0 & 0.10 & 0.180 & 300.0 \\
\hline 03 & WG & FFDP & FD & N2 & 25 & 1025 & 1000 . & 8.0 & 0.10 & 1.500 & 2300.0 \\
\hline 04 & WG & FFPT & FD & N2 & 25 & 850 & 8500 & 0.0 & 0.10 & 1.250 & 300.0 \\
\hline 05 & WG & FFPT & FD & N2 & 25 & 850. & 8500 & 0.0 & 1.00 & 1.250 & 300.0 \\
\hline
\end{tabular}

Figure2: Input file for operating conditions testplan.dat 


\section{I.3. DEVOLATILIZATION}

\section{I.3.1. Moisture Release:}

Output file to look at is,

$\mathrm{CFDC}_{\mathrm{i}} \mathrm{T}_{\mathrm{j}} \cdot \mathrm{rpt}:\left\{\right.$ for moisture flux in $\left.\mathrm{kg} / \mathrm{m}^{2}-\mathrm{s}\right\}$

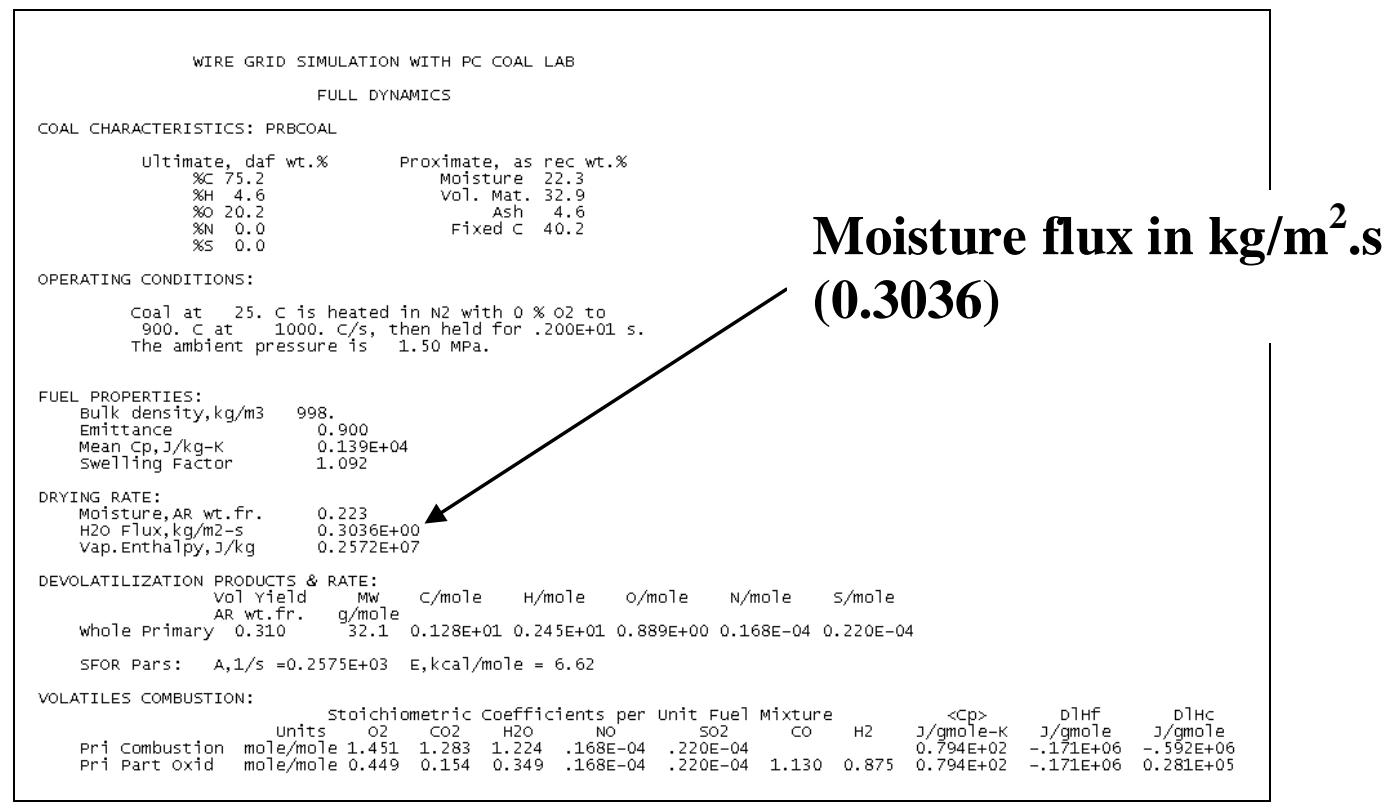

Changes to be made in rrates.f

The moisture flux is in $\mathrm{kg} / \mathrm{m}^{2}$.s hence convert it into $\mathrm{gm} / \mathrm{cm}^{3}$.s, so the expression becomes,

\section{RXNGF $=(\text { Moisture flux })^{*} 0.1 *\left(6 * E P \_s 1(I J K) / D \_p(I J K, 1)\right) * X \_s(I J K, 1,3)$}

$\{0.1$ is conversion factor $\}$

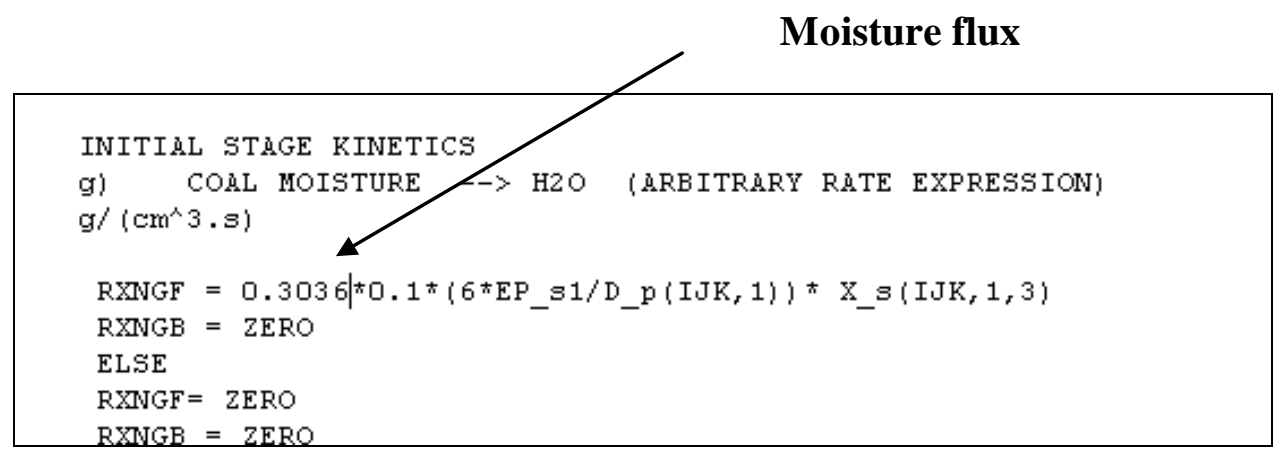




\section{I.3.2. DEVOLATILIZATION :}

I.3.2.1. Output files to look:

- $\mathrm{CFDC}_{\mathrm{i}} \mathrm{T}_{\mathrm{j}}$.rpt : [for Arrhenius constant/frequency factor (A) in 1/sec; Activation Energy (E) in $\mathrm{kcal} / \mathrm{mol}](\mathrm{A}=257.51 / \mathrm{s} ; \mathrm{E}=6620 \mathrm{kcal} / \mathrm{mol})$

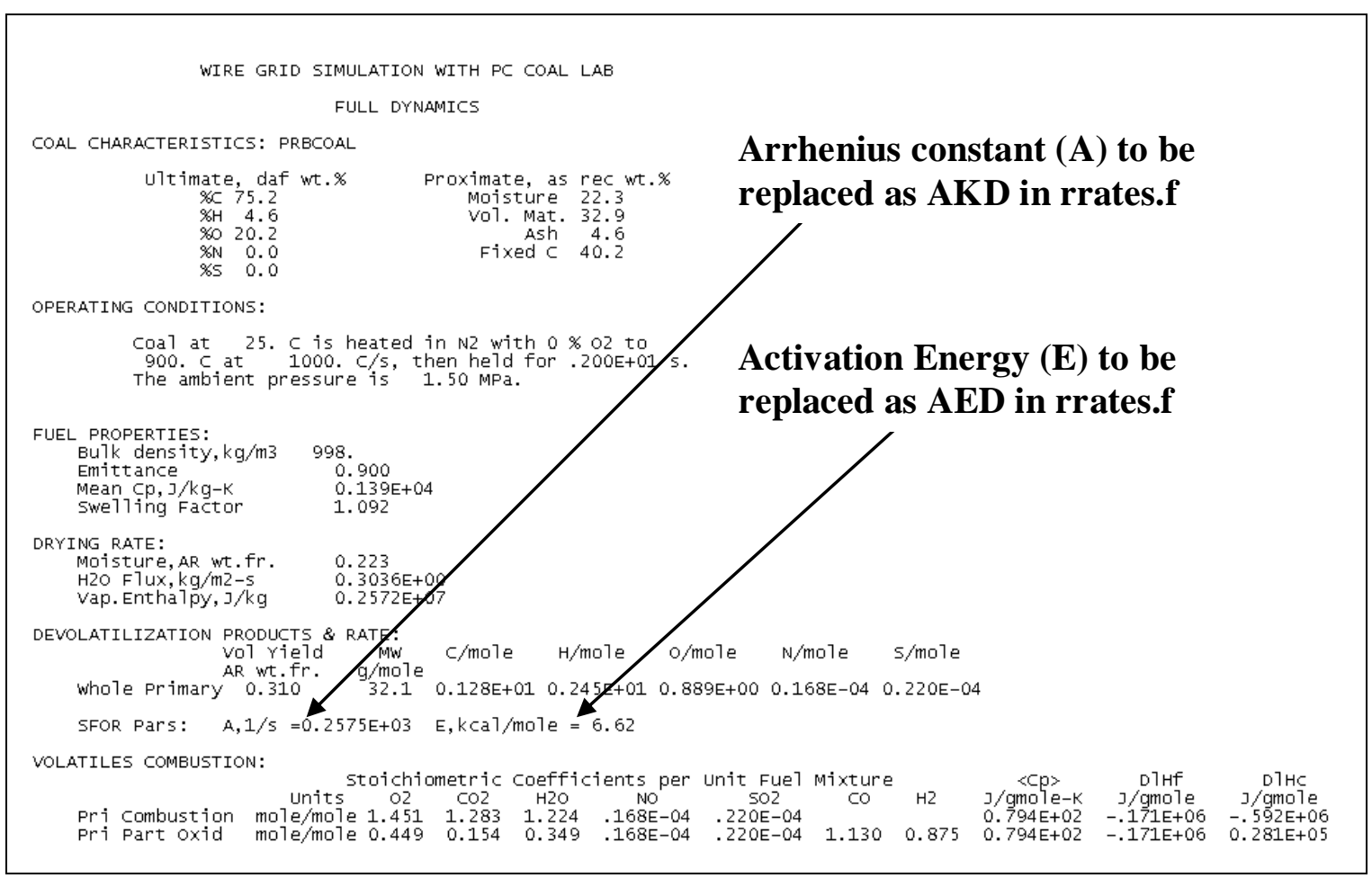

- $\quad \mathrm{FDC}_{\mathrm{i}} \mathrm{NG}_{\mathrm{j}} . \mathrm{rpt}$ : [for \% dry ash free basis yields of $\mathrm{CO}_{2}(9.2), \mathrm{H}_{2} \mathrm{O}(8.5), \mathrm{CO}(5.9)$ and $\left.\mathrm{CH}_{4}(6.7)\right]$ 


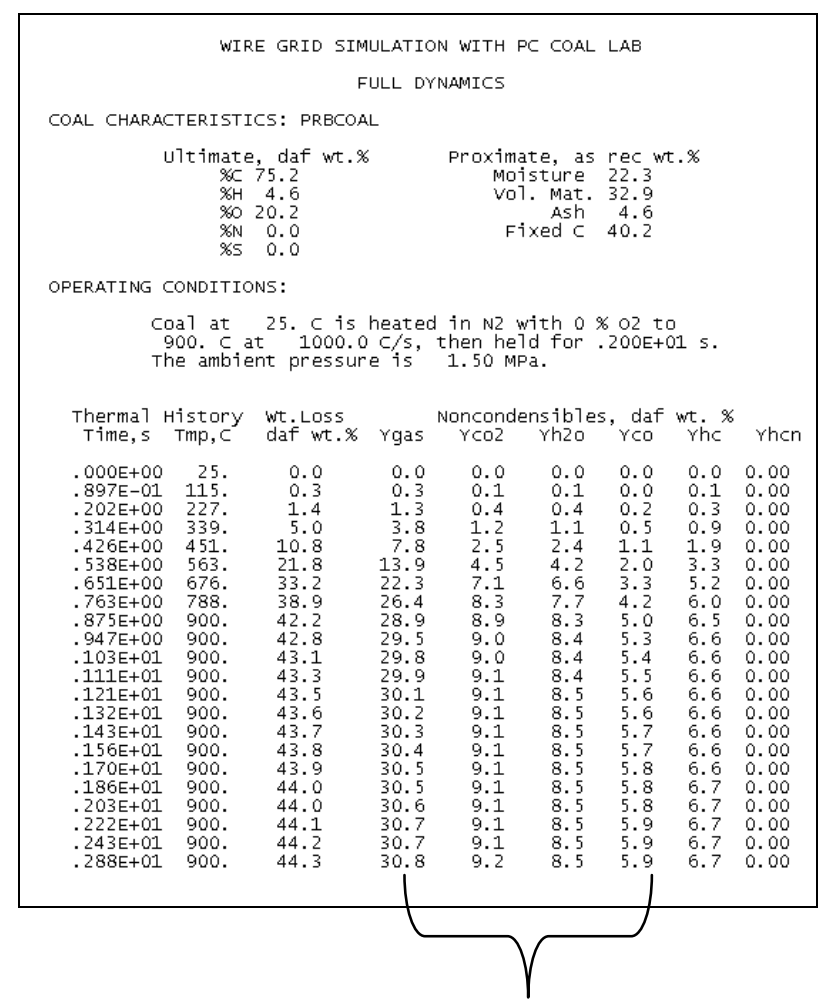

\% daf yield of $\mathrm{CO}_{2}, \mathrm{H}_{2} \mathrm{O}, \mathrm{CO}$ and $\mathrm{CH}_{4}$ (total hydrocarbon yield is assumed to be $\mathrm{CH}_{4}$ yield)

- FDCiHCj.rpt:[for \% dry ash free basis yield of H2(0.55) 


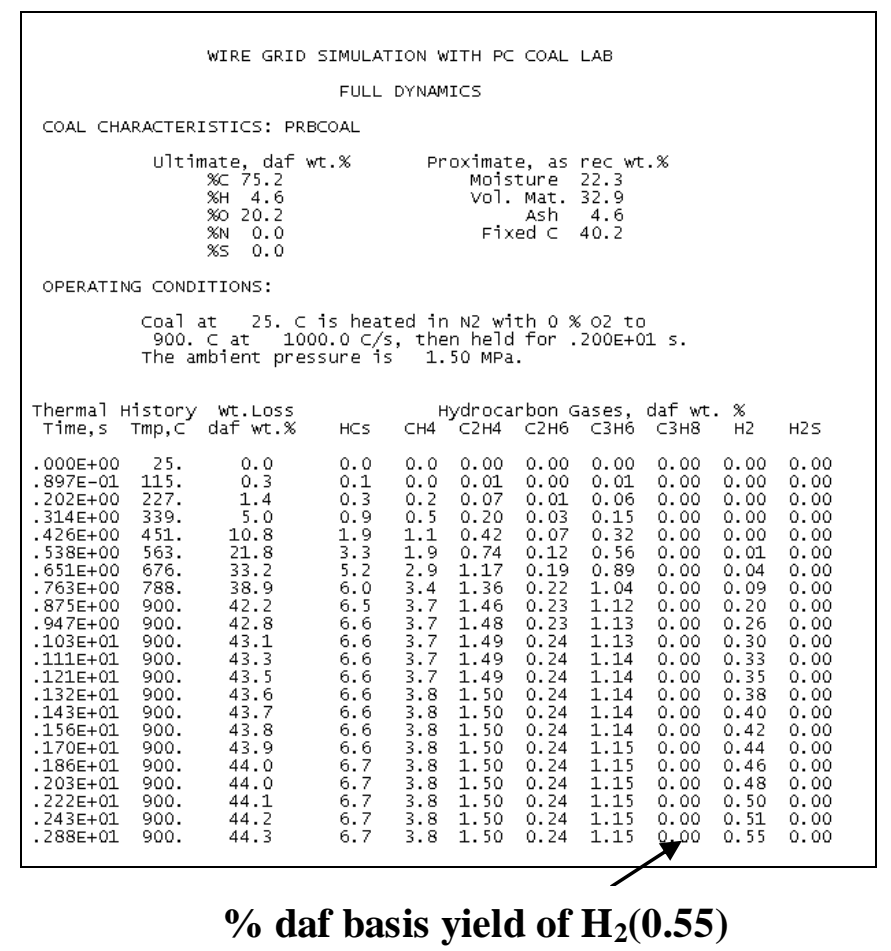

- $\quad \mathrm{FDC}_{\mathrm{i}} \mathrm{TC}_{\mathrm{j}} . \mathrm{rpt}$ : [ for \% dry ash free basis yield of Tar(13.4), molecular weight(291.9) ]

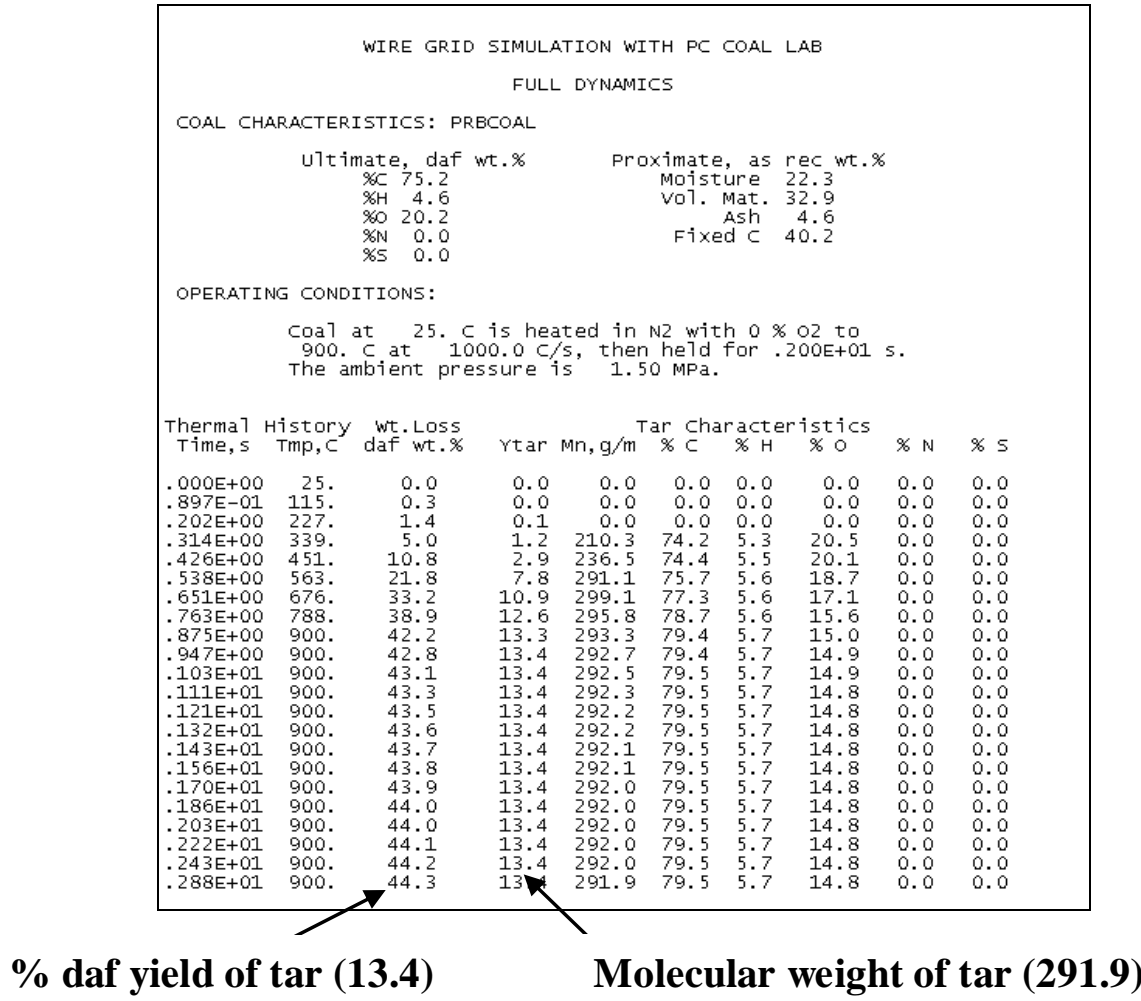


I.3.2.2. Convert $\%$ daf basis yields into gm yield

If $X$ is the $\%$ daf basis yield then gm yield will be [ $X \times(\mathrm{FC}+\mathrm{VM}) / 100]$ (here $\mathrm{FC}+\mathrm{VM}=40.2+32.9=73.1$ )

\begin{tabular}{|c|c|c|}
\hline Products & \% yield daf & yield in gm \\
\hline $\mathrm{CO}$ & 5.9 & $5.9 \times 0.731=4.3129$ \\
\hline $\mathrm{CO}_{2}$ & 9.2 & $9.2 \times 0.731=6.7252$ \\
\hline $\mathrm{CH}_{4}$ & 6.7 & $6.7 \times 0.731=4.8977$ \\
\hline $\mathrm{H}_{2}$ & 0.55 & $0.55 \times 0.731=0.4021$ \\
\hline $\mathrm{H}_{2} \mathrm{O}$ & 8.5 & $8.5 \times 0.731=6.2135$ \\
\hline tar & 13.4 & $13.4 \times 0.731=9.7954$ \\
\hline
\end{tabular}

I.3.2.3. Find total VM by summation of all gm yields:

Total $\mathrm{VM}=\sum$ (Yield in gm of all devolatilization products)

\begin{tabular}{|c|c|}
\hline Products & yield in gm \\
\hline $\mathbf{C O}$ & 4.3129 \\
\hline $\mathbf{C O}_{\mathbf{2}}$ & 6.7252 \\
\hline $\mathbf{C H}_{\mathbf{4}}$ & 4.8977 \\
\hline $\mathbf{H}_{\mathbf{2}}$ & 0.4021 \\
\hline $\mathbf{H}_{\mathbf{2}} \mathbf{O}$ & 6.2135 \\
\hline $\mathbf{t a r}$ & 9.7954 \\
\hline $\mathbf{V M}$ & 32.3468 \\
\hline
\end{tabular}

I.3.2.4 Convert gm yield into mass fractions (per $1 \mathrm{gm}$ of VM):

Stoichiometric coefficient $=($ Yield in gm of product $) /($ VM yield in $\mathrm{gm})$

For tar just to match stoichiometric coefficients summation as one,

Stoichiometric coefficient of Tar= 1- Sum (Stoichiometric coefficients of

$\left.\mathrm{CO}, \mathrm{CO} 2, \mathrm{CH} 4, \mathrm{H}_{2}, \mathrm{H}_{2} \mathrm{O}\right)$ 


\begin{tabular}{|c|c|c|c|}
\hline Products & Yield in gm & $\begin{array}{c}\text { Stoichiometric } \\
\text { Coefficient }\end{array}$ & $\begin{array}{c}\text { Stoichiometric } \\
\text { Coefficient }\end{array}$ \\
\hline $\mathbf{C O}$ & 4.3129 & 0.1333 & $\operatorname{BETAD}(2)$ \\
\hline $\mathbf{C O}_{\mathbf{2}}$ & 6.7252 & 0.2079 & $\operatorname{BETAD}(3)$ \\
\hline $\mathbf{C H}_{\mathbf{4}}$ & 4.8977 & 0.1514 & $\operatorname{BETAD}(4)$ \\
\hline $\mathbf{H}_{\mathbf{2}}$ & 0.4021 & 0.0124 & $\mathrm{BETAD}(5)$ \\
\hline $\mathbf{H}_{\mathbf{2}} \mathbf{O}$ & 6.2135 & 0.1921 & $\mathrm{BETAD}(6)$ \\
\hline & & $\{1-0.1333-0.2079-0.1514-$ & ALPHAD \\
$\mathbf{t a r}$ & 9.7954 & $0.0124-0.1921)=0.3029$ & \\
\hline $\mathbf{V M}$ & 32.3468 & 1.0000 & \\
\hline
\end{tabular}

I.3.2.5. Changes to be made in rrates.f of MFIX:

- (modifying rrates.f) :Change devolatilization rate parameters $\operatorname{AKD}(\mathrm{A})(257.5)$ and $\operatorname{AED}(\mathrm{E})(6620)$

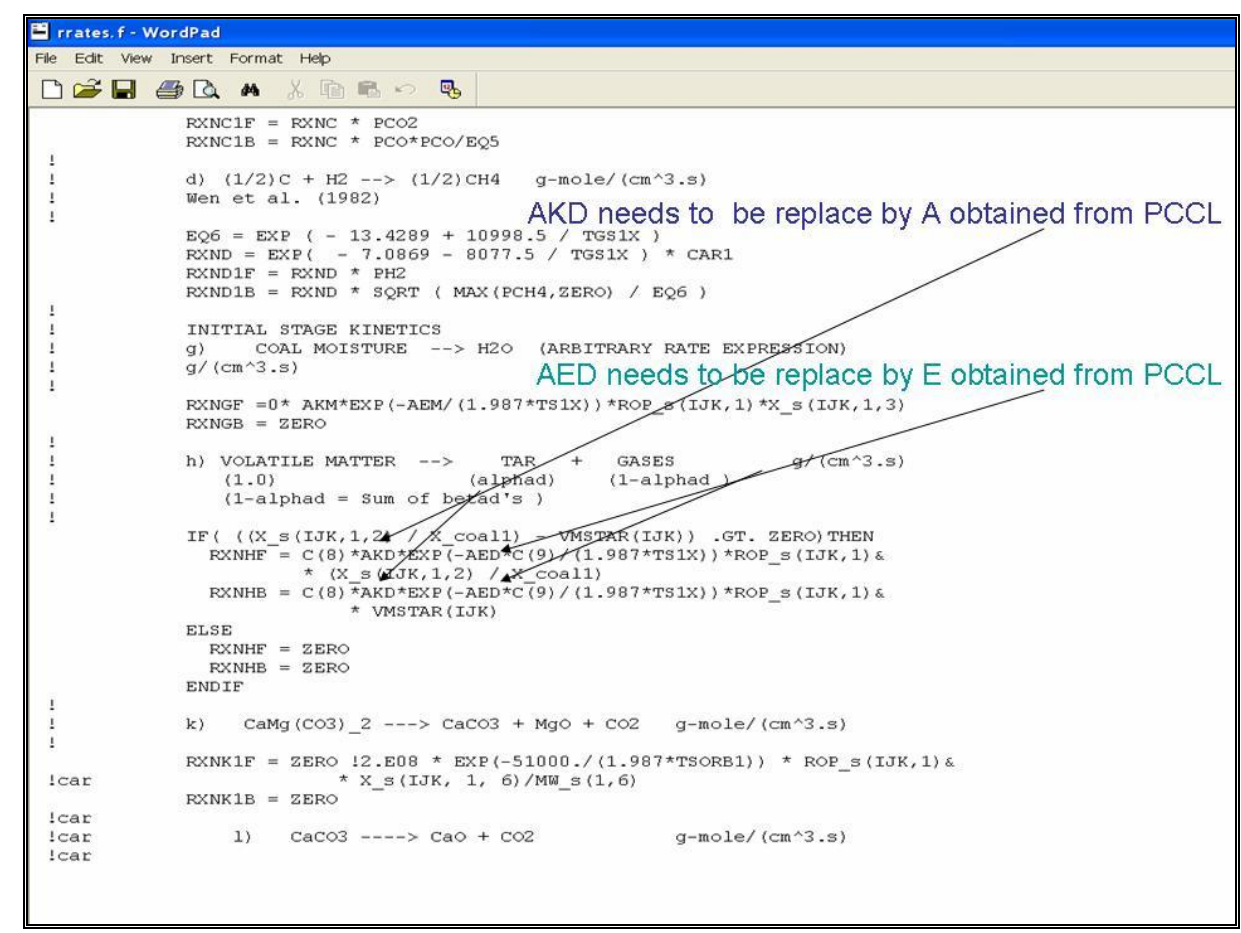

- Changing stoichiometric coefficients BETAD (2-6) and ALPHAD 

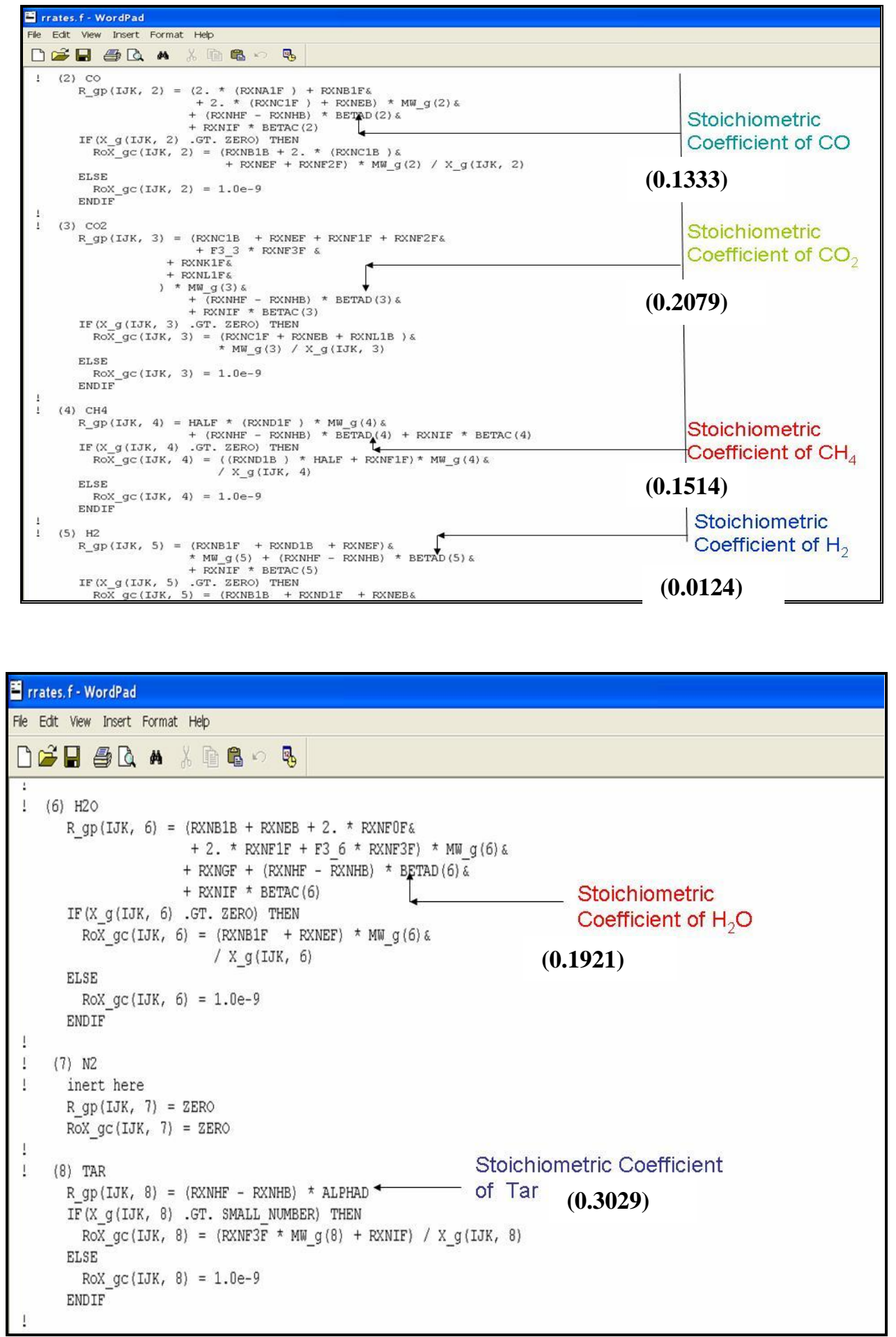

I.3.2.6. Changes to be made in usro.f: 
Stoichiometric coefficient used to calculate heat of devolatilization (HEATD) need to be replaced with new calculated coefficients.

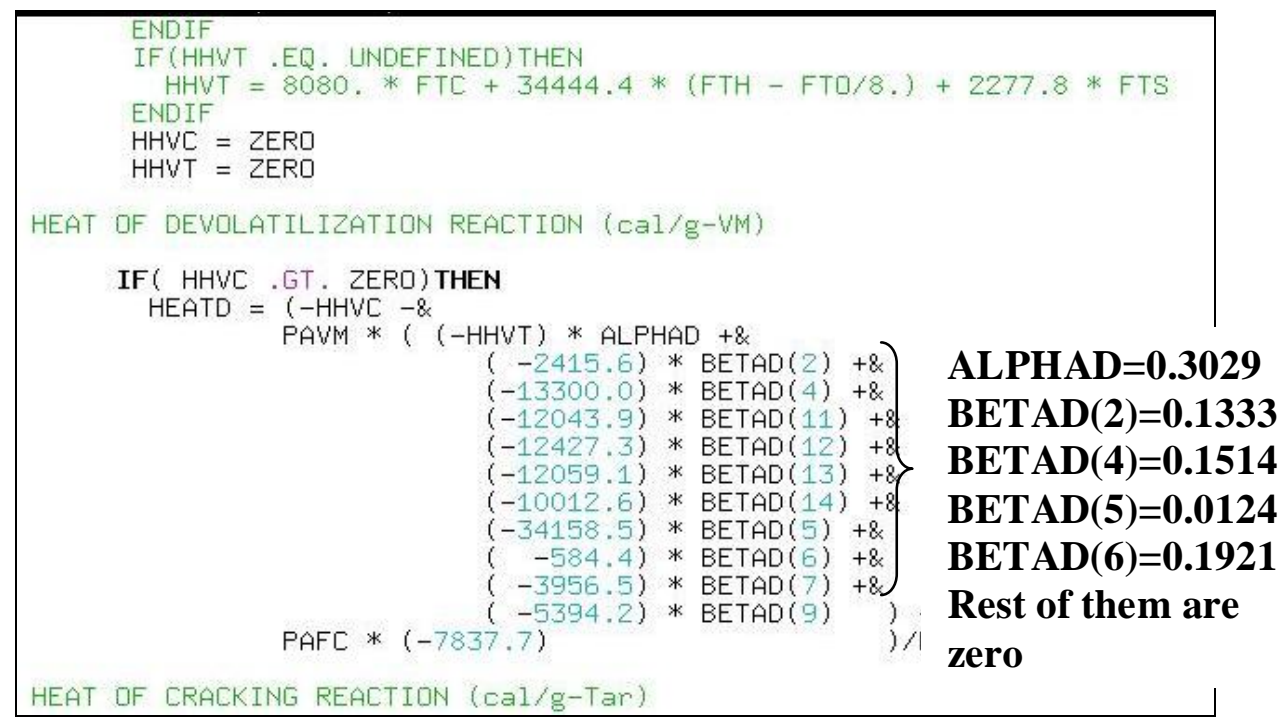




\section{I.4. Tar Cracking Algorithm:}

I.4.1. Modifying Input files in PC Coal Lab (PCCL)

There is no change in "Coalpc.dat".

While specifying operating conditions in "Testplan.dat", ninth entry in sixth row must be specified as " $T$ " for tar cracking.

\begin{tabular}{|c|c|c|c|c|c|c|c|c|c|c|c|}
\hline CF & TR & TS & OR & Gas & $T_{\text {initial }}$ & $T_{\text {gas }}$ & $\mathrm{Q},{ }^{\circ} \mathrm{C} / \mathrm{s}$ & $\% \mathrm{O}_{2}$ & $\mathrm{P}, \mathrm{MPa}$ & Time, $\mathbf{s}$ & $D_{p}, \mu m$ \\
\hline A2 & A3 & A5 & A3 & A3 & F6.0 & F6.0 & F7.0 & F6.1 & F6.2 & F8.3 & F6.1 \\
\hline 01 & WG & FFTG & UD & N2 & 25 & 1000 & 200 & 0.0 & 1.50 & 2.125 & 90.0 \\
\hline $\mathrm{UC}$ & WG & FFTG & UD & N2 & 25 & 600 & 60 & 0.0 & 0.10 & 25.000 & 90.0 \\
\hline 03 & WG & FFTG & UD & $\mathrm{N} 2$ & 25 & 558 & 2000 & 0.0 & 0.10 & 2.233 & 90.0 \\
\hline 04 & WG & FFTG & UD & N2 & 25 & 558 & 2000 & 0.0 & 0.10 & 2.233 & 0.0 \\
\hline 05 & WG & FFTG & UD & N2 & 25 & 725 & 2000 & 0.0 & 0.10 & 2.150 & 0.0 \\
\hline
\end{tabular}
YYYYYYYNTIN. YNN YYYYYYYYYYYYY|_-

For Tar Cracking $9^{\text {th }}$ Entry in sixth row must be $T$.

I.4.2. Moisture release and devolatilization are the initial steps in the tar cracking mechanism.

For moisture release and devolatilization kinetics user should refer back to algorithm described before for devolatilization step (I.3) only.

\section{I.4.3. Output files to look for:}

- $\mathrm{SRTRC}_{\mathrm{i}} \mathrm{T}_{\mathrm{j}}$.rpt: [for Arrhenius constant/frequency factor $(A)$ in $1 / \mathrm{sec}$; Activation Energy $(E)$ in $\mathrm{kcal} / \mathrm{mol}](A=17.2 / \mathrm{s} ; E=5800 \mathrm{cal} / \mathrm{mol})$ 


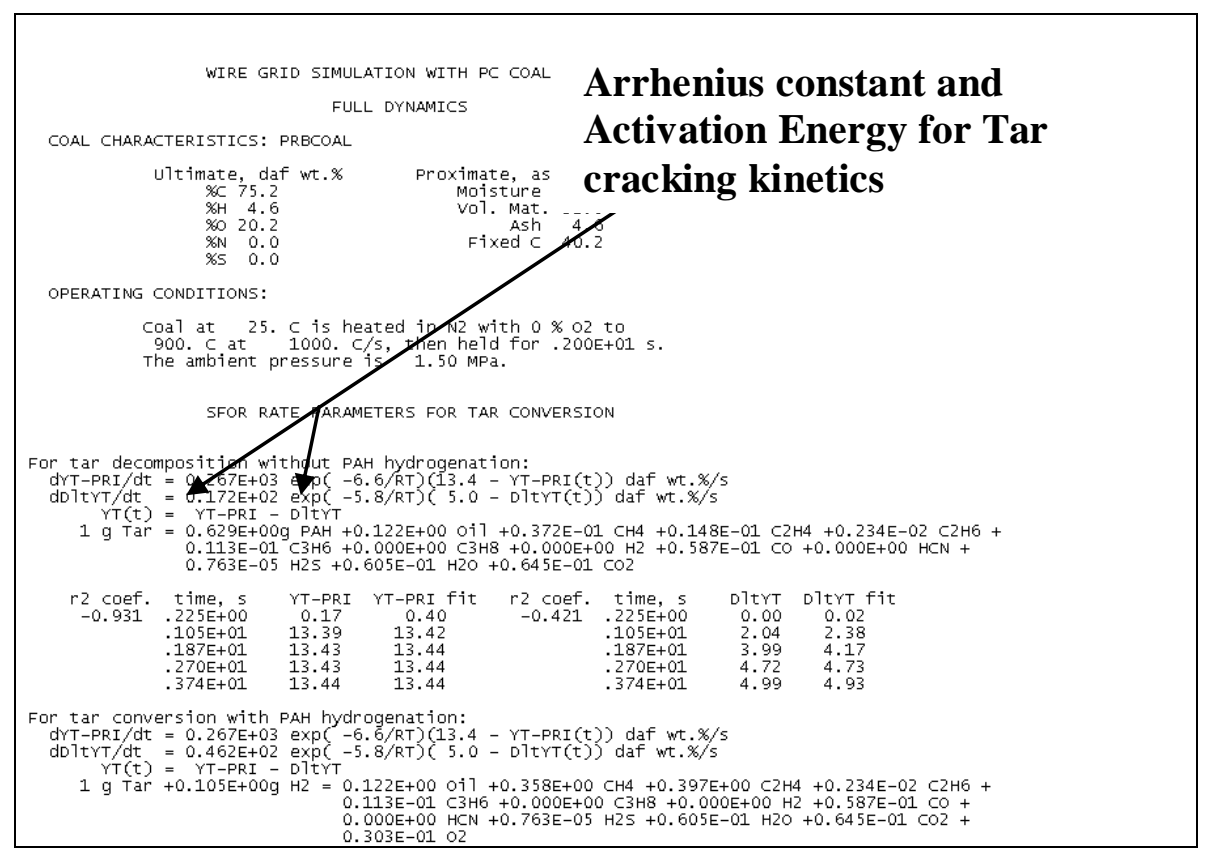

- $\quad \mathrm{SRTRC}_{\mathrm{i}} \mathrm{T}_{\mathrm{j}}$.rpt: To get stoichiometric coefficients for the tar cracking reaction where $\mathrm{PAH}$, oil, $\mathrm{CO}, \mathrm{CO}_{2}, \mathrm{CH}_{4}, \mathrm{H} 2$ and $\mathrm{H}_{2} \mathrm{O}$ are the products formed during tar cracking. We need to get mass fractions of these products from the output file.

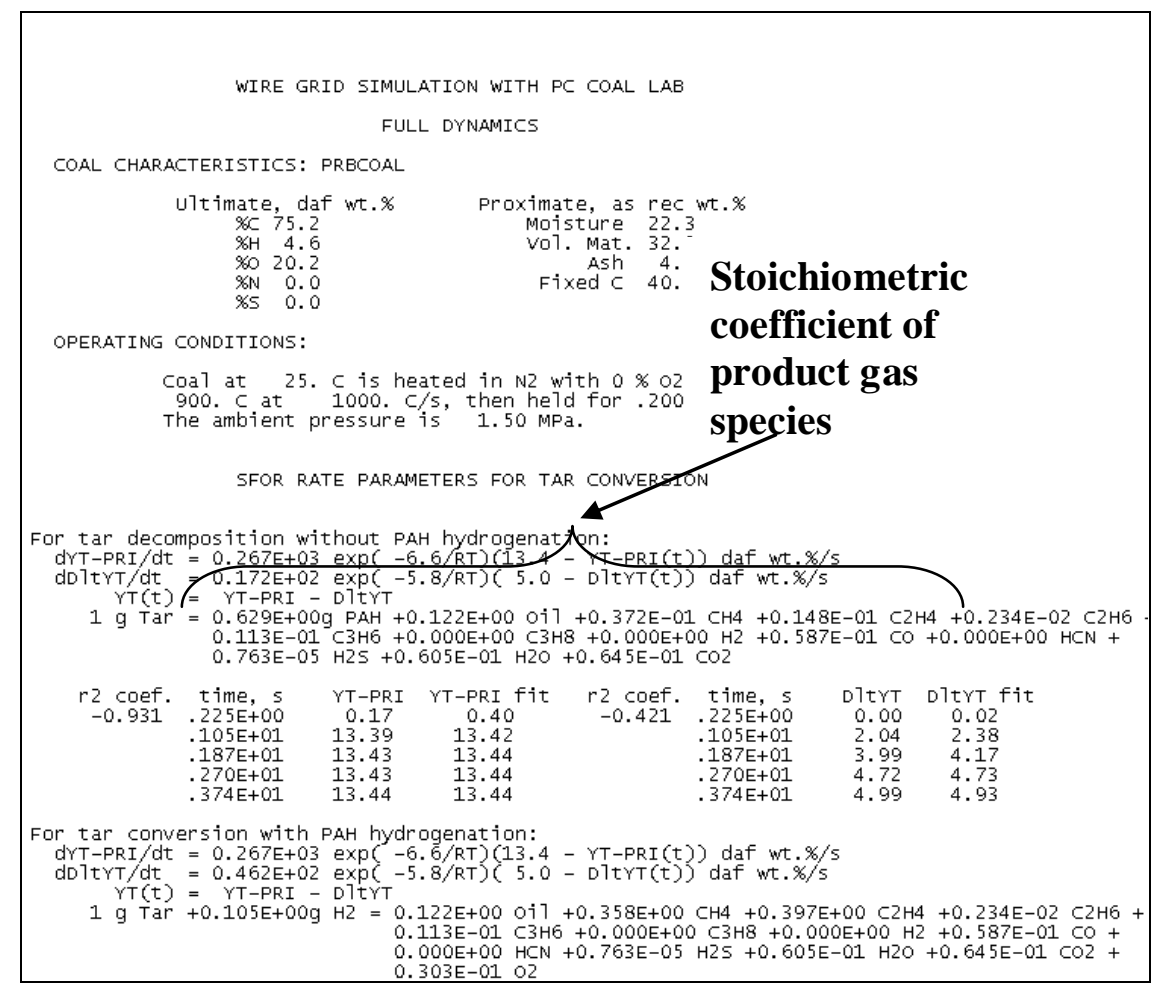


I.4.4. Assigning mass fraction to respective gas species:

\begin{tabular}{|c|c|c|}
\hline Product & Mass fraction & $\begin{array}{c}\text { Mass fraction in } \\
\text { MFIX rrates.f }\end{array}$ \\
\hline PAH & 0.6290 & \\
\hline oil & 0.1220 & \\
\hline $\mathbf{C O}$ & 0.0587 & BETAC(2) \\
\hline $\mathbf{C O}_{\mathbf{2}}$ & 0.0695 & BETAC(3) \\
\hline $\mathbf{H}_{\mathbf{2}}$ & 0 & BETAC(5) \\
\hline $\mathbf{H}_{\mathbf{2}} \mathbf{O}$ & 0.0605 & BETAC(6) \\
\hline $\begin{array}{c}\mathbf{C H}_{\mathbf{4}} \\
\text { (As other } \\
\text { hydrocarbons can } \\
\text { not be lumped in } \\
\left.\mathbf{C H}_{\mathbf{4}}\right)\end{array}$ & $+1-(0.6290+0.1220$ & BETAC(4) \\
& $+0.0587+0.0695+0$ & \\
\hline
\end{tabular}

\section{I.4.5. Changes to be made in rrates.f of MFIX:}

- Change the kinetic parameters for tar cracking reaction. AKC and AEC to be replaced by new Arrhenius constant and Activation energy obtained from PCCL.

[ AKC $\left.=17.2 \mathrm{sec}^{-1}, \mathrm{AEC}=5800 \mathrm{cal} / \mathrm{mol}\right]$

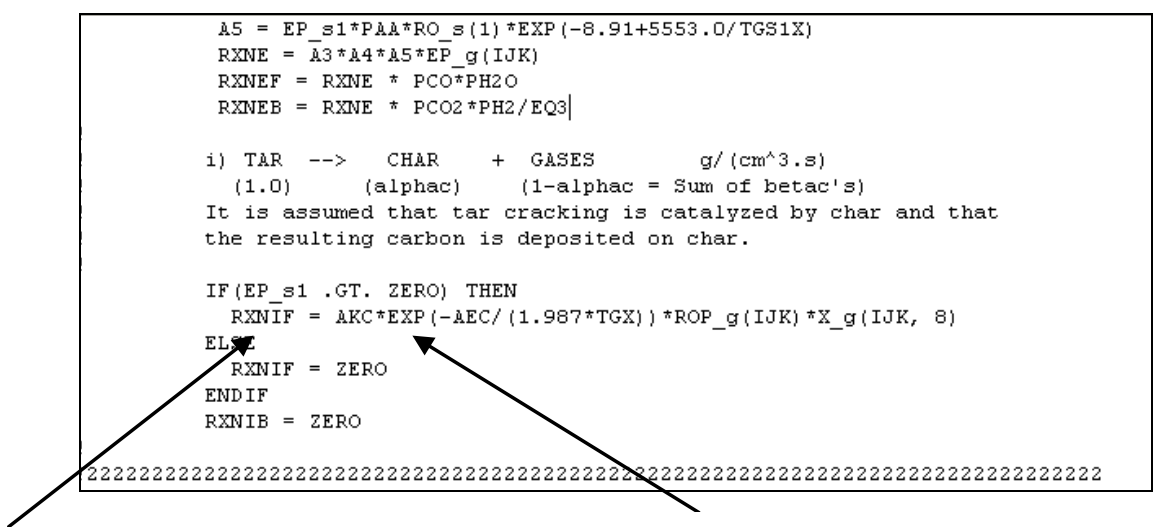

AKC to be replaced with

Arrhenius constant obtained

from $\mathrm{SFTRC}_{\mathrm{i}} \mathbf{T}_{\mathbf{j}} \mathbf{. r p t}$

$\left(\right.$ here $\mathrm{AKC}=17.2 \mathrm{sec}^{-1}$ )
AEC to be replaced with Activation Energy Obtained from $S F T R C_{i} T_{j} . r p t$ (here AEC $=5800 \mathrm{cal} / \mathrm{mol}$ ) 
- Substitute the stoichiometric coefficient for the product species of tar cracking reaction in rrates.f

Change stoichiometric coefficients BETAC (2-6) and add stoichiometric coefficients for Oil and PAH.
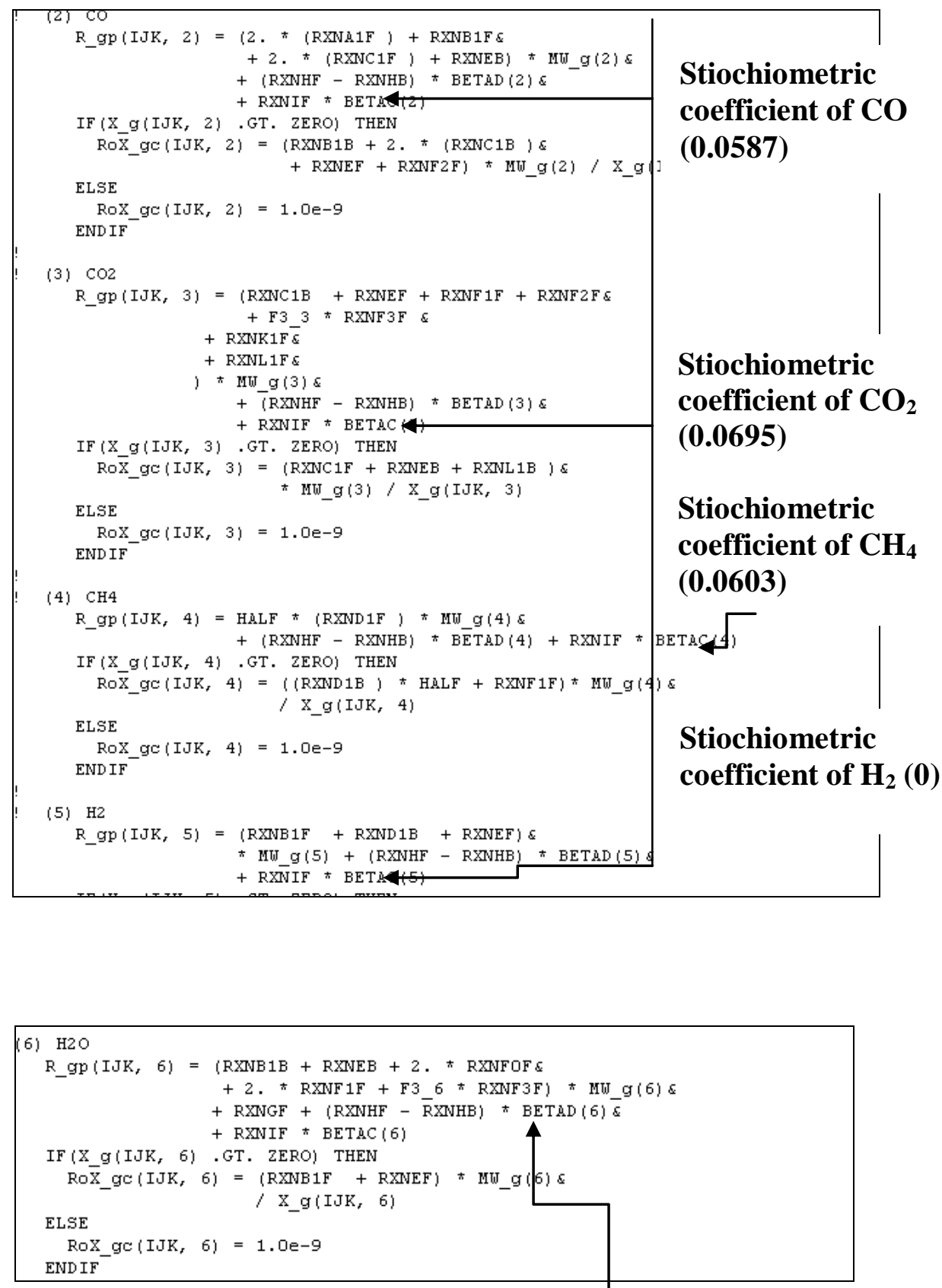

Stiochiometric coefficient of $\mathrm{H}_{2} \mathrm{O}(\mathbf{0 . 0 6 0 5})$ 


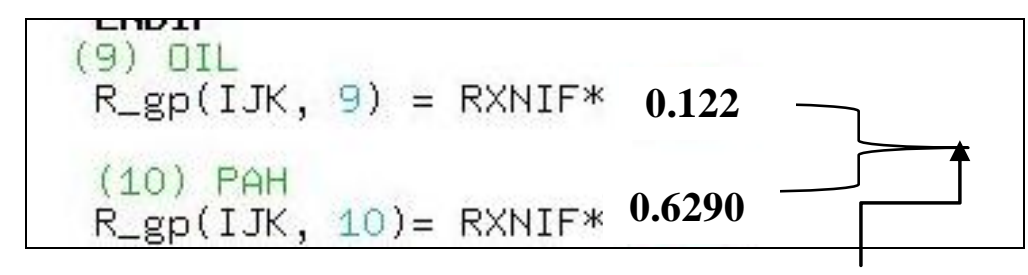

Stiochiometric coefficient for Oil (0. 122) and PAH

(0.629)

I.4.6. Changes to be made in usr0.f:

Stiochiometric coefficients used to calculate heat of cracking reaction need to be replaced with new coefficients.

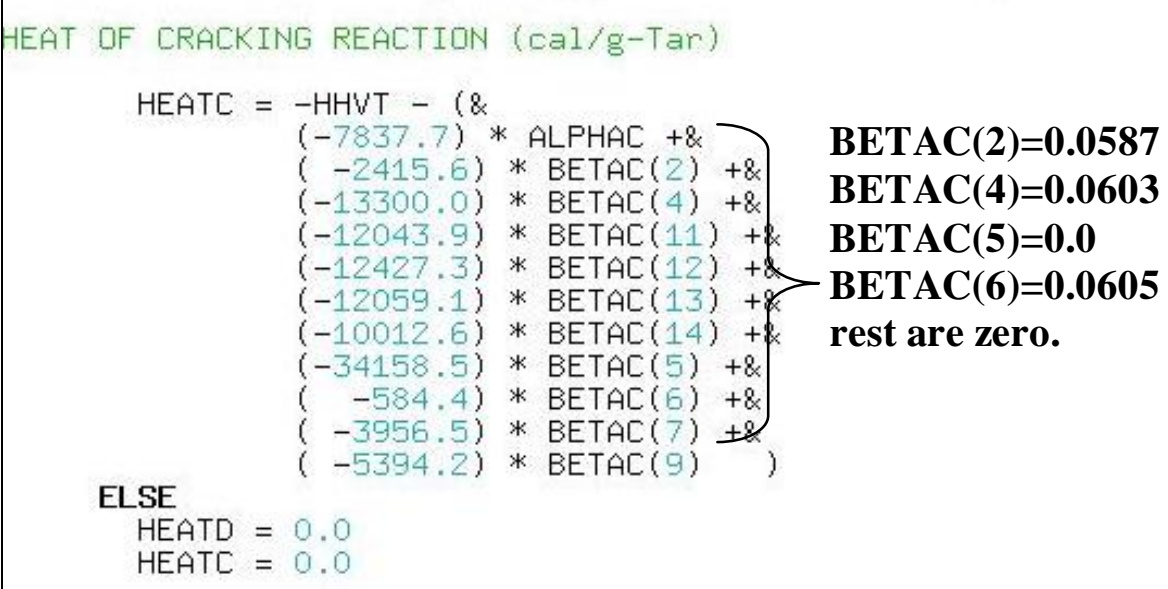




\section{I.5. Secondary Pyrolysis with soot oxidation:}

I.5.1. Algorithm for moisture release to be referred back to devolatilization step (I.3) described before.

I.5.2. Output file to look at is:

- $\mathrm{CFDC}_{\mathrm{i}} \mathrm{T}_{\mathrm{j}} . \mathrm{rpt}$ : [for Arrhenius constant/frequency factor $(A)$ in 1/sec; Activation Energy (E) in $\mathrm{kcal} / \mathrm{mol}](A=257.51 / \mathrm{s} ; E=6620 \mathrm{kcal} / \mathrm{mol})$

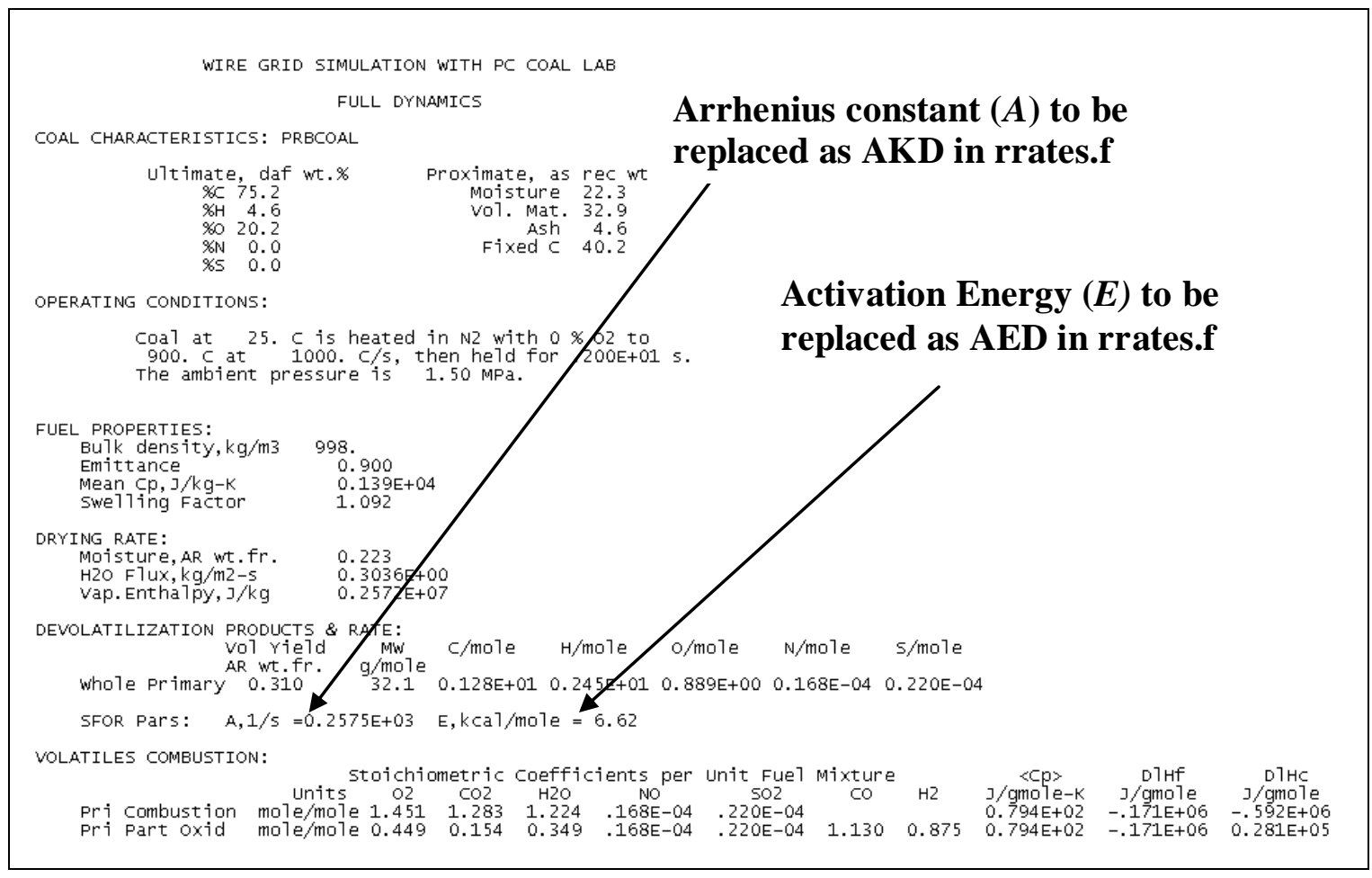

- $\quad \mathrm{FDC}_{\mathrm{i}} \mathrm{SP}_{\mathrm{j}}$. rpt: This files gives the yields of product formed after devolatilization and secondary pyrolysis. 


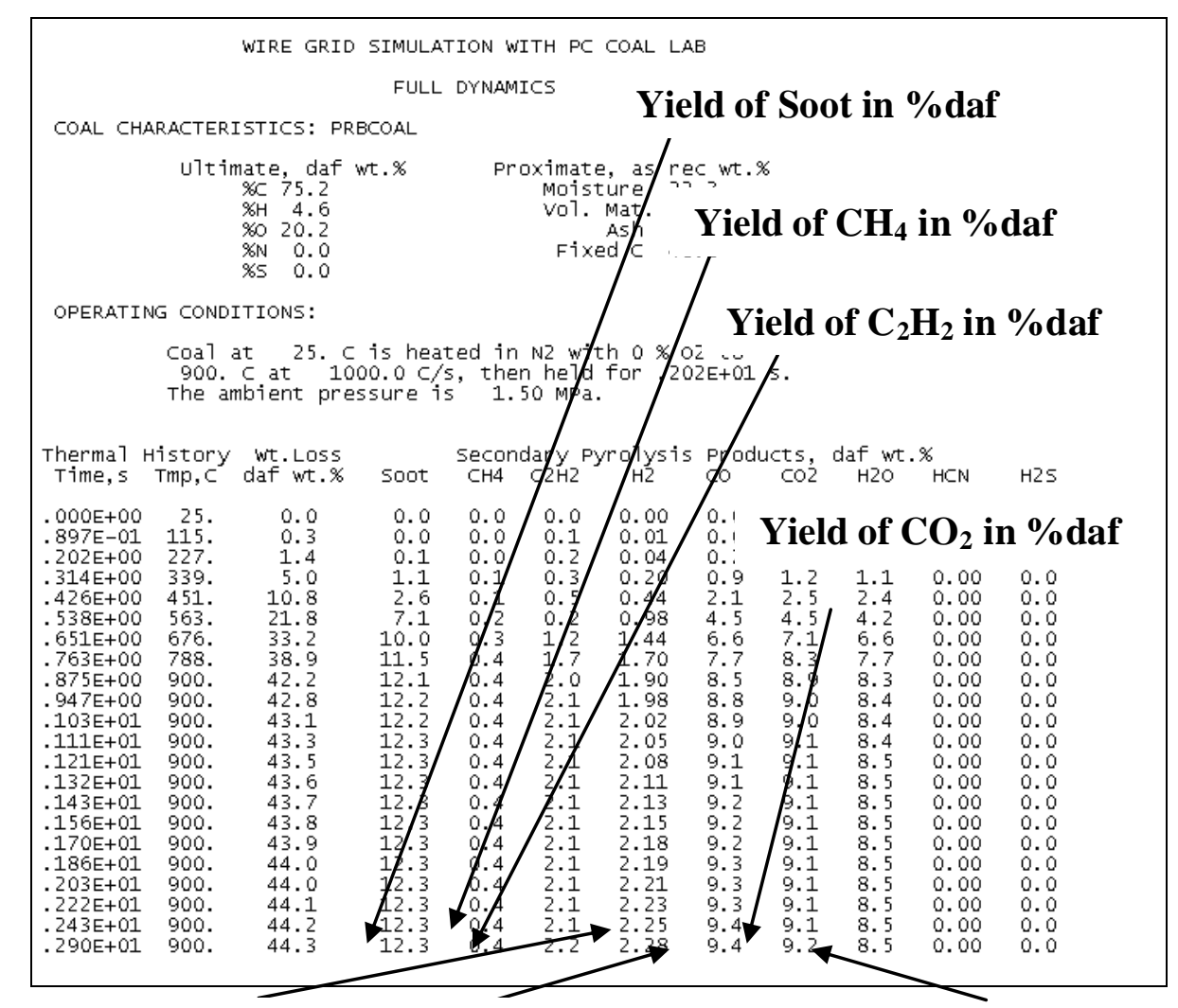

Yield of $\mathrm{H}_{2}$ in \%daf Yield of $\mathrm{CO}$ in \%daf Yield of $\mathrm{H}_{2} \mathrm{Oin} \%$ daf

I.5.3 Convert $\%$ daf basis yields into gm yield

If $X$ is the $\%$ daf basis yield then gm yield will be $[X \times(\mathrm{FC}+\mathrm{VM}) / 100]$

(here $\mathrm{FC}+\mathrm{VM}=40.2+32.9=73.1$ )

\begin{tabular}{|c|c|c|}
\hline Products & \% yield daf & yield in gm \\
\hline $\mathbf{C O}$ & 9.4 & $9.4 \times 0.731=6.8714$ \\
\hline $\mathbf{C O}_{\mathbf{2}}$ & 9.2 & $9.2 \times 0.731=6.7252$ \\
\hline $\mathbf{C H}_{\mathbf{4}}$ & 0.4 & $0.4 \times 0.731=0.2924$ \\
\hline $\mathbf{H}_{\mathbf{2}}$ & 2.28 & $2.28 \times 0.731=1.6667$ \\
\hline $\mathbf{H}_{\mathbf{2}} \mathbf{O}$ & 8.5 & $8.5 \times 0.731=6.2135$ \\
\hline $\mathbf{C}_{2} \mathbf{H}_{2}$ & 2.2 & $2.2 \times 0.731=1.6082$ \\
\hline soot & 12.3 & $12.3 \times 0.731=8.9913$ \\
\hline
\end{tabular}


I.5.4. Find total VM by summation of all gm yields:

Total VM= $\sum$ (Yield in gm of all devolatilization and secondary pyrolysis products)

\begin{tabular}{|c|c|}
\hline Products & yield in gm \\
\hline $\mathbf{C O}$ & 6.8714 \\
\hline $\mathbf{C O}_{\mathbf{2}}$ & 6.7252 \\
\hline $\mathbf{C H}_{\mathbf{4}}$ & 0.2924 \\
\hline $\mathbf{H}_{\mathbf{2}}$ & 1.6667 \\
\hline $\mathbf{H}_{\mathbf{2}} \mathbf{O}$ & 6.2135 \\
\hline $\mathbf{C}_{\mathbf{2}} \mathbf{H}_{\mathbf{2}}$ & 1.6082 \\
\hline Soot & 8.9913 \\
\hline $\mathbf{V M}$ & 32.3687 \\
\hline
\end{tabular}

I.5.5. Convert gm yield into mass fractions (per $1 \mathrm{gm}$ of $\mathrm{VM}$ ):

Stoichiometric coefficient $=($ Yield in gm of product $) /($ VM yield in gm $)$

For Soot just to match stoichiometric coefficients summation as one,

Stoichiometric coefficient of Soot= 1 - Sum (Stoichiometric coefficients of $\mathrm{CO}, \mathrm{CO}_{2}, \mathrm{CH}_{4}, \mathrm{H}_{2}$ , $\mathrm{H}_{2} \mathrm{O}, \mathrm{C}_{2} \mathrm{H}_{2}$ )

\begin{tabular}{|c|c|c|c|}
\hline Products & Yield in gm & Stoichiometric Coefficient & $\begin{array}{c}\text { Stoichiometric } \\
\text { Coefficient }\end{array}$ \\
\hline CO & 6.8714 & 0.2123 & BETAD(2) \\
\hline $\mathbf{C O}_{\mathbf{2}}$ & 6.7252 & 0.2078 & BETAD(3) \\
\hline $\mathbf{C H}_{\mathbf{4}}$ & 0.2924 & 0.0090 & BETAD(4) \\
\hline $\mathbf{H}_{\mathbf{2}}$ & 1.6667 & 0.0515 & $\mathrm{BETAD}(5)$ \\
\hline $\mathbf{H}_{\mathbf{2}} \mathbf{O}$ & 6.2135 & 0.1920 & $\mathrm{BETAD}(6)$ \\
\hline $\mathbf{C}_{\mathbf{2}} \mathbf{H}_{\mathbf{2}}$ & 1.6082 & 0.0497 & \\
\hline & & $\{1-0.2123-0.2078-0.0090-0.515-$ & \\
\hline Soot & 8.9913 & $0.1920-0.0497)=0.2777$ & \\
\hline VM & 32.3687 & 1.0000 & \\
\hline
\end{tabular}


I.5.6. Changes to be made in MFIX.:

- (modifying rrates.f) :Change devolatilization rate parameters $\operatorname{AKD}(A)$

$\left(257.5 \mathrm{sec}^{-1}\right)$ and $\operatorname{AED}(E)(6620 \mathrm{cal} / \mathrm{mol})$

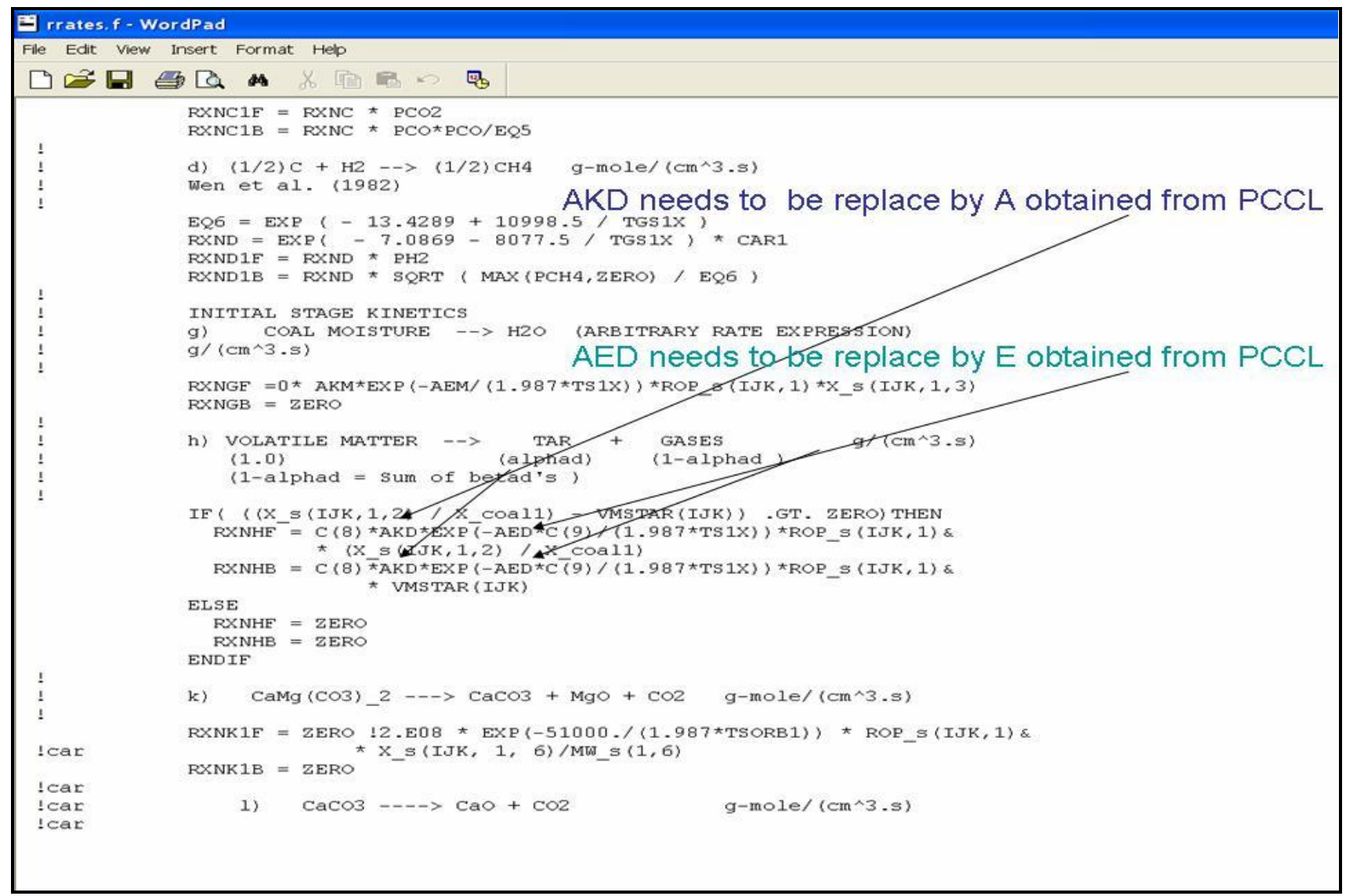




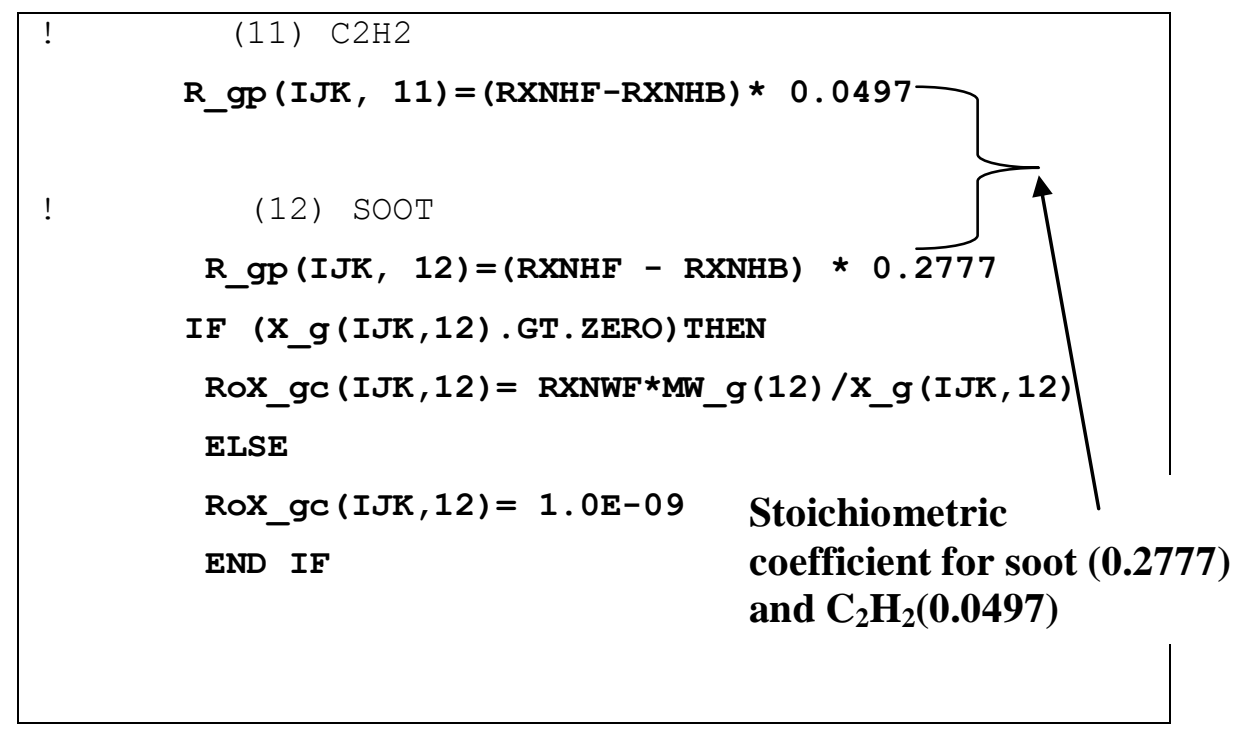

\section{Fate of $\mathrm{H} 2 \mathrm{~S}$ and $\mathrm{HCN}$ is not yet decided}

